Review

\title{
Ribosome-Inactivating and Related Proteins
}

\section{Joachim Schrot, Alexander Weng and Matthias F. Melzig *}

Institute of Pharmacy, Freie Universitaet Berlin, Koenigin-Luise-Str. $2+4,14195$ Berlin, Germany; E-Mails: joachim.schrot@fu-berlin.de (J.S.); alexander.weng@fu-berlin.de (A.W.)

* Author to whom correspondence should be addressed; E-Mail: melzig@zedat.fu-berlin.de; Tel.: +49-30-838-51451; Fax: +49-30-838-51461.

Academic Editor: Nilgun E. Tumer

Received: 31 March 2015 / Accepted: 28 April 2015 / Published: 8 May 2015

\begin{abstract}
Ribosome-inactivating proteins (RIPs) are toxins that act as $N$-glycosidases (EC 3.2.2.22). They are mainly produced by plants and classified as type 1 RIPs and type 2 RIPs. There are also RIPs and RIP related proteins that cannot be grouped into the classical type 1 and type 2 RIPs because of their different sizes, structures or functions. In addition, there is still not a uniform nomenclature or classification existing for RIPs. In this review, we give the current status of all known plant RIPs and we make a suggestion about how to unify those RIPs and RIP related proteins that cannot be classified as type 1 or type 2 RIPs.
\end{abstract}

Keywords: ribosome-inactivating proteins; RIPs; type 1 RIP; RIP 1; type 2 RIP; RIP 2; $N$-glycosidase; nomenclature of RIPs; classification of RIPs

\section{Introduction}

Because of their $N$-glycosidase activity, ribosome-inactivating proteins inhibit protein synthesis by cleaving a specific adenine residue $\left(\mathrm{A}^{4324}\right)$ from the $28 \mathrm{~S}$ ribosomal RNA of the large 60S subunit of rat ribosomes followed by cell death [1]. In addition, certain RIPs can remove adenine from DNA and other polynucleotides for which reason they are also known as polynucleotide adenosine glycosidases [2]. PAP, an RIP from Phytolacca americana, can cleave not only adenine, but also guanine from the rRNA of Escherichia coli [3].

There are mainly two different types of RIPs: type 1 RIPs (RIP 1) and type 2 RIPs (RIP 2). Type 1 RIPs are single chain proteins, whereas type 2 RIPs consist of two polypeptide chains (A- and B-chain) 
that are usually linked through a disulfide bridge. The A-chain contains the enzymatic function and the B-chain has lectin properties enabling these proteins to bind to galactose residues on the cell surface. This facilitates the A-chain to enter the cell. Beside these different types of RIPs, there was the proposal to categorize an additional group of RIPs as type 3 RIPs including a protein from maize (b-32) and from barley (JIP60). The protein from maize, b-32, is synthesized as an inactive proenzyme, which is activated after the removal of an internal peptide segment obtaining two segments of $16.5 \mathrm{kDa}$ and $8.5 \mathrm{kDa}$ [4] that seem to act together as $N$-glycosidase. JIP60 consists of an amino-terminal domain resembling type 1 RIPs linked to a carboxyl-terminal domain, which has a similarity to eukaryotic translation initiation factor 4E [5,6]. Due to their different structures, these two proteins cannot be grouped into the classical type 1 RIPs. However, the necessity of denominating a new group of RIPs for only these two proteins is not realistic. Therefore, the suggestion was made to consider these two proteins as peculiar type 1 RIPs [7,8]. Beside the $N$-glycosidases, there is a second kind of RIPs belonging to the RNA hydrolase [9,10]. Both kinds of RIPs strongly inhibit the protein synthesis but show different mechanisms of action. The RNA hydrolases, like $\alpha$-sarcin as the best-known representative, catalytically cleave a phosphodiester bond between $\mathrm{G}^{4325}$ and $\mathrm{A}^{4326}$ of the rat $28 \mathrm{~S}$ rRNA. With the exception of crotin II, another representative of the RNA hydrolases (see Section 3.5), these kinds of RIPs are not described in detail in this review.

RIPs have mostly been found in plants, but the hypothesis that RIPs are ubiquitous should be discarded, because a gene encoding for an RIP has not been detected in the genome of Arabidopsis thaliana [11]. On the other hand, there are plants in which several RIPs occur simultaneously, and recently, it was shown that there are 31 genes in the rice genome encoding for type 1 RIPs [12]. Beside the plant RIPs, a type 1 RIP was also found from the species algae Saccharina japonica, which were denominated as lamjapin [13]. In addition, researchers are also aware of some type 1 RIPs from fungi, such as pleuturegin from Pleurotus tuberregium [14], lyophyllin from Lyophyllum shimeji [15], flammutin and velutin from Flammulina velutipes [16], hypsin and marmorin from Hypsizygus marmoreus [17,18], and volvarin from Volvariella volvaceae [19]. There are also two type 1 RIPs from bacteria: shiga toxin from Shigella dysenteria [20], and verotoxin 1 (shiga-like toxin) from Escherichia coli [21]. At last, adenine glycosylase activity was even found in some mammalian tissues [2].

RIPs show several enzymatic activities, such as chitinase activity [22], superoxide dismutase activity [23], DNase activity [24], and lipase activity [25]. Due to the $N$-glycosidase activity on viral RNA, RIPs have an antiviral effect, which is considered as a physiological function. But the enzymatic activity could also be related to a role in the defense of plants against predators and fungi $[7,8,26]$. Because of the $N$-glycosidase activity on genomic plant DNA, it is also believed that RIPs could play an undefined role in plant senescence [27]. RIPs might also give the plants evolutionary advantages as a kind of protection under unfavorable situations [28]. Anyway, no precise biological role has yet been assigned to RIPs [29], but most of the authors favor the antiviral role. Thus, in agriculture, research was performed to increase the resistance against viruses by using DNA recombinant technology (reviewed in [11]). In medicine, research for treatment of HIV diseases was performed leading to phase II study [30]. But most research of the use of RIPs is aimed at anti-cancer therapy in leading RIPs selectively to malignant tumor cells to be eliminated. Therefore, type 1 RIPs and the A-chains of type 2 RIPs are coupled to antibodies or other targeting moieties like growth factors, other hormones or smaller peptides 
generating targeted toxins [31-33]. These conjugates, however, contain highly potent toxins with a high potential of side effects, because they are partly taken up non-specifically by macrophages or other somatic cells. Another issue regarding the application of these conjugates in an anti-cancer therapy is the response of the immune system, because they are antigens. To reduce at least the high potential of side effects, it is necessary to begin the dosage of these conjugates as low as possible. That seemed to be possible since a synergistic effect of saponins and type 1 RIPs increasing the toxic effect of type 1 RIPs drastically [34-36] has been discovered. For that, the saponins must consist of certain molecule units [37], and it has been found that the synergistic effect is not based on stimulating phagocytosis [38], but increasing the endosomal escape in a certain way [39,40]; thus, the type 1 RIPs enter the cytosol.

In the last decade, several reviews about RIPs were published setting the focus on the chemical and biological properties and activities, distribution in nature or possible use of the RIPs (e.g., [8,11,41-44]). There is one review that contains a table of all hitherto known RIPs [7]. During our investigations, we found that this table needs to be added with several more RIPs and RIP related proteins. Moreover, we found that some proteins were designated with different terms, e.g., nigrin b from Sambucus nigra or sieboldin-b from Sambucus sieboldiana were also designated as SNA-V or SSA-b-2, respectively. In addition, in some cases, the same term was used to designate different proteins, e.g., the term momordin II was used for a protein from Momordica balsamina as well as for a protein from Momordica charantia or the term MAP was used for a protein (MAP 30) from Momorica charantia and for a protein from Mirabilis jalapa $(\mathrm{MAP}=$ Mirabilis antiviral protein). These examples are intended to illustrate that there is still no unambiguous nomenclature for the RIPs. There are also ambiguities about the classification of some proteins, whether they are type 2 RIPs or just lectins, because no assay concerning the toxicity was performed or there was no information given about the structure: SGSL from Trichosanthes anguina, TCSL from Trichosanthes cucumerina, TKL-1 from Trichosanthes kirilowii, TDSL from Tichosanthes dioica, and BDA from Bryonia dioica. At least since the knowledge that RIPs and lectins evolved from common ancestral genes [29], it is very likely that there are a number of other RIPs not detected to date. This assumption is corroborated by the investigation of several Adenia species, in which some new lectins were found, some of which may be referred to as type 2 RIP [45]. Therefore, with this review we created a summary table (Table 1) with all known RIPs and those proteins, which probably can be classified as RIPs, and we listed all terms that were used for the designation of these proteins. Since there is a phylogenetic relationship between RIPs and lectins, as mentioned above, we also listed the lectins from those plants, which are members of families that are known to include plants that synthesize one or more RIPs. For this, we focused on RIPs from plants, whereas other RIPs from algae, bacteria, and fungi are not considered further. 


\section{Table of RIPs from plants}

Table 1. Summary table of ribosome-inactivating proteins (RIPs) and RIP related proteins from plants.

\begin{tabular}{|c|c|c|c|c|c|c|c|}
\hline Family & Species $^{1}$ & Protein & Classific. & $\mathbf{M w}^{2}$ & $\mathrm{IC}_{50}{ }^{3}$ & Source & References \\
\hline \multirow{27}{*}{ Adoxaceae } & \multirow{12}{*}{$\begin{array}{l}\text { Sambucus } \\
\text { ebulus L. }\end{array}$} & Ebulitin $\alpha$ & RIP 1 & $32 \mathrm{kDa}$ & $10 \mathrm{ng} / \mathrm{mL}$ & leaves & {$[46]$} \\
\hline & & Ebulitin $\beta$ & RIP 1 & $29 \mathrm{kDa}$ & $10 \mathrm{ng} / \mathrm{mL}$ & leaves & {$[46]$} \\
\hline & & Ebulitin $\gamma$ & RIP 1 & $29 \mathrm{kDa}$ & $10 \mathrm{ng} / \mathrm{mL}$ & leaves & {$[46]$} \\
\hline & & Ebulin $\mathrm{f}$ & RIP 2 & $56 \mathrm{kDa}$ & $\begin{array}{c}96 \mathrm{ng} / \mathrm{mL} ; \\
0.3 \mathrm{nM}(\mathrm{A})^{5}\end{array}$ & $\begin{array}{l}\text { green } \\
\text { fruits }\end{array}$ & {$[29,47]$} \\
\hline & & Ebulin 1 & RIP 2 & $56 \mathrm{kDa}$ & $\begin{array}{c}8.5 \mathrm{ng} / \mathrm{mL} \\
0.15 \mathrm{nM}(\mathrm{A})^{5}\end{array}$ & leaves & {$[29,48,49]$} \\
\hline & & Ebulin r1 & RIP 2 & $56 \mathrm{kDa}$ & $2.3 \mathrm{ng} / \mathrm{mL}$ & rhizomes & [49] \\
\hline & & Ebulin r2 & RIP 2 & $56 \mathrm{kDa}$ & $2.3 \mathrm{ng} / \mathrm{mL}$ & rhizomes & [49] \\
\hline & & SEA & RIP 2 & $135,630 \mathrm{Da}$ & $1 \mathrm{nM}$ & bark & {$[50]$} \\
\hline & & SEAII & lectin & $33.5 \mathrm{kDa}$ & - & rhizomes & [49] \\
\hline & & SELfd & lectin & $68 \mathrm{kDa}$ & $820 \mathrm{ng} / \mathrm{mL}$ & $\begin{array}{l}\text { green } \\
\text { fruits }\end{array}$ & {$[47]$} \\
\hline & & SELld & lectin & $67,906 \mathrm{Da}$ & - & leaves & {$[51,52]$} \\
\hline & & SELlm & lectin & $34,239 \mathrm{Da}$ & - & $\begin{array}{l}\text { young } \\
\text { shoots }\end{array}$ & {$[53]$} \\
\hline & \multirow{15}{*}{ Sambucus nigra L. } & $\alpha$-Nigritin & RIP 1 & $29 \mathrm{kDa}$ & $2.44-34 \mathrm{ng} / \mathrm{mL}$ & leaves & {$[54]$} \\
\hline & & $\beta$-Nigritin & RIP 1 & $40 \mathrm{kDa}$ & $2.44-34 \mathrm{ng} / \mathrm{mL}$ & leaves & {$[54]$} \\
\hline & & $\gamma$-Nigritin & RIP 1 & $27.5 \mathrm{kDa}$ & $2.44-34 \mathrm{ng} / \mathrm{mL}$ & leaves & {$[54]$} \\
\hline & & Nigritin fl & RIP 1 & $24,095 \mathrm{Da}$ & $100 \mathrm{ng} / \mathrm{mL}$ & $\begin{array}{c}\text { green and } \\
\text { mature } \\
\text { fruits } \\
\end{array}$ & {$[55]$} \\
\hline & & Nigritin $\mathrm{f} 2$ & RIP 1 & $23,565 \mathrm{Da}$ & $100 \mathrm{ng} / \mathrm{mL}$ & $\begin{array}{c}\text { mature } \\
\text { fruits }\end{array}$ & {$[55]$} \\
\hline & & basic Nigrin $b$ & RIP 2 & $63,469 \mathrm{Da}$ & $\begin{array}{c}18 \mathrm{pg} / \mathrm{mL} \\
0.3 \mathrm{pM}(\mathrm{A})^{5}\end{array}$ & bark & {$[56]$} \\
\hline & & $\begin{array}{c}\text { Nigrin } b= \\
\text { SNA-V }\end{array}$ & RIP 2 & $120 \mathrm{kDa}$ & $\begin{array}{c}261 \mathrm{pM} ; \\
0.03 \mathrm{nM}(\mathrm{A})^{5}\end{array}$ & bark & {$[29,57-59]$} \\
\hline & & $\begin{array}{l}\text { Nigrin } \mathrm{f}= \\
\text { SNA-Vf }\end{array}$ & RIP 2 & $120 \mathrm{kDa}$ & $\begin{array}{c}1.9 \mathrm{ng} / \mathrm{mL} ; \\
1.8 \mathrm{ng} / \mathrm{mL} ; \\
0.03 \mathrm{nM}(\mathrm{A})^{5}\end{array}$ & fruits & {$[29,60-62]$} \\
\hline & & Nigrin 11 & RIP 2 & n.a. ${ }^{4}$ & n.a. ${ }^{4}$ & leaves & [63] \\
\hline & & Nigrin 12 & RIP 2 & n.a. ${ }^{4}$ & n.a. ${ }^{4}$ & leaves & [63] \\
\hline & & Nigrin $\mathrm{s}$ & RIP 2 & $57 \mathrm{kDa}$ & $\sim 1 \mu \mathrm{g} / \mathrm{mL}$ & seeds & [64] \\
\hline & & SNA-I & RIP 2 & $240 \mathrm{kDa}$ & $\begin{array}{c}150 \mathrm{ng} / \mathrm{mL} ; \\
600 \mathrm{pM} \\
\end{array}$ & bark & {$[58,65-68]$} \\
\hline & & SNA-I' & RIP 2 & $120 \mathrm{kDa}$ & $150 \mathrm{ng} / \mathrm{mL}$ & bark & {$[67,69]$} \\
\hline & & SNA-If & RIP 2 & $240 \mathrm{kDa}$ & n.a. ${ }^{4}$ & fruits & {$[69,70]$} \\
\hline & & SNAflu-I & RIP 2 & $\begin{array}{l}\text { subunits of } \\
30-33 \mathrm{kDa}\end{array}$ & n.a. ${ }^{4}$ & $\begin{array}{l}\text { inflorescen } \\
\text {-ces }\end{array}$ & {$[71,72]$} \\
\hline
\end{tabular}


Table 1. Cont.

\begin{tabular}{|c|c|c|c|c|c|c|c|}
\hline Family & Species ${ }^{1}$ & Protein & Classific. & $\mathbf{M w}^{2}$ & $\mathrm{IC}_{50}{ }^{3}$ & Source & References \\
\hline \multirow{19}{*}{ Adoxaceae } & \multirow{12}{*}{ Sambucus nigra L. } & SNLRP1 & RIP 2 & $62 \mathrm{kDa}$ & $\begin{array}{c}0.5 \mu \mathrm{g} / \mathrm{mL} \\
5.74 \mathrm{nM}(\mathrm{A})^{5}\end{array}$ & bark & {$[29,73,74]$} \\
\hline & & SNLRP2 & RIP 2 & $60-62 \mathrm{kDa}$ & n.a. ${ }^{4}$ & bark & {$[74]$} \\
\hline & & SNA-ld & lectin & n.a. ${ }^{4}$ & - & leaves & {$[63]$} \\
\hline & & SNA-lm & lectin & n.a. ${ }^{4}$ & - & leaves & {$[63]$} \\
\hline & & SNA-II & lectin & $60 \mathrm{kDa}$ & - & bark & {$[58,68,75]$} \\
\hline & & SNA-III & lectin & $50 \mathrm{kDa}$ & - & seeds & {$[58,76]$} \\
\hline & & $\begin{array}{l}\text { SNA-IV = } \\
\text { SNA-IVf }\end{array}$ & lectin & $60 \mathrm{kDa}$ & - & fruits & {$[58,62,77,78]$} \\
\hline & & SNA-IV1 & lectin & n.a. ${ }^{4}$ & - & leaves & {$[63]$} \\
\hline & & SNApol-I & lectin & $\begin{array}{c}\text { subunits of } \\
26 \mathrm{kDa}\end{array}$ & - & pollen & {$[71]$} \\
\hline & & SNApol-II & lectin & $\begin{array}{c}\text { subunits of } \\
20 \mathrm{kDa}\end{array}$ & - & pollen & {$[71]$} \\
\hline & & TrSNA-I & lectin & $22 \mathrm{kDa}$ & - & bark & {$[70]$} \\
\hline & & TrSNA-If & lectin & $22 \mathrm{kDa}$ & - & fruits & {$[70]$} \\
\hline & \multirow{3}{*}{$\begin{array}{l}\text { Sambucus } \\
\text { racemosa L. }\end{array}$} & basic racemosin $b$ & RIP 2 & n.a. ${ }^{4}$ & n.a. ${ }^{4}$ & bark & [72] \\
\hline & & SRA & RIP 2 & $120 \mathrm{kDa}$ & n.a. ${ }^{4}$ & bark & {$[72,79]$} \\
\hline & & $\begin{array}{l}\text { SRLbm }= \\
\text { SRAbm }\end{array}$ & lectin & $30 \mathrm{kDa}$ & - & bark & {$[72,80]$} \\
\hline & \multirow{4}{*}{$\begin{array}{c}\text { Sambucus } \\
\text { sieboldiana (Miq.) } \\
\text { Blume ex Graebn. }\end{array}$} & $\mathrm{SSA}=\mathrm{SSA}-\mathrm{b}-1$ & RIP 2 & $160 \mathrm{kDa}$ & $\begin{array}{c}985 \mathrm{ng} / \mathrm{mL} \\
16.4 \mathrm{nM}(\mathrm{A})^{5}\end{array}$ & bark & [81-83] \\
\hline & & $\begin{array}{c}\text { Sieboldin- } \mathrm{b}= \\
\text { SSA-b-2 }\end{array}$ & RIP 2 & $59.4 \mathrm{kDa}$ & $\begin{array}{c}0.9 \mathrm{ng} / \mathrm{mL} ; \\
0.015 \mathrm{nM}(\mathrm{A})^{5}\end{array}$ & bark & {$[29,83,84]$} \\
\hline & & SSA-b-3 & lectin & $34,262 \mathrm{Da}$ & $20-30 \mu \mathrm{g} / \mathrm{mL}$ & bark & [83] \\
\hline & & SSA-b-4 & lectin & $32,333 \mathrm{Da}$ & $20-30 \mu \mathrm{g} / \mathrm{mL}$ & bark & [83] \\
\hline Aizoaceae & $\begin{array}{l}\text { Mesembryanthe- } \\
\text { mum crystallinum } \\
\text { L. }\end{array}$ & RIP1 & RIP 1 & $31.6 \mathrm{kDa}$ & n.a. ${ }^{4}$ & leaves & {$[85]$} \\
\hline \multirow{5}{*}{ Amaranthaceae } & $\begin{array}{l}\text { Amaranthus } \\
\text { caudatus L. }\end{array}$ & $\begin{array}{c}\text { Amaranthin }= \\
\text { ACA }\end{array}$ & lectin & $63.5 \mathrm{kDa}$ & - & seeds & [86-88] \\
\hline & $\begin{array}{l}\text { Amaranthus } \\
\text { cruentus L. }\end{array}$ & $\mathrm{ACL}$ & lectin & $66 \mathrm{kDa}$ & - & seeds & [89] \\
\hline & $\begin{array}{c}\text { Amaranthus } \\
\text { hypochondriacus L. } \\
\text { [Syn.: Amaranthus } \\
\text { leucocarpus } \\
\text { S. Watson] }\end{array}$ & $\begin{array}{c}\text { A. leucocarpus } \\
\text { lectin }\end{array}$ & lectin & $45 \mathrm{kDa}$ & - & seeds & {$[90]$} \\
\hline & $\begin{array}{c}\text { Amaranthus } \\
\text { mangostanus L. }\end{array}$ & Amaramangin & RIP 1 & $29 \mathrm{kDa}$ & n.a. ${ }^{4}$ & seeds & [91] \\
\hline & $\begin{array}{c}\text { Amaranthus } \\
\text { tricolor L. }\end{array}$ & AAP-27 & RIP 1 & $27 \mathrm{kDa}$ & n.a. ${ }^{4}$ & leaves & [92] \\
\hline
\end{tabular}


Table 1. Cont.

\begin{tabular}{|c|c|c|c|c|c|c|c|}
\hline Family & Species ${ }^{1}$ & Protein & Classific. & $\mathbf{M w}^{2}$ & $\mathrm{IC}_{50}{ }^{3}$ & Source & References \\
\hline \multirow{9}{*}{ Amaranthaceae } & $\begin{array}{c}\text { Amaranthus } \\
\text { viridis } \mathrm{L} .\end{array}$ & Amaranthin & RIP 1 & $30 \mathrm{kDa}$ & $25 \mathrm{pM}$ & leaves & {$[93,94]$} \\
\hline & \multirow{3}{*}{ Beta vulgaris L. } & Beetin-27 = BE27 & RIP 1 & $27,592 \mathrm{Da}$ & $1.15 \mathrm{ng} / \mathrm{mL}$ & leaves & [95-97] \\
\hline & & Beetin-29= BE29 & RIP 1 & $29 \mathrm{kDa}$ & n.a. ${ }^{4}$ & leaves & [95-97] \\
\hline & & Betavulgin & RIP 1 & $30 \mathrm{kDa}$ & n.a. ${ }^{4}$ & seedlings & [98] \\
\hline & \multirow{2}{*}{$\begin{array}{c}\text { Celosia argentea L. } \\
\text { [Syn.: Celosia } \\
\text { cristata L.] }\end{array}$} & CCP-25 & RIP 1 & $25 \mathrm{kDa}$ & n.a. ${ }^{4}$ & leaves & {$[99,100]$} \\
\hline & & CCP-27 & RIP 1 & $27 \mathrm{kDa}$ & $25 \mathrm{ng} / \mathrm{mL}$ & leaves & [99-101] \\
\hline & $\begin{array}{c}\text { Chenopodium } \\
\text { album } \mathrm{L} .\end{array}$ & CAP30 & RIP 1 & $30 \mathrm{kDa}$ & $2.26 \mathrm{pM}$ & leaves & {$[102,103]$} \\
\hline & Spinacia & SoRIP1 = BP31 & RIP 1 & $31 \mathrm{kDa}$ & n.a. ${ }^{4}$ & $\begin{array}{c}\text { cell } \\
\text { cultures }\end{array}$ & [104-107] \\
\hline & oleracea L. & SoRIP2 & $\begin{array}{c}\text { RIP } 1 \\
\text { candidate }\end{array}$ & $36 \mathrm{kDa}$ & n.a. ${ }^{4}$ & $\begin{array}{c}\text { cell } \\
\text { cultures }\end{array}$ & {$[106,107]$} \\
\hline \multirow{3}{*}{ Araliaceae } & $\begin{array}{c}\text { Aralia elata (Miq.) } \\
\text { Seem. }\end{array}$ & Aralin & RIP 2 & $62 \mathrm{kDa}$ & n.a. ${ }^{4}$ & shoots & {$[108,109]$} \\
\hline & $\begin{array}{c}\text { Panax ginseng } \\
\text { C.A.Mey }\end{array}$ & Panaxagin & $\begin{array}{c}\text { peculiar } \\
\text { RIP } 1 \\
\text { candidate/ } \\
\text { RNase }\end{array}$ & $52 \mathrm{kDa}$ & $0.28 \mathrm{nM}$ & roots & [110] \\
\hline & $\begin{array}{c}\text { Panax } \\
\text { quinquefolius } \mathrm{L} .\end{array}$ & Quinqueginsin & $\begin{array}{l}\text { peculiar } \\
\text { RIP } 1 \\
\text { candidate/ } \\
\text { RNase }\end{array}$ & $53 \mathrm{kDa}$ & $0.26 \mathrm{nM}$ & roots & [111] \\
\hline \multirow{10}{*}{ Asparagaceae } & \multirow{2}{*}{$\begin{array}{l}\text { Asparagus } \\
\text { officinalis L. }\end{array}$} & Asparin 1 & RIP 1 & $30.5 \mathrm{kDa}$ & $0.27 \mathrm{nM}$ & seeds & {$[112,113]$} \\
\hline & & Asparin 2 & RIP 1 & $29.8 \mathrm{kDa}$ & $0.15 \mathrm{nM}$ & seeds & {$[112,113]$} \\
\hline & $\begin{array}{c}\text { Drimia maritima } \\
\text { (L.) Stearn } \\
\text { [Syn.: Charybdis } \\
\text { maritima (L.) Speta] }\end{array}$ & Charybdin & RIP 1 & $29 \mathrm{kDa}$ & $27.2 \mathrm{nM}$ & bulbs & [114] \\
\hline & \multirow{4}{*}{$\begin{array}{c}\text { Muscari } \\
\text { armeniacum } \\
\text { Leichtlin ex Baker }\end{array}$} & Musarmin 1 & RIP 1 & $28,708 \mathrm{Da}$ & $7 \mathrm{ng} / \mathrm{mL}$ & bulbs & [115] \\
\hline & & Musarmin 2 & RIP 1 & $30,003 \mathrm{Da}$ & $9.5 \mathrm{ng} / \mathrm{mL}$ & bulbs & [115] \\
\hline & & Musarmin 3 & RIP 1 & $27,626 \mathrm{Da}$ & $4 \mathrm{ng} / \mathrm{mL}$ & bulbs & [115] \\
\hline & & Musarmin 4 & RIP 1 & $28 \mathrm{kDa}$ & $\begin{array}{c}1.4-8.2 \mathrm{ng} / \mathrm{mL} ; \\
50-280 \mathrm{nM} \\
\end{array}$ & recomb. ${ }^{6}$ & {$[116]$} \\
\hline & \multirow{2}{*}{$\begin{array}{c}\text { Polygonatum } \\
\text { multiflorum (L.) All. }\end{array}$} & PMRIPm & RIP 2 & $60 \mathrm{kDa}$ & n.a. ${ }^{4}$ & leaves & {$[117]$} \\
\hline & & PMRIPt & RIP 2 & $240 \mathrm{kDa}$ & n.a. ${ }^{4}$ & leaves & {$[117]$} \\
\hline & $\begin{array}{c}\text { Yucca gloriosa var. } \\
\text { tristis Carrière } \\
\text { [Syn.: Yucca } \\
\text { recurvifolia Salisb.] }\end{array}$ & $\begin{array}{c}\text { Yucca leaf } \\
\text { protein = YLP }\end{array}$ & RIP 1 & $23 \mathrm{kDa}$ & n.a. ${ }^{4}$ & leaves & {$[118,119]$} \\
\hline \multirow{3}{*}{ Basellaceae } & \multirow{3}{*}{ Basella rubra L. } & Basella RIP 2a & RIP 1 & $30.6 \mathrm{kDa}$ & $1.70 \mathrm{ng} / \mathrm{mL}$ & seeds & {$[120]$} \\
\hline & & Basella RIP 2b & RIP 1 & $31.2 \mathrm{kDa}$ & $1.70 \mathrm{ng} / \mathrm{mL}$ & seeds & {$[120]$} \\
\hline & & Basella RIP 3 & RIP 1 & $31.2 \mathrm{kDa}$ & $1.66 \mathrm{ng} / \mathrm{mL}$ & seeds & {$[120]$} \\
\hline
\end{tabular}


Table 1. Cont.

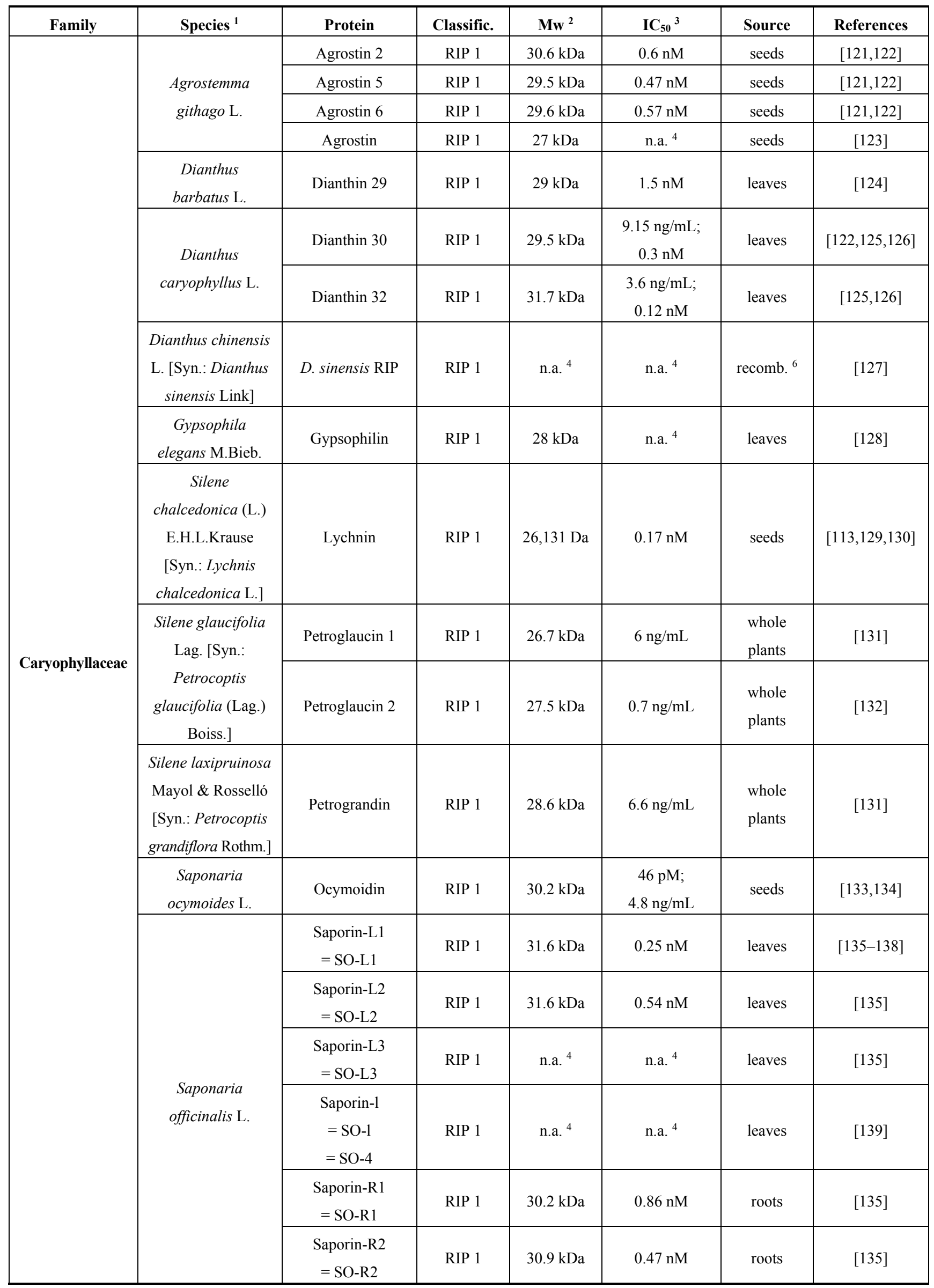


Table 1. Cont.

\begin{tabular}{|c|c|c|c|c|c|c|c|}
\hline Family & Species ${ }^{1}$ & Protein & Classific. & $\mathbf{M w}^{2}$ & $\mathrm{IC}_{50}{ }^{3}$ & Source & References \\
\hline \multirow{12}{*}{ Caryophyllaceae } & \multirow{9}{*}{$\begin{array}{l}\text { Saponaria } \\
\text { officinalis L. }\end{array}$} & $\begin{array}{l}\text { Saporin-R3 } \\
=\mathrm{SO}-\mathrm{R} 3\end{array}$ & RIP 1 & $30.9 \mathrm{kDa}$ & $0.48 \mathrm{nM}$ & roots & [135] \\
\hline & & SO3a & RIP 1 & $22.5 \mathrm{kDa}$ & n.a. ${ }^{4}$ & seeds & {$[140]$} \\
\hline & & SO3b & RIP 1 & $19.4 \mathrm{kDa}$ & n.a. ${ }^{4}$ & seeds & {$[140]$} \\
\hline & & $\begin{array}{l}\text { Saporin-S5 } \\
=\text { Saporin } 5 \\
=\text { SO-S5 }\end{array}$ & RIP 1 & $30.5 \mathrm{kDa}$ & $\begin{array}{c}0.05 \mathrm{nM} \\
10.3 \mathrm{ng} / \mathrm{mL}\end{array}$ & seeds & {$[112,135,141]$} \\
\hline & & $\begin{array}{l}\text { Saporin-S6 } \\
\begin{array}{l}\text { = Saporin } 6 \\
=\text { SO-6 } \\
=\text { SO-S6 }\end{array}\end{array}$ & RIP 1 & $28,577 \mathrm{Da}$ & $\begin{array}{c}0.06 \mathrm{nM} \\
0.6 \mathrm{ng} / \mathrm{mL}\end{array}$ & seeds & $\begin{array}{c}{[112,135,139,} \\
141-145]\end{array}$ \\
\hline & & $\begin{array}{l}\text { Saporin-S8 } \\
=\text { SO-S8 }\end{array}$ & RIP 1 & n.a. ${ }^{4}$ & n.a. ${ }^{4}$ & seeds & [135] \\
\hline & & $\begin{array}{l}\text { Saporin-S9 } \\
=\text { Saporin } 9 \\
=\text { SO-S9 }\end{array}$ & RIP 1 & $28,495 \mathrm{Da}$ & $0.037 \mathrm{nM}$ & seeds & $\begin{array}{c}{[112,122,135,} \\
146]\end{array}$ \\
\hline & & SAP-C & RIP 1 & $28.5 \mathrm{kDa}$ & $125 \mathrm{pM}$ & recomb. ${ }^{6}$ & [147] \\
\hline & & SAP-S & RIP 1 & $28,560 \mathrm{Da}$ & $12 \mathrm{pM}$ & seeds & [147] \\
\hline & $\begin{array}{c}\text { Myosoton } \\
\text { aquaticum (L.) } \\
\text { Moench [Syn.: } \\
\text { Stellaria aquatica } \\
\text { (L.) Scop.] }\end{array}$ & Stellarin & RIP 1 & $25 \mathrm{kDa}$ & $0.04 \mathrm{nM}$ & leaves & [148] \\
\hline & $\begin{array}{l}\text { Stellaria media } \\
\text { (L.) Vill. }\end{array}$ & RIP Q3 & RIP 1 & $28.2 \mathrm{kDa}$ & n.a. ${ }^{4}$ & recomb. ${ }^{6}$ & [149] \\
\hline & $\begin{array}{c}\text { Vaccaria hispanica } \\
\text { (Mill.) Rauschert } \\
\text { [Syn.: Vaccaria } \\
\text { pyramidata Medik.] }\end{array}$ & Pyramidatin & RIP 1 & $28.0 \mathrm{kDa}$ & $\begin{array}{c}89 \mathrm{pM} \\
3.6 \mathrm{ng} / \mathrm{mL}\end{array}$ & seeds & [133] \\
\hline \multirow{8}{*}{ Cucurbitaceae } & \multirow{3}{*}{$\begin{array}{c}\text { Benincasa hispida } \\
\text { (Thunb.) Cogn. }\end{array}$} & Hispin & RIP 1 & $21 \mathrm{kDa}$ & $165 \mathrm{pM}$ & seeds & {$[150]$} \\
\hline & & $\alpha$-benincasin & sRIP 1 & $12 \mathrm{kDa}$ & $\begin{array}{c}20 \mathrm{pM} \\
0.22 \mathrm{ng} / \mathrm{mL} \\
\end{array}$ & seeds & [151] \\
\hline & & $\beta$-benincasin & sRIP 1 & $12 \mathrm{kDa}$ & $\begin{array}{c}320 \mathrm{pM} \\
3.4 \mathrm{ng} / \mathrm{mL}\end{array}$ & seeds & [151] \\
\hline & \multirow{5}{*}{$\begin{array}{l}\text { Bryonia cretica } \\
\text { subsp. dioica } \\
\text { (Jacq.) Tutin. } \\
\text { [Syn.: Bryonia } \\
\text { dioica } \text { L.] }\end{array}$} & Bryodin 1 = BD1 & RIP 1 & $29 \mathrm{kDa}$ & $\begin{array}{c}0.12 \mathrm{nM} \\
3.6 \mathrm{ng} / \mathrm{mL} \\
7 \mathrm{pM}\end{array}$ & roots & {$[152,153]$} \\
\hline & & Bryodin 2 & RIP 1 & $27 \mathrm{kDa}$ & $9 \mathrm{pM}$ & roots & [153] \\
\hline & & Bryodin-L & RIP 1 & $28.8 \mathrm{kDa}$ & $0.09 \mathrm{nM}$ & leaves & [113] \\
\hline & & Bryodin- $\mathrm{R}$ & RIP 1 & n.a. ${ }^{4}$ & n.a. ${ }^{4}$ & seeds & {$[154,155]$} \\
\hline & & BDA & $\begin{array}{l}\text { lectin/ } \\
\text { RIP } 2 \text { like }\end{array}$ & $61 \mathrm{kDa}$ & $>1500 \mathrm{~nm}$ & roots & {$[73,156]$} \\
\hline
\end{tabular}


Table 1. Cont.

\begin{tabular}{|c|c|c|c|c|c|c|c|}
\hline Family & Species $^{1}$ & Protein & Classific. & $\mathbf{M w}^{2}$ & $\mathrm{IC}_{50}{ }^{3}$ & Source & References \\
\hline \multirow{22}{*}{ Cucurbitaceae } & $\begin{array}{c}\text { Citrullus } \\
\text { colocynthis (L.) }\end{array}$ & Colocin 1 & RIP 1 & $26.3 \mathrm{kDa}$ & $0.04 \mathrm{nM}$ & seeds & [113] \\
\hline & Schrad. & Colocin 2 & RIP 1 & $26.3 \mathrm{kDa}$ & $0.13 \mathrm{nM}$ & seeds & [113] \\
\hline & \multirow{2}{*}{$\begin{array}{c}\text { Cucurbita } \\
\text { foetidissima Kunth }\end{array}$} & Foetidissimin & $\begin{array}{c}\text { peculiar } \\
\text { RIP } 2 \\
\end{array}$ & $63 \mathrm{kDa}$ & $25.9 \mathrm{nM}$ & roots & {$[157]$} \\
\hline & & Foetidissimin II & RIP 2 & $61 \mathrm{kDa}$ & $251.6 \mathrm{nM}$ & roots & {$[158]$} \\
\hline & $\begin{array}{c}\text { Cucumis ficifolius } \\
\text { A.Rich. [Syn.: } \\
\text { Cucumis figarei } \\
\text { Delile ex Naudin] }\end{array}$ & $\begin{array}{l}\text { Cucumis figarei } \\
\text { RIP = CF-RIP }\end{array}$ & $\begin{array}{c}\text { RIP } 1 \\
\text { candidate }\end{array}$ & n.a. ${ }^{4}$ & n.a. ${ }^{4}$ & recomb. ${ }^{6}$ & [159] \\
\hline & $\begin{array}{c}\text { Cucurbita maxima } \\
\text { Duchesne }\end{array}$ & Cucurmoschin & $\begin{array}{c}\text { sRIP } 1 \\
\text { candidate }\end{array}$ & $9 \mathrm{kDa}$ & $1.2 \mu \mathrm{M}$ & seeds & {$[160]$} \\
\hline & \multirow{8}{*}{$\begin{array}{c}\text { Cucurbita } \\
\text { moschata } \\
\text { Duchesne } \\
\text { [Syn.: Cucurbita } \\
\text { moschata } \\
\text { (Duchesne ex } \\
\text { Lam.) Duchesne ex } \\
\text { Poir.] }\end{array}$} & Cucurmosin & RIP 1 & $27-28 \mathrm{kDa}$ & n.a. ${ }^{4}$ & sarcocarp & [161-163] \\
\hline & & Cucurmosin 2 & RIP 1 & $27,183 \mathrm{Da}$ & n.a. ${ }^{4}$ & sarcocarp & {$[164,165]$} \\
\hline & & C. moschata RIP & RIP 1 & $30,665 \mathrm{Da}$ & $\begin{array}{l}0.035 \mathrm{nM} \\
1.08 \mathrm{ng} / \mathrm{mL}\end{array}$ & $\begin{array}{l}\text { skinned } \\
\text { fruit }\end{array}$ & {$[155]$} \\
\hline & & Moschatin & RIP 1 & $29 \mathrm{kDa}$ & $0.26 \mathrm{nM}$ & seeds & {$[166]$} \\
\hline & & PRIP 1 & RIP 1 & $31 \mathrm{kDa}$ & $0.82 \mathrm{nM}$ & leaves & {$[167]$} \\
\hline & & PRIP 2 & RIP 1 & $30.5 \mathrm{kDa}$ & $0.79 \mathrm{nM}$ & leaves & {$[167]$} \\
\hline & & $\alpha$-moschin & $\begin{array}{c}\text { sRIP } 1 \\
\text { candidate }\end{array}$ & $12 \mathrm{kDa}$ & $17 \mu \mathrm{M}$ & seeds & {$[168]$} \\
\hline & & $\beta$-moschin & $\begin{array}{c}\text { sRIP } 1 \\
\text { candidate }\end{array}$ & $12 \mathrm{kDa}$ & $300 \mathrm{nM}$ & seeds & {$[168]$} \\
\hline & Cucurbita pepo L. & Pepocin & RIP 1 & $26 \mathrm{kDa}$ & $15.4 \mathrm{pM}$ & sarcocarp & [169] \\
\hline & $\begin{array}{c}\text { Cucurbita pepo } \\
\text { var. texana } \\
\text { (Scheele) } \\
\text { D.S.Decker } \\
\text { [Syn.: Cucurbita } \\
\text { texana (Scheele) } \\
\text { A. Gray] }\end{array}$ & Texanin & RIP 1 & $29.7 \mathrm{kDa}$ & n.a. ${ }^{4}$ & fruits & [158] \\
\hline & $\begin{array}{c}\text { Gynostemma } \\
\text { pentaphyllum } \\
\text { (Thunb.) Makino } \\
\end{array}$ & Gynostemmin & RIP 1 & $27 \mathrm{kDa}$ & n.a. ${ }^{4}$ & $\begin{array}{l}\text { leaves and } \\
\text { stems }\end{array}$ & {$[170]$} \\
\hline & $\begin{array}{c}\text { Lagenaria } \\
\text { siceraria (Molina) } \\
\text { Standl. }\end{array}$ & Lagenin & $\begin{array}{c}\text { RIP } 1 \\
\text { candidate }\end{array}$ & $20 \mathrm{kDa}$ & $0.21 \mathrm{nM}$ & seeds & [171] \\
\hline & & Luffaculin-1 & RIP 1 & $28 \mathrm{kDa}$ & $\begin{array}{c}3.6 \mathrm{ng} / \mathrm{mL} ; \\
124 \mathrm{pM}\end{array}$ & seeds & {$[172,173]$} \\
\hline & Luffa acutangula & Luffaculin-2 & RIP 1 & $28 \mathrm{kDa}$ & n.a. ${ }^{4}$ & seeds & [173] \\
\hline & (L.) Roxb. & Luffangulin & sRIP 1 & $5.6 \mathrm{kDa}$ & $3.5 \mathrm{nM}$ & seeds & [174] \\
\hline & & $\begin{array}{c}\text { Luffa acutangula } \\
\text { fruit lectin }\end{array}$ & lectin & $48 \mathrm{kDa}$ & - & fruits & [175] \\
\hline
\end{tabular}


Table 1. Cont.

\begin{tabular}{|c|c|c|c|c|c|c|c|}
\hline Family & Species ${ }^{1}$ & Protein & Classific. & $\mathrm{Mw}^{2}$ & $\mathrm{IC}_{50}{ }^{3}$ & Source & References \\
\hline \multirow{26}{*}{ Cucurbitaceae } & \multirow{12}{*}{$\begin{array}{c}\text { Luffa cylindrica } \\
\text { (L.) M.Roem } \\
\text { [Syn.: Luffa } \\
\text { aegyptiaca Mill.] }\end{array}$} & Luffin & RIP 1 & $26 \mathrm{kDa}$ & $0.42 \mathrm{ng} / \mathrm{mL}$ & seeds & {$[176]$} \\
\hline & & Luffin-a & RIP 1 & $27,021 \mathrm{Da}$ & $1.64 \mathrm{ng} / \mathrm{mL}$ & seeds & {$[177,178]$} \\
\hline & & Luffin-b & RIP 1 & $27,275 \mathrm{Da}$ & $0.84 \mathrm{ng} / \mathrm{mL}$ & seeds & {$[177,178]$} \\
\hline & & $\alpha$-luffin & RIP 1 & $28 \mathrm{kDa}$ & $\begin{array}{c}10 \mathrm{ng} / \mathrm{mL} ; \\
34.1 \mathrm{pM} \\
\text { (recomb. }^{6} \text { ) }\end{array}$ & seeds & [179-181] \\
\hline & & $\beta$-luffin & RIP 1 & $29 \mathrm{kDa}$ & $50 \mathrm{ng} / \mathrm{mL}$ & seeds & {$[180,182]$} \\
\hline & & LRIP & RIP 1 & $30 \mathrm{kDa}$ & $8 \mathrm{pM}$ & seeds & [183] \\
\hline & & Luffacylin & sRIP 1 & $7.8 \mathrm{kDa}$ & $0.14 \mathrm{nM}$ & seeds & [184] \\
\hline & & Luffin P1 & sRIP 1 & $5226.1 \mathrm{Da}$ & $0.88 \mathrm{nM}$ & seeds & [185] \\
\hline & & Luffin-S & $\begin{array}{c}\text { sRIP } 1 \\
\text { candidate }\end{array}$ & $10 \mathrm{kDa}$ & $0.34 \mathrm{nM}$ & seeds & {$[186]$} \\
\hline & & LuffinS(1) & $\begin{array}{c}\text { sRIP } 1 \\
\text { candidate }\end{array}$ & $8 \mathrm{kDa}$ & $130 \mathrm{nM}$ & seeds & [187] \\
\hline & & $\begin{array}{l}\text { LuffinS(2) } \\
=\text { luffin S2 }\end{array}$ & $\begin{array}{c}\text { sRIP } 1 \\
\text { candidate }\end{array}$ & $7.8 \mathrm{kDa}$ & $10 \mathrm{nM}$ & seeds & {$[187,188]$} \\
\hline & & LuffinS(3) & $\begin{array}{c}\text { sRIP } 1 \\
\text { candidate }\end{array}$ & $8 \mathrm{kDa}$ & $630 \mathrm{nM}$ & seeds & [187] \\
\hline & \multirow{2}{*}{$\begin{array}{c}\text { Marah oreganus } \\
\text { (Torr. \& A. Gray) } \\
\text { Howell } \\
\end{array}$} & MOR-I & RIP 1 & $27,989 \mathrm{Da}$ & $0.063 \mathrm{nM}$ & seeds & [189] \\
\hline & & MOR-II & RIP 1 & $27,632 \mathrm{Da}$ & $0.071 \mathrm{nM}$ & seeds & [189] \\
\hline & \multirow{3}{*}{$\begin{array}{c}\text { Momordica } \\
\text { balsamina L. }\end{array}$} & Balsamin & RIP 1 & $28.6 \mathrm{kDa}$ & $90.6 \mathrm{ng} / \mathrm{mL}$ & seeds & {$[190]$} \\
\hline & & MbRIP-1 & RIP 1 & $30 \mathrm{kDa}$ & n.a. ${ }^{4}$ & seeds & {$[191,192]$} \\
\hline & & Momordin II & RIP 1 & n.a. ${ }^{4}$ & n.a. ${ }^{4}$ & recomb. ${ }^{6}$ & [193] \\
\hline & \multirow{9}{*}{$\begin{array}{l}\text { Momordica } \\
\text { charantia L. }\end{array}$} & MAP 30 & RIP 1 & $30 \mathrm{kDa}$ & $3.3 \mathrm{nM}$ & $\begin{array}{c}\text { seeds } \\
\text { and fruits }\end{array}$ & {$[194,195]$} \\
\hline & & $\begin{array}{c}\alpha \text {-momorcharin } \\
\quad=\alpha-\mathrm{MC} \\
=\alpha-\mathrm{MMC}\end{array}$ & RIP 1 & $\begin{array}{c}28,625- \\
28,795 \mathrm{Da}\end{array}$ & $0.23 \mathrm{nM}$ & seeds & [196-204] \\
\hline & & $\begin{array}{c}\beta \text {-momorcharin } \\
=\beta-\mathrm{MC} \\
=\beta-\mathrm{MMC}\end{array}$ & RIP 1 & $\begin{array}{c}29,074- \\
29,076 \mathrm{Da}\end{array}$ & $0.19 \mathrm{nM}$ & seeds & $\begin{array}{l}\text { [196-198, } \\
200-203]\end{array}$ \\
\hline & & $\begin{array}{c}\gamma \text {-momorcharin } \\
\quad=\gamma \text {-MMC }\end{array}$ & sRIP 1 & $11.5 \mathrm{kDa}$ & $55 \mathrm{nM}$ & seeds & [205] \\
\hline & & $\begin{array}{c}\delta \text {-momorcharin } \\
=\delta \text {-MMC }\end{array}$ & RIP 1 & $30 \mathrm{kDa}$ & $0.15 \mathrm{nM}$ & seeds & [203] \\
\hline & & $\varepsilon$-momorcharin & $\begin{array}{c}\text { RIP } 1 \\
\text { candidate }\end{array}$ & $24 \mathrm{kDa}$ & $170 \mathrm{nM}$ & fruits & [203] \\
\hline & & Momordin & RIP 1 & $31 \mathrm{kDa}$ & n.a. ${ }^{4}$ & seeds & [206] \\
\hline & & $\begin{array}{c}\text { Momordin } \\
=\text { Momordica } \\
\text { charantia } \\
\text { inhibitor }\end{array}$ & RIP 1 & $23-24 \mathrm{kDa}$ & $1.8 \mathrm{ng} / \mathrm{mL}$ & seeds & [207-212] \\
\hline & & Momordin II & RIP 1 & n.a. ${ }^{4}$ & n.a. ${ }^{4}$ & seeds & [213] \\
\hline
\end{tabular}


Table 1. Cont.

\begin{tabular}{|c|c|c|c|c|c|c|c|}
\hline Family & Species $^{1}$ & Protein & Classific. & $\mathbf{M w}^{2}$ & $\mathrm{IC}_{50}{ }^{3}$ & Source & References \\
\hline \multirow{21}{*}{ Cucurbitaceae } & \multirow{11}{*}{$\begin{array}{l}\text { Momordica } \\
\text { charantia L. }\end{array}$} & Momordin-a & RIP 1 & $29.4 \mathrm{kDa}$ & n.a. ${ }^{4}$ & seeds & {$[214,215]$} \\
\hline & & Momordin-b & RIP 1 & $29.4 \mathrm{kDa}$ & n.a. ${ }^{4}$ & seeds & [214] \\
\hline & & Charantin & sRIP 1 & $9.7 \mathrm{kDa}$ & $400 \mathrm{nM}$ & seeds & [216] \\
\hline & & $\begin{array}{c}\text { MCL } \\
=M \cdot \text { charantia } \\
\text { lectin }\end{array}$ & lectin & $12.4 \mathrm{kDa}$ & - & seeds & [217] \\
\hline & & $\begin{array}{c}\text { MCL } \\
=\text { Momordica } \\
\text { charantia } \text { seed } \\
\text { lectin } \\
=\text { Momordica } \\
\text { charantia lectin }\end{array}$ & RIP 2 & $\begin{array}{c}115- \\
124 \mathrm{kDa}\end{array}$ & $\begin{array}{c}1.74 \mu \mathrm{g} / \mathrm{mL} \\
5 \mu \mathrm{g} / \mathrm{mL}\end{array}$ & seeds & [207,218-220] \\
\hline & & MCL1 & RIP 2 & $60,993 \mathrm{Da}$ & $1.9 \mathrm{nM}$ & seeds & [221] \\
\hline & & anti-H Lectin & lectin & $150 \mathrm{kDa}$ & - & seeds & [222] \\
\hline & & $\begin{array}{l}\text { Momordica } \\
\text { agglutinin }\end{array}$ & lectin & $30 \mathrm{kDa}$ & - & seeds & [223] \\
\hline & & Momordin & lectin & $22-23 \mathrm{kDa}$ & - & seeds & [223] \\
\hline & & protein fraction 1 & lectin & $49 \mathrm{kDa}$ & - & seeds & [224] \\
\hline & & protein fraction 2 & lectin & $49 \mathrm{kDa}$ & - & seeds & [224] \\
\hline & \multirow{3}{*}{$\begin{array}{c}\text { Momordica } \\
\text { cochinchinensis } \\
\text { Spreng. } \\
\end{array}$} & Cochinin B & RIP 1 & $28 \mathrm{kDa}$ & $0.36 \mathrm{nM}$ & seeds & [225] \\
\hline & & Momorcochin & RIP 1 & $32 \mathrm{kDa}$ & n.a. ${ }^{4}$ & tubers & {$[200,226]$} \\
\hline & & Momorcochin-S & RIP 1 & $30 \mathrm{kDa}$ & $0.12 \mathrm{nM}$ & seeds & {$[225,227]$} \\
\hline & $\begin{array}{c}\text { Siraitia } \\
\text { grosvenorii } \\
\text { (Swingle) } \\
\text { C.Jeffrey ex } \\
\text { A.M.Lu \& Zhi } \\
\text { Y.Zhang [Syn.: } \\
\text { Momordica } \\
\text { grosvenorii } \\
\text { Swingle] }\end{array}$ & Momorgrosvin & RIP 1 & $27.7 \mathrm{kDa}$ & $0.3 \mathrm{nM}$ & seeds & [228] \\
\hline & \multirow{2}{*}{$\begin{array}{c}\text { Sechium edule } \\
\text { (Jacq.) Sw. }\end{array}$} & Sechiumin & RIP 1 & $27 \mathrm{kDa}$ & $0.7 \mathrm{nM}$ & seeds & [229] \\
\hline & & $\begin{array}{c}\text { Sechium edule } \\
\text { fruit lectin }\end{array}$ & lectin & $44 \mathrm{kDa}$ & - & fruits & [230] \\
\hline & \multirow{2}{*}{$\begin{array}{c}\text { Trichosanthes } \\
\text { anguina } \mathrm{L} .\end{array}$} & Trichoanguin & RIP 1 & $35 \mathrm{kDa}$ & $0.08 \mathrm{nM}$ & seeds & [231] \\
\hline & & SGSL & $\begin{array}{c}\text { lectin/ } \\
\text { RIP } 2 \text { like }\end{array}$ & $62 \mathrm{kDa}$ & n.a. ${ }^{4}$ & seeds & [232-234] \\
\hline & \multirow{2}{*}{$\begin{array}{l}\text { Trichosanthes } \\
\text { cordata } \text { Roxb. }\end{array}$} & TCA-I & lectin & $59 \mathrm{kDa}$ & n.a. ${ }^{4}$ & seeds & [235] \\
\hline & & TCA-II & lectin & $52 \mathrm{kDa}$ & n.a. ${ }^{4}$ & seeds & [235] \\
\hline
\end{tabular}


Table 1. Cont.

\begin{tabular}{|c|c|c|c|c|c|c|c|}
\hline Family & Species $^{1}$ & Protein & Classific. & $\mathbf{M w}^{2}$ & $\mathrm{IC}_{50}{ }^{3}$ & Source & References \\
\hline \multirow{21}{*}{ Cucurbitaceae } & $\begin{array}{l}\text { Trichosanthes } \\
\text { cucumerina L. }\end{array}$ & TCSL & $\begin{array}{c}\text { lectin/ } \\
\text { RIP } 2 \\
\text { candidate }\end{array}$ & $69 \mathrm{kDa}$ & n.a. ${ }^{4}$ & seeds & [236] \\
\hline & $\begin{array}{l}\text { Trichosanthes } \\
\text { cucumeroides } \\
\text { (Ser.) Maxim. }\end{array}$ & $\begin{array}{l}\beta \text {-trichosanthin } \\
\quad=\beta \text {-TCS }\end{array}$ & RIP 1 & $28 \mathrm{kDa}$ & $\begin{array}{c}2.8 \mathrm{ng} / \mathrm{mL} \\
0.1 \mathrm{nM}\end{array}$ & root tubers & {$[200,237,238]$} \\
\hline & \multirow{19}{*}{$\begin{array}{c}\text { Trichosanthes } \\
\text { kirilowii Maxim. }\end{array}$} & $\alpha$-kirilowin & RIP 1 & $28.8 \mathrm{kDa}$ & $\begin{array}{c}1.2-1.8 \mathrm{ng} / \mathrm{mL} \\
0.044- \\
0.066 \mathrm{mM}\end{array}$ & seeds & [239] \\
\hline & & $\beta$-kirilowin & RIP 1 & $27.5 \mathrm{kDa}$ & $1.8 \mathrm{ng} / \mathrm{mL}$ & seeds & [240] \\
\hline & & TAP 29 & RIP 1 & $29 \mathrm{kDa}$ & $3.7 \mathrm{nM}$ & root tubers & {$[241,242]$} \\
\hline & & TK-35 & RIP 1 & $35,117 \mathrm{Da}$ & $2.45 \mathrm{nM}$ & cell cultures & [243] \\
\hline & & Trichobitacin & RIP 1 & $27,228 \mathrm{Da}$ & n.a. ${ }^{4}$ & root tubers & [244-246] \\
\hline & & Trichokirin & RIP 1 & $27 \mathrm{kDa}$ & $0.06-0.13 \mathrm{nM}$ & seeds & [247] \\
\hline & & $\begin{array}{l}\text { Trichomislin } \\
\quad=\mathrm{TCM}\end{array}$ & RIP 1 & $27,211 \mathrm{Da}$ & $2.26 \mathrm{nM}$ & recomb. ${ }^{6}$ & [248] \\
\hline & & $\begin{array}{l}\text { Trichosanthin } \\
=\text { Trichosanthes } \\
\text { antiviral protein } \\
=\mathrm{TAP} \\
=\mathrm{TCS} \\
=\alpha \text {-trichosanthin } \\
=\alpha \text {-TCS } \\
=\text { GLQ223 }\end{array}$ & RIP 1 & $26-28 \mathrm{kDa}$ & $\begin{array}{c}6.1 \mathrm{ng} / \mathrm{mL} \\
0.23 \mathrm{nM} \\
0.36 \mathrm{ng} / \mathrm{mL} \\
1.31 \mathrm{nM}\end{array}$ & root tubers & $\begin{array}{c}{[198,200,238,} \\
248-256]\end{array}$ \\
\hline & & Trichosanthin & RIP 1 & $25 \mathrm{kDa}$ & n.a. ${ }^{4}$ & root tubers & [257] \\
\hline & & $\begin{array}{c}\beta \text {-trichosanthin } \\
=\beta \text {-TCS }\end{array}$ & RIP 1 & $26 \mathrm{kDa}$ & $7 \mathrm{ng} / \mathrm{mL}$ & root tubers & [255] \\
\hline & & $\begin{array}{c}\gamma \text {-trichosanthin } \\
\quad=\gamma \text {-TCS }\end{array}$ & RIP 1 & $26 \mathrm{kDa}$ & $12 \mathrm{ng} / \mathrm{mL}$ & root tubers & [255] \\
\hline & & Trichokirin S1 & sRIP 1 & $11,426 \mathrm{Da}$ & $0.7 \mathrm{nM}$ & seeds & {$[258]$} \\
\hline & & S-Trichokirin & sRIP 1 & $8 \mathrm{kDa}$ & $115 \mathrm{pM}$ & seeds & [259] \\
\hline & & Trichosanthrip & sRIP 1 & $10,964 \mathrm{Da}$ & $1.6 \mathrm{ng} / \mathrm{mL}$ & seeds & [256] \\
\hline & & $\begin{array}{c}\text { TKL-1 } \\
=\text { Trichosanthes } \\
\text { kirilowii lectin-1 }\end{array}$ & $\begin{array}{c}\text { lectin/ } \\
\text { RIP } 2 \\
\text { candidate }\end{array}$ & $60 \mathrm{kDa}$ & n.a. ${ }^{4}$ & root tubers & {$[260,261]$} \\
\hline & & TK-I & lectin & n.a. ${ }^{4}$ & - & root tubers & {$[262,263]$} \\
\hline & & TK-II & lectin & n.a. ${ }^{4}$ & - & root tubers & {$[262,263]$} \\
\hline & & TK-III & lectin & n.a. ${ }^{4}$ & - & root tubers & {$[262,263]$} \\
\hline & & $\begin{array}{l}\text { Trichosanthes } \\
\text { kirilowii lectin }\end{array}$ & lectin & $57 \mathrm{kDa}$ & - & seeds & [264] \\
\hline
\end{tabular}


Table 1. Cont.

\begin{tabular}{|c|c|c|c|c|c|c|c|}
\hline Family & Species $^{1}$ & Protein & Classific. & $\mathbf{M w}^{2}$ & $\mathrm{IC}_{50}{ }^{3}$ & Source & References \\
\hline \multirow{6}{*}{ Cucurbitaceae } & \multirow{3}{*}{$\begin{array}{c}\text { Trichosanthes } \\
\text { kirilowii } \\
\text { Maximovicz var. } \\
\text { japonica (Miquel) } \\
\text { Kitamura }\end{array}$} & Karasurin-A & RIP 1 & $27,215 \mathrm{Da}$ & $0.1-0.3 \mathrm{ng} / \mathrm{mL}$ & root tubers & [265-268] \\
\hline & & Karasurin-B & RIP 1 & $27,214 \mathrm{Da}$ & $0.1-0.3 \mathrm{ng} / \mathrm{mL}$ & root tubers & [267] \\
\hline & & Karasurin-C & RIP 1 & $27,401 \mathrm{Da}$ & $0.1-0.3 \mathrm{ng} / \mathrm{mL}$ & root tubers & [267] \\
\hline & $\begin{array}{c}\text { Trichosanthes } \\
\text { lepiniate }\end{array}$ & Trichomaglin & RIP 1 & $24,673 \mathrm{Da}$ & $10.1 \mathrm{nM}$ & root tuber & [269] \\
\hline & $\begin{array}{l}\text { Trichosanthes } \\
\text { dioica Roxb. }\end{array}$ & TDSL & $\begin{array}{c}\text { lectin/ } \\
\text { RIP } 2 \\
\text { candidate }\end{array}$ & $55 \mathrm{kDa}$ & n.a. ${ }^{4}$ & seeds & {$[270]$} \\
\hline & $\begin{array}{c}\text { Trichosanthes sp. } \\
\text { Bac Kan 8-98 }\end{array}$ & Trichobakin & RIP 1 & $27 \mathrm{kDa}$ & $3.5 \mathrm{pM}$ & leaves & [271] \\
\hline Cupressaceae & $\begin{array}{c}\text { Thuja } \\
\text { occidentalis L. }\end{array}$ & Arborvitae RIP & $\begin{array}{c}\text { RIP } \\
\text { candidate }\end{array}$ & n.a. ${ }^{4}$ & n.a. ${ }^{4}$ & seeds & [272] \\
\hline \multirow{15}{*}{ Euphorbiaceae } & \multirow[t]{2}{*}{ Croton tiglium $\mathrm{L}$. } & Crotin I & $\begin{array}{c}\text { RIP } 1 \\
\text { candidate }\end{array}$ & $40 \mathrm{kDa}$ & n.a. ${ }^{4}$ & seeds & [273-275] \\
\hline & & Crotin 2 & RIP 1 & n.a. ${ }^{4}$ & n.a. ${ }^{4}$ & seeds & {$[276-278]$} \\
\hline & $\begin{array}{c}\text { Euphorbia } \\
\text { characias L. }\end{array}$ & $\begin{array}{c}\text { E. characias } \\
\text { lectin }\end{array}$ & lectin & $80 \mathrm{kDa}$ & - & latex & [279] \\
\hline & $\begin{array}{c}\text { Suregada } \\
\text { multiflora (A.Juss.) } \\
\text { Baill. } \\
\text { [Syn.: Gelonium } \\
\text { multiflorum A.Juss.] }\end{array}$ & $\begin{aligned} & \text { Gelonin } \\
= & \text { GAP } 31\end{aligned}$ & RIP 1 & $30-31 \mathrm{kDa}$ & $\begin{array}{c}0.406 \mathrm{ng} / \mathrm{mL} \\
0.32 \mathrm{nM}\end{array}$ & seeds & {$[126,280-283]$} \\
\hline & \multirow{6}{*}{ Hura Crepitans L. } & $\begin{array}{c}\text { Hura crepitans } \\
\text { RIP }\end{array}$ & RIP 1 & $28 \mathrm{kDa}$ & n.a. ${ }^{4}$ & $\begin{array}{l}\text { latex, } \\
\text { leaves }\end{array}$ & {$[27,112]$} \\
\hline & & $\begin{array}{c}\text { Hura crepitans } \\
\text { RIP-5 }\end{array}$ & RIP 1 & n.a. ${ }^{4}$ & n.a. ${ }^{4}$ & latex & [284] \\
\hline & & $\begin{array}{c}\text { Hura crepitans } \\
\text { latex lectin }\end{array}$ & RIP 2 & $112 \mathrm{kDa}$ & - & latex & [279] \\
\hline & & Crepitin & lectin & n.a. ${ }^{4}$ & n.a. ${ }^{4}$ & latex & {$[285,286]$} \\
\hline & & Hurin & lectin & $70 \mathrm{kDa}$ & - & seeds & {$[287,288]$} \\
\hline & & $\begin{array}{c}\text { Hura crepitans } \\
\text { seed lectin }\end{array}$ & lectin & $120 \mathrm{kDa}$ & - & seeds & [286] \\
\hline & \multirow{4}{*}{ Jatropha curcas L. } & Curcin & RIP 1 & $28.2 \mathrm{kDa}$ & $0.42 \mathrm{nM}$ & seeds & {$[273,289]$} \\
\hline & & Curcin 2 & RIP 1 & $30.1 \mathrm{kDa}$ & n.a. ${ }^{4}$ & recomb. ${ }^{6}$ & {$[290,291]$} \\
\hline & & Curcin-L & RIP 1 & $32 \mathrm{kDa}$ & $4 \mu \mathrm{g} / \mathrm{mL}$ & leaves & {$[292,293]$} \\
\hline & & Jc-SCRIP & RIP 1 & $38,938 \mathrm{Da}$ & n.a. ${ }^{4}$ & seed coat & [294] \\
\hline & $\begin{array}{l}\text { Manihot palmata } \\
\text { Müll. Arg. }\end{array}$ & Mapalmin & RIP 1 & $32.3 \mathrm{kDa}$ & $0.05 \mathrm{nM}$ & seeds & [113] \\
\hline
\end{tabular}


Table 1. Cont.

\begin{tabular}{|c|c|c|c|c|c|c|c|}
\hline Family & Species $^{1}$ & Protein & Classific. & $\mathbf{M w}^{2}$ & $\mathrm{IC}_{50}{ }^{3}$ & Source & References \\
\hline \multirow{15}{*}{ Euphorbiaceae } & \multirow{2}{*}{$\begin{array}{l}\text { Manihot esculenta } \\
\text { Crantz. } \\
\text { [Syn.: Manihot } \\
\text { utilissima } \text { Pohl] }\end{array}$} & Manutin 1 & RIP 1 & n.a. ${ }^{4}$ & $0.05 \mathrm{nM}$ & seeds & {$[284,295]$} \\
\hline & & Manutin 2 & RIP 1 & n.a. ${ }^{4}$ & $0.12 \mathrm{nM}$ & seeds & [295] \\
\hline & \multirow{4}{*}{$\begin{array}{c}\text { Ricinus } \\
\text { communis L. }\end{array}$} & $\begin{aligned} & \text { Ricin } \\
= & \text { crystalline } \\
& \text { Ricin } \\
= & \text { Ricin D }\end{aligned}$ & RIP 2 & $62.8 \mathrm{kDa}$ & $\begin{array}{c}0.14 \mathrm{nM}(\mathrm{A})^{5} \\
814 \mathrm{pM} \\
5.5 \mathrm{ng} / \mathrm{mL}\end{array}$ & seeds & $\begin{array}{c}{[59,281,296-} \\
309]\end{array}$ \\
\hline & & Ricin E & RIP 2 & $64 \mathrm{kDa}$ & n.a. ${ }^{4}$ & seeds & [310-312] \\
\hline & & $\begin{array}{c}\text { RCA } \\
=\text { Ricinus } \\
\text { communis } \\
\text { agglutinin } \\
=\mathrm{RCA}_{\mathrm{I}} \\
=\mathrm{RCA}_{120} \\
=\text { R. communis } \\
\text { hemagglutinin } \\
=\text { RCB-PHA I }\end{array}$ & RIP 2 & $\begin{array}{c}118- \\
130 \mathrm{kDa}\end{array}$ & n.a. ${ }^{4}$ & seeds & {$[303,313-321]$} \\
\hline & & $\begin{array}{c}\text { RCA }_{I I} \\
=\text { RCA }_{60} \\
=\text { RCB-PHA II }\end{array}$ & RIP 2 & $60 \mathrm{kDa}$ & n.a. ${ }^{4}$ & seeds & $\begin{array}{l}{[313,314,} \\
316,317]\end{array}$ \\
\hline & \multirow{3}{*}{$\begin{array}{c}\text { Ricinus communis, } \\
\text { USA }\end{array}$} & Ricin 1 & RIP 2 & $66 \mathrm{kDa}$ & n.a. ${ }^{4}$ & seeds & {$[303,322]$} \\
\hline & & Ricin 2 & RIP 2 & $66 \mathrm{kDa}$ & n.a. ${ }^{4}$ & seeds & {$[303,322]$} \\
\hline & & Ricin 3 & RIP 2 & $66 \mathrm{kDa}$ & n.a. ${ }^{4}$ & seeds & {$[303,322]$} \\
\hline & \multirow{3}{*}{$\begin{array}{c}\text { Ricinus communis, } \\
\text { India }\end{array}$} & Ricin I & RIP 2 & $64 \mathrm{kDa}$ & n.a. ${ }^{4}$ & seeds & {$[322,323]$} \\
\hline & & Ricin II & RIP 2 & $64 \mathrm{kDa}$ & n.a. ${ }^{4}$ & seeds & {$[322,323]$} \\
\hline & & Ricin III & RIP 2 & $64 \mathrm{kDa}$ & n.a. ${ }^{4}$ & seeds & {$[322,323]$} \\
\hline & \multirow{3}{*}{$\begin{array}{c}\text { Ricinus } \\
\text { sanguienus, France }\end{array}$} & $\operatorname{Ricin}_{11}$ & RIP 2 & $57,805 \mathrm{Da}$ & n.a. ${ }^{4}$ & seeds & {$[322,324]$} \\
\hline & & $\operatorname{Ricin}_{12}$ & RIP 2 & $62,163 \mathrm{Da}$ & n.a. ${ }^{4}$ & seeds & {$[322,324]$} \\
\hline & & $\operatorname{Ricin}_{2}$ & RIP 2 & $63,116 \mathrm{Da}$ & n.a. ${ }^{4}$ & seeds & {$[322,324]$} \\
\hline \multirow{6}{*}{ Fabaceae } & \multirow{6}{*}{$\begin{array}{c}\text { Abrus } \\
\text { precatorius } \mathrm{L} .\end{array}$} & Abrin & RIP 2 & $260 \mathrm{kDa}$ & $0.5 \mathrm{nM}(\mathrm{A})^{5}$ & seeds & $\begin{array}{c}{[29,307,315,3} \\
23,325-330] \\
\end{array}$ \\
\hline & & $\begin{aligned} & \text { Abrin-a } \\
= & \text { Abrin C } \\
= & \text { Abrin-III }\end{aligned}$ & RIP 2 & $\begin{array}{c}63- \\
65.5 \mathrm{kDa}\end{array}$ & $60 \mathrm{pM}(\mathrm{A})^{5}$ & seeds & [331-340] \\
\hline & & Abrin-b & RIP 2 & $67 \mathrm{kDa}$ & n.a. ${ }^{4}$ & seeds & [333-335,338] \\
\hline & & $\begin{aligned} & \text { Abrin-c } \\
= & \text { Abrin A } \\
= & \text { Abrin-I }\end{aligned}$ & RIP 2 & $\begin{array}{c}60.1- \\
62.5 \mathrm{kDa}\end{array}$ & n.a. ${ }^{4}$ & seeds & $\begin{array}{l}{[331,332,} \\
334-337]\end{array}$ \\
\hline & & Abrin-d & RIP 2 & $67 \mathrm{kDa}$ & n.a. ${ }^{4}$ & seeds & {$[334,335,338]$} \\
\hline & & Abrin-II & RIP 2 & $63 \mathrm{kDa}$ & n.a. ${ }^{4}$ & seeds & {$[337]$} \\
\hline
\end{tabular}


Table 1. Cont.

\begin{tabular}{|c|c|c|c|c|c|c|c|}
\hline Family & Species $^{1}$ & Protein & Classific. & $\mathbf{M w}^{2}$ & $\mathrm{IC}_{50}{ }^{3}$ & Source & References \\
\hline \multirow{10}{*}{ Fabaceae } & \multirow[t]{3}{*}{$\begin{array}{c}\text { Abrus } \\
\text { precatorius L. }\end{array}$} & $\begin{array}{c}\text { APA } \\
=\text { Abrus } \\
\text { precatorius } \\
\text { agglutinin } \\
=\text { Abrus lectin } \\
=\mathrm{AAG}\end{array}$ & RIP 2 & $\begin{array}{c}126- \\
134 \mathrm{kDa}\end{array}$ & $3.5 \mathrm{nM}$ & seeds & $\begin{array}{l}{[315,334,} \\
341-345]\end{array}$ \\
\hline & & APA-I & RIP 2 & $130 \mathrm{kDa}$ & n.a. ${ }^{4}$ & seeds & {$[337,346]$} \\
\hline & & APA-II & RIP 2 & $128 \mathrm{kDa}$ & n.a. ${ }^{4}$ & seeds & [337] \\
\hline & \multirow{4}{*}{$\begin{array}{c}\text { Abrus pulchellus } \\
\text { Thwaites }\end{array}$} & Pulchellin & RIP 2 & $62 \mathrm{kDa}$ & n.a. ${ }^{4}$ & seeds & [347-349] \\
\hline & & Pulchellin PI & RIP 2 & $\begin{array}{c}61.5- \\
63 \mathrm{kDa}\end{array}$ & n.a. ${ }^{4}$ & seeds & [350] \\
\hline & & Pulchellin PII & RIP 2 & $\begin{array}{c}61.5- \\
63 \mathrm{kDa}\end{array}$ & n.a. ${ }^{4}$ & seeds & {$[350]$} \\
\hline & & Pulchellin PIII & RIP 2 & $\begin{array}{l}61.5- \\
63 \mathrm{kDa}\end{array}$ & n.a. ${ }^{4}$ & seeds & {$[350]$} \\
\hline & \multirow{2}{*}{$\begin{array}{c}\text { Pisum sativum } \\
\text { subsp. sativum L. } \\
\text { [Syn.: Pisum } \\
\text { sativum var. } \\
\text { arvense (L.) Poir.] }\end{array}$} & $\alpha$-pisavin & RIP 1 & $20.5 \mathrm{kDa}$ & $0.5 \mathrm{nM}$ & seeds & {$[351]$} \\
\hline & & $\beta$-pisavin & RIP 1 & $18.7 \mathrm{kDa}$ & $0.5 \mathrm{nM}$ & seeds & [351] \\
\hline & $\begin{array}{c}\text { Pisum sativum var. } \\
\text { macrocarpon }\end{array}$ & Sativin & $\begin{array}{c}\text { RIP } 1 \\
\text { candidate }\end{array}$ & $38 \mathrm{kDa}$ & $14 \mu \mathrm{M}$ & legumes & [352] \\
\hline \multirow{7}{*}{ Iridaceae } & \multirow{7}{*}{$\begin{array}{l}\text { Iris hollandica var. } \\
\text { Professor Blaauw }\end{array}$} & IrisRIP = IRIP & RIP 1 & $28 \mathrm{kDa}$ & $0.1-0.16 \mathrm{nM}$ & bulbs & {$[353,354]$} \\
\hline & & IrisRIP.A1 & RIP 1 & $29 \mathrm{kDa}$ & $0.16 \mathrm{nM}$ & bulbs & [353] \\
\hline & & IrisRIP.A2 & RIP 1 & $29 \mathrm{kDa}$ & $0.12 \mathrm{nM}$ & bulbs & [353] \\
\hline & & IrisRIP.A3 & RIP 1 & $29 \mathrm{kDa}$ & $0.10 \mathrm{nM}$ & bulbs & [353] \\
\hline & & IRA & RIP 2 & $60.4 \mathrm{kDa}$ & n.a. ${ }^{4}$ & bulbs & [355] \\
\hline & & IRAb & RIP 2 & $65 \mathrm{kDa}$ & n.a. ${ }^{4}$ & bulbs & {$[356,357]$} \\
\hline & & IRAr & RIP 2 & $65 \mathrm{kDa}$ & n.a. ${ }^{4}$ & bulbs & {$[356]$} \\
\hline \multirow{4}{*}{ Lamiaceae } & $\begin{array}{c}\text { Clerodendrum } \\
\text { aculeatum (L.) } \\
\text { Schltdl. }\end{array}$ & CA-SRI & $\begin{array}{c}\text { RIP } 1 \\
\text { candidate }\end{array}$ & $34 \mathrm{kDa}$ & $<0.01 \mathrm{nM}$ & leaves & {$[358,359]$} \\
\hline & \multirow{2}{*}{$\begin{array}{c}\text { Clerodendrum } \\
\text { inerme (L.) Gaertn. }\end{array}$} & CIP-29 & RIP 1 & $29 \mathrm{kDa}$ & $\begin{array}{c}0.548 \mathrm{nM} \\
16 \mathrm{ng} / \mathrm{mL} \\
\end{array}$ & leaves & {$[360,361]$} \\
\hline & & CIP-34 & $\begin{array}{c}\text { RIP } 1 \\
\text { candidate } \\
\end{array}$ & $34 \mathrm{kDa}$ & $\begin{array}{l}87.4 \mathrm{nM} \\
3 \mu \mathrm{g} / \mathrm{mL}\end{array}$ & leaves & {$[360,361]$} \\
\hline & $\begin{array}{c}\text { Leonurus } \\
\text { japonicus Houtt. }\end{array}$ & Leonurin & $\begin{array}{c}\text { RIP } \\
\text { candidate }\end{array}$ & n.a. ${ }^{4}$ & n.a. ${ }^{4}$ & seeds & [362] \\
\hline Lauraceae & $\begin{array}{c}\text { Cinnamomum } \\
\text { bodinieri H. Lév. }\end{array}$ & Bodinierin & RIP 2 & $65 \mathrm{kDa}$ & $1.2 \mathrm{nM}(\mathrm{A})^{5}$ & kernel & [363] \\
\hline
\end{tabular}


Table 1. Cont.

\begin{tabular}{|c|c|c|c|c|c|c|c|}
\hline Family & Species $^{1}$ & Protein & Classific. & $\mathbf{M w}^{2}$ & $\mathrm{IC}_{50}{ }^{3}$ & Source & References \\
\hline \multirow[b]{7}{*}{ Lauraceae } & \multirow{6}{*}{$\begin{array}{l}\text { Cinnamomum } \\
\text { camphora (L.) } \\
\text { J.Presl }\end{array}$} & Camphorin & RIP 1 & $23 \mathrm{kDa}$ & $0.098 \mathrm{nM}$ & seeds & {$[364,365]$} \\
\hline & & Cinnamomin & RIP 2 & $61 \mathrm{kDa}$ & $9.7 \mathrm{nM}(\mathrm{A})^{5}$ & seeds & [364-367] \\
\hline & & Cinnamomin 1 & RIP 2 & $61 \mathrm{kDa}$ & n.a. ${ }^{4}$ & seeds & [364] \\
\hline & & Cinnamomin 2 & RIP 2 & n.a. ${ }^{4}$ & n.a. ${ }^{4}$ & seeds & [364] \\
\hline & & Cinnamomin 3 & RIP 2 & n.a. ${ }^{4}$ & n.a. ${ }^{4}$ & seeds & [364] \\
\hline & & Cinphorin & sRIP 2 & $46 \mathrm{kDa}$ & $1.2 \mathrm{nM}$ & seeds & {$[367,368]$} \\
\hline & $\begin{array}{c}\text { Cinnamomum } \\
\text { parthenoxylon } \\
\text { (Jack) Meisn. } \\
\text { [Syn.: } \\
\text { Cinnamomum } \\
\text { porrectum (Roxb.) } \\
\text { Kosterm.] }\end{array}$ & Porrectin & RIP 2 & $64.5 \mathrm{kDa}$ & $0.11 \mu \mathrm{M}$ & seeds & [369] \\
\hline Malvaceae & $\begin{array}{c}\text { Abelmoschus } \\
\text { esculentus (L.) } \\
\text { Moench }\end{array}$ & Abelesculin & RIP 1 & $30 \mathrm{kDa}$ & n.a. ${ }^{4}$ & seeds & [370] \\
\hline \multirow{13}{*}{ Nyctaginaceae } & $\begin{array}{c}\text { Boerhaavia } \\
\text { diffusa } \mathrm{L} .\end{array}$ & $\begin{array}{c}\text { Boerhaavia } \\
\text { inhibitor } \\
\end{array}$ & $\begin{array}{c}\text { RIP } 1 \\
\text { candidate }\end{array}$ & $16-20 \mathrm{kDa}$ & n.a. ${ }^{4}$ & roots & [371-373] \\
\hline & & BAP I & RIP 1 & $28 \mathrm{kDa}$ & n.a. ${ }^{4}$ & roots & [374] \\
\hline & $\begin{array}{c}\text { Bougainvillea } \\
\text { spectabilis Willd. }\end{array}$ & $\begin{array}{c}\text { Bouganin } \\
=\text { Bougainvillea } \\
\text { RIP I } \\
\end{array}$ & RIP 1 & $26.2 \mathrm{kDa}$ & $10.5 \mathrm{ng} / \mathrm{mL}$ & leaves & {$[120,375]$} \\
\hline & \multirow{2}{*}{$\begin{array}{c}\text { Bougainvillea } \times \\
\text { buttiana } c v . \text { Enid } \\
\text { Lancester }\end{array}$} & BBP-24 & RIP 1 & $24 \mathrm{kDa}$ & n.a. ${ }^{4}$ & leaves & {$[376,377]$} \\
\hline & & BBP-28 & RIP 1 & $28 \mathrm{kDa}$ & n.a. ${ }^{4}$ & leaves & {$[376,377]$} \\
\hline & $\begin{array}{c}\text { Bougainvillea } \times \\
\text { buttiana cv. } \\
\text { Mahara } \\
\end{array}$ & BBAP1 & RIP 1 & $35.49 \mathrm{kDa}$ & n.a. ${ }^{4}$ & leaves & {$[378,379]$} \\
\hline & \multirow{2}{*}{$\begin{array}{c}\text { Mirabilis expansa } \\
\text { (Ruiz \& Pav.) } \\
\text { Standl. }\end{array}$} & ME1 & RIP 1 & $29,208 \mathrm{Da}$ & n.a. ${ }^{4}$ & roots & {$[380,381]$} \\
\hline & & ME2 & RIP 1 & $27 \mathrm{kDa}$ & n.a. ${ }^{4}$ & roots & [380] \\
\hline & \multirow{5}{*}{ Mirabilis jalapa L. } & MAP & RIP 1 & $27,788 \mathrm{Da}$ & $5.4 \mathrm{ng} / \mathrm{mL}$ & roots/seeds & {$[373,382,383]$} \\
\hline & & MAP-2 & RIP 1 & $30,412 \mathrm{Da}$ & $41.4 \mathrm{ng} / \mathrm{mL}$ & seeds & [383] \\
\hline & & MAP-3 & RIP 1 & $29,771 \mathrm{Da}$ & $13.3 \mathrm{ng} / \mathrm{mL}$ & seeds & [383] \\
\hline & & MAP-4 & RIP 1 & $29,339 \mathrm{Da}$ & $15.3 \mathrm{ng} / \mathrm{mL}$ & $\begin{array}{c}\text { seeds and } \\
\text { leaves }\end{array}$ & [383] \\
\hline & & MAP-S & RIP 1 & $27,789 \mathrm{Da}$ & n.a. ${ }^{4}$ & seeds & [146] \\
\hline Olacaceae & $\begin{array}{l}\text { Malania oleifera } \\
\text { Chun \& S. K. Lee }\end{array}$ & Malanin & $\begin{array}{c}\text { lectin/ } \\
\text { RIP } 2 \\
\text { candidate }\end{array}$ & $61875 \mathrm{Da}$ & n.a. ${ }^{4}$ & seeds & [384] \\
\hline
\end{tabular}


Table 1. Cont.

\begin{tabular}{|c|c|c|c|c|c|c|c|}
\hline Family & Species $^{1}$ & Protein & Classific. & $\mathbf{M w}^{2}$ & $\mathrm{IC}_{50}{ }^{3}$ & Source & References \\
\hline \multirow{3}{*}{ Olacaceae } & \multirow{3}{*}{$\begin{array}{c}\text { Ximenia } \\
\text { americana L. }\end{array}$} & $\begin{array}{l}\text { Riproximin } \\
\quad=\mathrm{Rpx}\end{array}$ & RIP 2 & $56 \mathrm{kDa}$ & n.a. ${ }^{4}$ & $\begin{array}{c}\text { fruit } \\
\text { kernels }\end{array}$ & {$[385,386]$} \\
\hline & & Rpx-I & RIP 2 & $50 \mathrm{kDa}$ & n.a. ${ }^{4}$ & $\begin{array}{c}\text { fruit } \\
\text { kernels }\end{array}$ & {$[386]$} \\
\hline & & Rpx-II & RIP 2 & $53 \mathrm{kDa}$ & n.a. ${ }^{4}$ & $\begin{array}{c}\text { fruit } \\
\text { kernels }\end{array}$ & [386] \\
\hline \multirow{13}{*}{ Passifloraceae } & \multirow[t]{2}{*}{$\begin{array}{l}\text { Adenia digitata } \\
\text { (Harv.) Engl. }\end{array}$} & $\begin{aligned} & \text { Modeccin } \\
= & \text { Modeccin 4B }\end{aligned}$ & RIP 2 & $57-63 \mathrm{kDa}$ & $\begin{array}{c}4 \mu \mathrm{g} / \mathrm{mL} ; \\
2.52 \mu \mathrm{g} / \mathrm{mL} \\
66 \mathrm{ng} / \mathrm{mL}(\mathrm{A})^{5}\end{array}$ & roots & [387-390] \\
\hline & & Modeccin 6B & RIP 2 & $57 \mathrm{kDa}$ & $0.31 \mu \mathrm{g} / \mathrm{mL}$ & roots & [390] \\
\hline & $\begin{array}{c}\text { Adenia ellenbeckii } \\
\text { Harms }\end{array}$ & $\begin{array}{c}\text { A. ellenbeckii } \\
\text { lectin }\end{array}$ & $\begin{array}{c}\text { RIP } 2 \\
\text { candidate }\end{array}$ & $60 \mathrm{kDa}$ & $\begin{array}{c}10.1 \mu \mathrm{g} / \mathrm{mL} ; \\
1.2 \mu \mathrm{g} / \mathrm{mL}(\mathrm{A})^{5}\end{array}$ & caudex & {$[45]$} \\
\hline & $\begin{array}{c}\text { Adenia fruticosa } \\
\text { Burtt Davy }\end{array}$ & A. fruticosa lectin & lectin & $30 \mathrm{kDa}$ & $>100 \mu \mathrm{g} / \mathrm{mL}$ & caudex & {$[45]$} \\
\hline & $\begin{array}{c}\text { Adenia glauca } \\
\text { Schinz } \\
\end{array}$ & A. glauca lectin & $\begin{array}{c}\text { RIP } 2 \\
\text { candidate }\end{array}$ & n.a. ${ }^{4}$ & $\begin{array}{c}>10 \mu \mathrm{g} / \mathrm{mL} \\
>5 \mu \mathrm{g} / \mathrm{mL}(\mathrm{A})^{5}\end{array}$ & caudex & {$[45]$} \\
\hline & $\begin{array}{c}\text { Adenia goetzei } \\
\text { Harms (unresolved } \\
\text { name) }\end{array}$ & A. goetzei lectin & RIP 2 & $60 \mathrm{kDa}$ & $\begin{array}{c}55.1 \mu \mathrm{g} / \mathrm{mL} \\
0.7 \mu \mathrm{g} / \mathrm{mL}(\mathrm{A})^{5}\end{array}$ & caudex & {$[45]$} \\
\hline & $\begin{array}{c}\text { Adenia } \\
\text { keramanthus } \\
\text { Harms } \\
\end{array}$ & $\begin{array}{c}\text { A. keramanthus } \\
\text { lectin }\end{array}$ & $\begin{array}{c}\text { RIP } 2 \\
\text { candidate }\end{array}$ & $60-65 \mathrm{kDa}$ & $\begin{array}{c}10.0 \mu \mathrm{g} / \mathrm{mL} \\
1.1 \mu \mathrm{g} / \mathrm{mL}(\mathrm{A})^{5}\end{array}$ & caudex & {$[45]$} \\
\hline & $\begin{array}{c}\text { Adenia lanceolata } \\
\text { Engl. }\end{array}$ & Lanceolin & RIP 2 & $60 \mathrm{kDa}$ & $\begin{array}{c}5.2 \mu \mathrm{g} / \mathrm{mL} \\
1.1 \mu \mathrm{g} / \mathrm{mL}(\mathrm{A})^{5}\end{array}$ & caudex & {$[45,391,392]$} \\
\hline & $\begin{array}{c}\text { Adenia racemosa } \\
\text { W. J. de Wilde }\end{array}$ & $\begin{array}{c}\text { A. racemosa } \\
\text { lectin } \\
\end{array}$ & lectin & $30 \mathrm{kDa}$ & $>400 \mu \mathrm{g} / \mathrm{mL}$ & caudex & {$[45]$} \\
\hline & $\begin{array}{c}\text { Adenia spinosa } \\
\text { Burtt Davy } \\
\end{array}$ & A. spinosa lectin & $\begin{array}{c}\text { RIP } 2 \\
\text { candidate }\end{array}$ & n.a. ${ }^{4}$ & $\begin{array}{c}4.7 \mu \mathrm{g} / \mathrm{mL} ; \\
0.8 \mu \mathrm{g} / \mathrm{mL}(\mathrm{A})^{5}\end{array}$ & caudex & {$[45]$} \\
\hline & $\begin{array}{c}\text { Adenia } \\
\text { stenodactyla } \\
\text { Harms } \\
\end{array}$ & Stenodactylin & RIP 2 & $60 \mathrm{kDa}$ & $\begin{array}{c}5.6 \mu \mathrm{g} / \mathrm{mL} \\
0.5 \mu \mathrm{g} / \mathrm{mL}(\mathrm{A})^{5}\end{array}$ & caudex & {$[45,391,392]$} \\
\hline & $\begin{array}{c}\text { Adenia venenata } \\
\text { Forssk. }\end{array}$ & A. venenata lectin & $\begin{array}{c}\text { RIP } 2 \\
\text { candidate }\end{array}$ & $60 \mathrm{kDa}$ & $\begin{array}{c}2.4 \mu \mathrm{g} / \mathrm{mL} \\
0.4 \mu \mathrm{g} / \mathrm{mL}(\mathrm{A})^{5}\end{array}$ & caudex & {$[45]$} \\
\hline & $\begin{array}{c}\text { Adenia volkensii } \\
\text { Harms }\end{array}$ & Volkensin & RIP 2 & $62 \mathrm{kDa}$ & $\begin{array}{c}5 \mu \mathrm{g} / \mathrm{mL} \\
84 \mathrm{nM} \\
0.37 \mathrm{nM}(\mathrm{A})^{5} \\
22 \mathrm{ng} / \mathrm{mL}(\mathrm{A})^{5} \\
7.5 \mu \mathrm{g} / \mathrm{mL} \\
0.66 \mu \mathrm{g} / \mathrm{mL} \\
\text { (A) }{ }^{5}\end{array}$ & roots & [45,393-395] \\
\hline
\end{tabular}


Table 1. Cont.

\begin{tabular}{|c|c|c|c|c|c|c|c|}
\hline Family & Species ${ }^{1}$ & Protein & Classific. & $\mathbf{M w}^{2}$ & $\mathrm{IC}_{50}{ }^{3}$ & Source & References \\
\hline \multirow{20}{*}{ Phytolaccaceae } & \multirow{11}{*}{$\begin{array}{l}\text { Phytolacca } \\
\text { americana L. }\end{array}$} & $\alpha$-PAP & RIP 1 & $33,068 \mathrm{kDa}$ & n.a. ${ }^{4}$ & recomb. ${ }^{6}$ & {$[396,397]$} \\
\hline & & $\begin{array}{c}\text { PAP } \\
=\text { Phytolacca } \\
\text { americana } \\
\text { protein } \\
=\text { pokeweed } \\
\text { antiviral protein }\end{array}$ & RIP 1 & $29-30 \mathrm{kDa}$ & $0.29 \mathrm{nM}$ & leaves & {$[29,398-403]$} \\
\hline & & PAP-I & RIP 1 & $30 \mathrm{kDa}$ & $2 \mathrm{pM}$ & $\begin{array}{l}\text { spring } \\
\text { leaves }\end{array}$ & [404] \\
\hline & & PAP-II & RIP 1 & $30-31 \mathrm{kDa}$ & $4 \mathrm{pM}$ & $\begin{array}{c}\text { early } \\
\text { summer } \\
\text { leaves }\end{array}$ & $\begin{array}{l}{[399,400} \\
404,405]\end{array}$ \\
\hline & & PAP-III & RIP 1 & $30 \mathrm{kDa}$ & $3 \mathrm{pM}$ & $\begin{array}{c}\text { late } \\
\text { summer } \\
\text { leaves }\end{array}$ & [404] \\
\hline & & PAP-C & RIP 1 & $29 \mathrm{kDa}$ & $\begin{array}{c}0.062 \mathrm{nM} \\
2 \mathrm{ng} / \mathrm{mL}\end{array}$ & $\begin{array}{c}\text { cell } \\
\text { cultures }\end{array}$ & [406] \\
\hline & & PAP-H & RIP 1 & $29.5 \mathrm{kDa}$ & n.a. ${ }^{4}$ & hairy roots & [407] \\
\hline & & PAP-R & RIP 1 & $29.8 \mathrm{kDa}$ & $0.05 \mathrm{nM}$ & roots & [113] \\
\hline & & PAP-S & RIP 1 & $30 \mathrm{kDa}$ & $\begin{array}{c}36-83 \mathrm{nM} \\
1.09- \\
2.5 \mathrm{ng} / \mathrm{mL}\end{array}$ & seeds & {$[399,408]$} \\
\hline & & PAP-S1 & RIP 1 & n.a. ${ }^{4}$ & n.a. ${ }^{4}$ & recomb. ${ }^{6}$ & [397] \\
\hline & & PAP-S2 & RIP 1 & n.a. ${ }^{4}$ & n.a. ${ }^{4}$ & recomb. ${ }^{6}$ & [397] \\
\hline & \multirow{9}{*}{$\begin{array}{c}\text { Phytolacca } \\
\text { dioica } \mathrm{L} .\end{array}$} & Diocin 1 & RIP 1 & $30,047 \mathrm{Da}$ & $\begin{array}{c}19.74 \mathrm{ng} / \mathrm{mL} ; \\
0.658 \mathrm{nM}\end{array}$ & $\begin{array}{c}\text { leaves of } \\
\text { young } \\
\text { plants }\end{array}$ & [409] \\
\hline & & Diocin 2 & RIP 1 & $29,910 \mathrm{Da}$ & $\begin{array}{c}6.85 \mathrm{ng} / \mathrm{mL} \\
0.229 \mathrm{nM}\end{array}$ & $\begin{array}{c}\text { leaves of } \\
\text { young } \\
\text { plants }\end{array}$ & [409] \\
\hline & & PD-L1 & RIP 1 & $32,715 \mathrm{Da}$ & $\begin{array}{c}102 \mathrm{pM} \\
3.32 \mathrm{ng} / \mathrm{mL} \\
8.5 \mathrm{pM} \\
\end{array}$ & leaves & {$[410,411]$} \\
\hline & & PD-L2 & RIP 1 & $31,542 \mathrm{Da}$ & $\begin{array}{c}110 \mathrm{pM} \\
3.46 \mathrm{ng} / \mathrm{mL}\end{array}$ & leaves & {$[410,412]$} \\
\hline & & PD-L3 & RIP 1 & $30,356 \mathrm{Da}$ & $\begin{array}{c}228 \mathrm{pM} \\
6.93 \mathrm{ng} / \mathrm{mL}\end{array}$ & leaves & {$[410,412]$} \\
\hline & & PD-L4 & RIP 1 & $29185 \mathrm{Da}$ & $\begin{array}{c}134 \mathrm{pM} \\
3.92 \mathrm{ng} / \mathrm{mL}\end{array}$ & leaves & {$[410,413]$} \\
\hline & & PD-S1 & RIP 1 & $30.9 \mathrm{kDa}$ & $0.12 \mathrm{nM}$ & seeds & [414] \\
\hline & & PD-S2 & RIP 1 & $29,586 \mathrm{Da}$ & $0.06 \mathrm{nM}$ & seeds & {$[414,415]$} \\
\hline & & PD-S3 & RIP 1 & $32 \mathrm{kDa}$ & $0.08 \mathrm{nM}$ & seeds & [414] \\
\hline
\end{tabular}


Table 1. Cont.

\begin{tabular}{|c|c|c|c|c|c|c|c|}
\hline Family & Species ${ }^{1}$ & Protein & Classific. & $\mathbf{M w}^{2}$ & $\mathrm{IC}_{50}{ }^{3}$ & Source & References \\
\hline \multirow{6}{*}{ Phytolaccaceae } & \multirow{2}{*}{$\begin{array}{c}\text { Phytolacca } \\
\text { dodecandra L'Hér. }\end{array}$} & Dodecandrin & RIP 1 & $29 \mathrm{kDa}$ & n.a. ${ }^{4}$ & leaves & {$[416,417]$} \\
\hline & & Dodecandrin $\mathrm{C}$ & RIP 1 & $31-32 \mathrm{kDa}$ & n.a. ${ }^{4}$ & $\begin{array}{c}\text { cell } \\
\text { cultures }\end{array}$ & {$[417]$} \\
\hline & \multirow{2}{*}{$\begin{array}{c}\text { Phytolacca } \\
\text { heterotepala } \mathrm{H} . \\
\text { Walter }\end{array}$} & Heterotepalin 4 & RIP 1 & $29,326 \mathrm{Da}$ & $82 \mathrm{pM}$ & leaves & [418] \\
\hline & & Heterotepalin $5 \mathrm{~b}$ & RIP 1 & $30,477 \mathrm{Da}$ & $52 \mathrm{pM}$ & leaves & [418] \\
\hline & \multirow[t]{2}{*}{$\begin{array}{c}\text { Phytolacca } \\
\text { insularis Nakai }\end{array}$} & $\begin{array}{c}\text { Insularin } \\
=\mathrm{PIP} \\
=\text { Phytolacca } \\
\text { insularis antiviral } \\
\text { protein }\end{array}$ & RIP 1 & $31 \mathrm{kDa}$ & n.a. ${ }^{4}$ & recomb. ${ }^{6}$ & {$[7,419]$} \\
\hline & & $\begin{array}{c}\text { PIP2 } \\
=P . \text { insularis } \\
\text { antiviral protein } 2\end{array}$ & RIP 1 & $29.6 \mathrm{kDa}$ & $0.04 \mathrm{nM}$ & recomb. ${ }^{6}$ & [420] \\
\hline \multirow{5}{*}{ Poaceae } & \multirow{5}{*}{$\begin{array}{l}\text { Hordeum } \\
\text { vulgare } \mathrm{L} .\end{array}$} & $\begin{array}{c}\text { Barley toxin } \\
=\text { Barley } \\
\text { translation } \\
\text { inhibitor } \\
=\text { Barley Protein } \\
\text { Synthesis } \\
\text { Inhibitor } \\
=\text { BPSI } \\
=\text { RIP } 30\end{array}$ & RIP 1 & $30 \mathrm{kDa}$ & $0.47 \mathrm{nM}$ & seeds & {$[281,421-424]$} \\
\hline & & $\begin{array}{l}\text { Barley toxin I } \\
\quad=\text { Barley } \\
\text { translation } \\
\text { inhibitor I }\end{array}$ & RIP 1 & $30 \mathrm{kDa}$ & $25 \mathrm{ng} / \mathrm{mL}$ & seeds & [422] \\
\hline & & $\begin{array}{c}\text { Barley toxin II } \\
=\text { Barley } \\
\text { translation } \\
\text { inhibitor II } \\
=\text { Barley Protein } \\
\text { Synthesis } \\
\text { Inhibitor II } \\
=\text { BPSI II }\end{array}$ & RIP 1 & $29,836 \mathrm{Da}$ & $25 \mathrm{ng} / \mathrm{mL}$ & seeds & $\begin{array}{l}{[281,421,} \\
422,425]\end{array}$ \\
\hline & & $\begin{array}{l}\text { Barley toxin III } \\
\quad=\text { Barley } \\
\text { translation } \\
\text { inhibitor III }\end{array}$ & RIP 1 & $30 \mathrm{kDa}$ & $15 \mathrm{ng} / \mathrm{mL}$ & seeds & {$[281,422]$} \\
\hline & & JIP60 & $\begin{array}{l}\text { RIP 3/ } \\
\text { peculiar } \\
\text { RIP 1 }\end{array}$ & $60 \mathrm{kDa}$ & n.a. ${ }^{4}$ & recomb. ${ }^{6}$ & {$[5,426]$} \\
\hline
\end{tabular}


Table 1. Cont.

\begin{tabular}{|c|c|c|c|c|c|c|c|}
\hline Family & Species $^{1}$ & Protein & Classific. & $\mathbf{M w}^{2}$ & $\mathrm{IC}_{50}{ }^{3}$ & Source & References \\
\hline \multirow{10}{*}{ Poaceae } & Oryza sativa L. & Oryza sativa RIP & RIP 1 & $27 \mathrm{kDa}$ & n.a. ${ }^{4}$ & recomb. ${ }^{6}$ & [427] \\
\hline & Secale cereale L. & RPSI & RIP 1 & $30,171 \mathrm{Da}$ & $0.42 \mu \mathrm{g} / \mathrm{mL}$ & seeds & {$[421,428]$} \\
\hline & \multirow{6}{*}{$\begin{array}{c}\text { Triticum } \\
\text { aestivum } \mathrm{L} .\end{array}$} & Tritin & RIP 1 & $30 \mathrm{kDa}$ & n.a. ${ }^{4}$ & germ & {$[421,429-431]$} \\
\hline & & Tritin 1 & RIP 1 & $30 \mathrm{kDa}$ & $250 \mathrm{ng} / \mathrm{mL}$ & $\begin{array}{l}\text { whole } \\
\text { wheat }\end{array}$ & [432] \\
\hline & & Tritin 2 & RIP 1 & $30 \mathrm{kDa}$ & $250 \mathrm{ng} / \mathrm{mL}$ & $\begin{array}{l}\text { whole } \\
\text { wheat }\end{array}$ & [432] \\
\hline & & Tritin 3 & RIP 1 & $30 \mathrm{kDa}$ & $250 \mathrm{ng} / \mathrm{mL}$ & $\begin{array}{l}\text { whole } \\
\text { wheat }\end{array}$ & {$[432]$} \\
\hline & & Tritin-S & RIP 1 & $\begin{array}{c}32.1- \\
32.8 \mathrm{kDa} \\
\end{array}$ & n.a. ${ }^{4}$ & seeds & [433] \\
\hline & & Tritin-L & RIP 1 & $\begin{array}{c}37.0- \\
37.9 \mathrm{kDa} \\
\end{array}$ & n.a. ${ }^{4}$ & leaves & [433] \\
\hline & \multirow{2}{*}{ Zea mays $\mathrm{L}$. } & $\begin{aligned} & \mathrm{b}-32 \\
= & \text { maize RIP } \\
= & \text { maize proRIP1 }\end{aligned}$ & $\begin{array}{l}\text { RIP 3/ } \\
\text { peculiar } \\
\text { RIP 1 } \\
\end{array}$ & $34 \mathrm{kDa}$ & $\begin{array}{c}28-60 \mathrm{pM} ; \\
0.7-1.5 \mathrm{ng} / \mathrm{mL} ; \\
0.065 \mathrm{nM} \\
\end{array}$ & seeds & {$[4,434-438]$} \\
\hline & & Maize proRIP2 & $\begin{array}{l}\text { RIP 3/ } \\
\text { peculiar } \\
\text { RIP 1 }\end{array}$ & $31.1 \mathrm{kDa}$ & n.a. ${ }^{4}$ & recomb. ${ }^{6}$ & {$[436,437]$} \\
\hline Ranunculaceae & $\begin{array}{c}\text { Eranthis hyemalis } \\
\text { (L.) Salisb. }\end{array}$ & EHL & RIP 2 & $62 \mathrm{kDa}$ & n.a. ${ }^{4}$ & root tubers & {$[439,440]$} \\
\hline \multirow{9}{*}{ Santalaceae } & $\begin{array}{l}\text { Phoradendron } \\
\text { californicum Nutt. }\end{array}$ & PCL & RIP 2 & $69 \mathrm{kDa}$ & n.a. ${ }^{4}$ & n.n & [441] \\
\hline & \multirow{5}{*}{$\begin{array}{l}\text { Viscum album L. } \\
\text { (Himalayan } \\
\text { mistletoe) }\end{array}$} & HmRip & RIP 2 & $65 \mathrm{kDa}$ & n.a. ${ }^{4}$ & leaves & {$[442-444]$} \\
\hline & & HmRip 1 & RIP 2 & $65 \mathrm{kDa}$ & n.a. ${ }^{4}$ & leaves & [442-444] \\
\hline & & HmRip 2 & RIP 2 & $65 \mathrm{kDa}$ & n.a. ${ }^{4}$ & leaves & [442-444] \\
\hline & & HmRip 3 & RIP 2 & $65 \mathrm{kDa}$ & n.a. ${ }^{4}$ & leaves & [442-444] \\
\hline & & HmRip 4 & RIP 2 & $65 \mathrm{kDa}$ & n.a. ${ }^{4}$ & leaves & [442-444] \\
\hline & \multirow{3}{*}{$\begin{array}{l}\text { Viscum album } \mathrm{L} \text {. } \\
\text { (European } \\
\text { mistletoe) }\end{array}$} & $\begin{array}{c}\text { ML-I } \\
=\text { Mistletoe lectin I } \\
=\text { Viscumin } \\
=\text { Eu-ML } \\
=\text { EML-1 } \\
=\text { VAA-I }\end{array}$ & RIP 2 & $\begin{array}{c}115- \\
125 \mathrm{kDa}\end{array}$ & $\begin{array}{c}2.6 \mu \mathrm{g} / \mathrm{mL} \\
0.21 \mu \mathrm{g} / \mathrm{mL} \\
(\mathrm{A})^{5} \\
3.7 \mathrm{pM}(\mathrm{A})^{5}\end{array}$ & leaves & {$[234,445-454]$} \\
\hline & & $\begin{array}{c}\text { ML-II } \\
=\text { Mistletoe lectin II } \\
=\text { VAA-II }\end{array}$ & RIP 2 & $60-64 \mathrm{kDa}$ & n.a. ${ }^{4}$ & leaves & {$[448,450-452]$} \\
\hline & & $\begin{aligned} & \text { ML-III } \\
&= \text { Mistletoe } \\
& \text { lectin III } \\
&=\text { VAA-III }\end{aligned}$ & RIP 2 & $50-61 \mathrm{kDa}$ & n.a. ${ }^{4}$ & leaves & {$[448,450-452]$} \\
\hline
\end{tabular}


Table 1. Cont.

\begin{tabular}{|c|c|c|c|c|c|c|c|}
\hline Family & Species ${ }^{1}$ & Protein & Classific. & $\mathbf{M w}^{2}$ & $\mathrm{IC}_{50}{ }^{3}$ & Source & References \\
\hline \multirow{6}{*}{ Santalaceae } & $\begin{array}{c}\text { Viscum } \\
\text { articulatum } \\
\text { Burm. } f .\end{array}$ & Articulatin-D & RIP 2 & $66 \mathrm{kDa}$ & n.a. ${ }^{4}$ & $\begin{array}{l}\text { whole } \\
\text { plant }\end{array}$ & {$[455]$} \\
\hline & \multirow{5}{*}{$\begin{array}{l}\text { Viscum coloratum } \\
\text { (Kom.) Nakai } \\
\text { [Syn.: Viscum } \\
\text { album subsp. } \\
\text { coloratum Kom.] }\end{array}$} & KML & RIP 2 & n.a. ${ }^{4}$ & n.a. ${ }^{4}$ & leaves & {$[456]$} \\
\hline & & KML-C & RIP 2 & $59.5 \mathrm{kDa}$ & n.a. ${ }^{4}$ & leaves & {$[454,457]$} \\
\hline & & KML-IIL & RIP 2 & $60 \mathrm{kDa}$ & n.a. ${ }^{4}$ & leaves & [457] \\
\hline & & KML-IIU & RIP 2 & $64 \mathrm{kDa}$ & n.a. ${ }^{4}$ & leaves & [457] \\
\hline & & VCA & RIP 2 & $60 \mathrm{kDa}$ & n.a. ${ }^{4}$ & leaves & {$[458,459]$} \\
\hline \multirow{2}{*}{ Solanaceae } & \multirow{2}{*}{$\begin{array}{l}\text { Nicotiana } \\
\text { tabacum L. }\end{array}$} & CIP31 & $\begin{array}{l}\text { RIP-like } \\
\text { protein }\end{array}$ & $31 \mathrm{kDa}$ & n.a. ${ }^{4}$ & leaves & {$[460]$} \\
\hline & & TRIP & $\begin{array}{c}\text { RIP } 1 \\
\text { candidate }\end{array}$ & $26 \mathrm{kDa}$ & $100 \mathrm{ng} / \mathrm{mL}$ & leaves & [461] \\
\hline Thymelaeaceae & $\begin{array}{c}\text { Phaleria } \\
\text { macrocarpa } \\
\text { (Scheff.) Boerl. }\end{array}$ & $\begin{array}{c}\text { P. macrocarpa } \\
\text { RIP }\end{array}$ & $\begin{array}{c}\text { RIP } \\
\text { candidate }\end{array}$ & n.a. ${ }^{4}$ & n.a. ${ }^{4}$ & seeds & [462] \\
\hline
\end{tabular}

\begin{abstract}
${ }^{1}$ For the botanical name of the plant species we chose the current accepted name from www.theplantlist.org. In some cases, there is also given a synonym, because the protein/RIP is derived from that synonym that is given in the corresponding reference;

${ }^{2}$ For the values of molecular weight $(\mathrm{Mw})$ we listed the latest values from the native unreduced proteins obtained from gel filtration or from SDS-PAGE. If there were too many different values from different authors, we listed a range. We listed the exact value obtained from MALDI-TOF, ESI-TOF or Q-TOF, if this was available; ${ }^{3} \mathrm{IC}_{50}$ is the half minimal inhibitory concentration (50\%) of the protein, which inhibits translation from a cell free system using rabbit reticulocyte lysate. For the $\mathrm{IC}_{50}$ values, we listed the values of the molar mass or concentration in $\mathrm{mg} / \mathrm{mL}$. In some cases, there were many different values from different laboratories that led us to list a range; ${ }^{4}$ n.a. $=$ not available; in the case of $\mathrm{IC}_{50}$ values there are several reasons for n.a.: 1. The translation-inhibitory assay was not performed; 2 . The translation-inhibitory assay was performed by using another system than the cell free system with rabbit reticulocyte lysate, e.g., cancer cells; 3 . The $\mathrm{IC}_{50}$ values were specified with another unit, e.g., $\mathrm{mg} / \mathrm{kg} ;{ }^{5}(\mathrm{~A})=\mathrm{A}$-chain; the $\mathrm{IC}_{50}$ value followed by (A) is for the reduced type $2 \mathrm{RIP} ;{ }^{6}$ recomb. = recombinant; Proteins obtained through biotechnological procedures.
\end{abstract}

\title{
3. Exceptions Prove the Rule
}

To be classified as "classical" type 1 or type 2 RIP, a protein needs both the structure and the $\mathrm{N}$-glycosidase activity including the conserved amino acid residues, which are believed to be present in all RIPs, of the putative active site region [94,101,463]. This active site region is also known as shiga/ricin toxic domain [106]. Beside the peculiar type 1 RIPs, b-32 and JIP60, there is a certain amount of other proteins that cannot be grouped into the classical type 1 or type 2 RIPs, because of structural and functional differences.

\subsection{Small RIPS}

First of all, there are "small type 1 RIPs" (sRIP 1; Table 2), which are single chain proteins exhibiting $N$-glycosidase activity with a smaller molecular weight than the classical type 1 RIPs. Interestingly, all known small type 1 RIPs are synthesized by plants belonging to the family Cucurbitaceae. $\alpha$-luffin and $\beta$-luffin from Luffa cylindrica indeed have the same size as the other small type 1 RIPs, but because of 
their lower toxicity of $17 \mu \mathrm{M}$ and $300 \mathrm{nM}$, respectively, and due to the unknown mechanism of action, they are classified as "small type 1 RIP candidates" (Table 3). Also luffin-S, luffinS(1), luffinS(2), and luffinS(3) have similar sizes as the other small type 1 RIPs and all of them inhibit protein synthesis in a cell-free system, but it was not analyzed, whether the translation-inhibitory is due to the $N$-glycosidase activity or not. In addition, a different mechanism of action was found for luffin-S [186]. For this reason, the luffinSs are considered as small type 1 RIP candidates (Table 3). Another small type 1 RIP candidate is cucurmoschin that was designated as an antifungal protein by the authors [160]. Cucurmoschin indeed inhibits protein synthesis in a cell-free system, but there was no homology with other type 1 RIPs or small type 1 RIPs concerning the amino acid sequence specified, but the fact that the $N$-glycosidase activity was neither verified nor excluded led us to the decision to classify cucurmoschin as a small type 1 RIP candidate. Lagenin, $\alpha$-pisavin and $\beta$-pisavin have molecular weights of $20 \mathrm{kDa}, 20.5 \mathrm{kDa}$ and $18.7 \mathrm{kDa}$, respectively; thus, they differ from the classical type 1 RIPs as well as from the small type 1 RIPs. Lagenin inhibits cell-free translation in a rabbit reticulocyte system, but it was not clarified whether this is due to the $N$-glycosidase activity [171]. Because the size of lagenin is closer to the classical type 1 RIPs than to the biggest known small type 1 RIPs ( $\alpha$-benincasin and $\beta$-benincasin, both of them $12 \mathrm{kDa}$ ), lagenin should be classified as a type 1 RIP candidate. $\alpha$-pisavin and $\beta$-pisavin have molecular weights that are also closer to the classical type 1 RIPs than to the small type 1 RIPs, but compared with lagenin, they both have the $N$-glycosidase activity and, in addition, show amino acid similarity with other type 1 RIPs. For that reason, $\alpha$-pisavin and $\beta$-pisavin are considered type 1 RIPs.

Cinphorin is a type 2 RIP from the seeds of Cinnamomum camphora with a molecular weight of $46 \mathrm{kDa}$, which is due to the smaller A-chain than the other classical type 2 RIPs [368]. It is proposed that cinphorin is a cleaving product of cinnamomin, another type 2 RIP from Cinnamomum camphora, or its mRNA [367]. Cleaving processes during the evolution of RIPs are not unusual [29], but cinphorin is the only type 2 RIP with a smaller A-chain known to date, and, therefore, it is questionable whether it is necessary to denominate an extra classification for cinphorin. Considering that there might be more RIPs that are not detected to date, of which one could be another type 2 RIP with a smaller A-chain, however, we propose to classify cinphorin as a "small type 2 RIP" (sRIP 2).

Table 2. Small RIPs.

\begin{tabular}{|c|c|c|c|c|}
\hline Protein & Source & Mw & Classification & References \\
\hline$\alpha$-benincasin & Benincasa hispida (Cucurbitaceae) & $12 \mathrm{kDa}$ & sRIP 1 & {$[151]$} \\
\hline$\beta$-benincasin & Benincasa hispida (Cucurbitaceae) & $12 \mathrm{kDa}$ & sRIP 1 & [151] \\
\hline Charantin & Momordica charantia (Cucurbitaceae) & $9.7 \mathrm{kDa}$ & sRIP 1 & [216] \\
\hline Cinphorin & Cinnamomum camphora (Lauraceae) & $46 \mathrm{kDa}$ & sRIP 2 & {$[367,368]$} \\
\hline Luffacylin & Luffa cylindrica (Cucurbitaceae) & $7.8 \mathrm{kDa}$ & sRIP 1 & [184] \\
\hline Luffangulin & Luffa acutangula (Cucurbitaceae) & $5.6 \mathrm{kDa}$ & sRIP 1 & [174] \\
\hline Luffin P1 & Luffa cylindrica (Cucurbitaceae) & $5226.1 \mathrm{Da}$ & sRIP 1 & [185] \\
\hline$\gamma$-momorcharin & Momordica charantia (Cucurbitaceae) & $11.5 \mathrm{kDa}$ & sRIP 1 & [205] \\
\hline S-trichokirin & Trichosanthes kirilowii (Cucurbitaceae) & $8 \mathrm{kDa}$ & sRIP 1 & [259] \\
\hline Trichokirin S1 & Trichosanthes kirilowii (Cucurbitaceae) & $11426 \mathrm{Da}$ & sRIP 1 & [258] \\
\hline Trichosanthrip & Trichosanthes kirilowii (Cucurbitaceae) & $10964 \mathrm{Da}$ & sRIP 1 & [256] \\
\hline
\end{tabular}


Table 3. RIP candidates and RIP-like proteins.

\begin{tabular}{|c|c|c|c|c|c|}
\hline Protein & Source & Mw & $\mathrm{IC}_{50}$ & Classification & References \\
\hline A. ellenbeckii lectin & Adenia ellenbeckii (Passifloraceae) & $60 \mathrm{kDa}$ & $\begin{array}{c}10.1 \mu \mathrm{g} / \mathrm{mL} ; \\
1.2 \mu \mathrm{g} / \mathrm{mL}\end{array}$ & RIP 2 candidate & {$[45]$} \\
\hline A. glauca lectin & Adenia glauca (Passifloraceae) & n.a. & $\begin{array}{l}>10 \mu \mathrm{g} / \mathrm{mL} \\
>5 \mu \mathrm{g} / \mathrm{mL}\end{array}$ & RIP 2 candidate & {$[45]$} \\
\hline A. keramanthus lectin & Adenia keramanthus (Passifloraceae) & $60-65 \mathrm{kDa}$ & $\begin{array}{c}10.0 \mu \mathrm{g} / \mathrm{mL} ; \\
1.1 \mu \mathrm{g} / \mathrm{mL}\end{array}$ & RIP 2 candidate & {$[45]$} \\
\hline A. spinosa lectin & Adenia spinosa (Passifloraceae) & n.a. & $\begin{array}{l}4.7 \mu \mathrm{g} / \mathrm{mL} \\
0.8 \mu \mathrm{g} / \mathrm{mL}\end{array}$ & RIP 2 candidate & {$[45]$} \\
\hline A. venenata lectin & Adenia venenata (Passifloraceae) & $60 \mathrm{kDa}$ & $\begin{array}{c}2.4 \mu \mathrm{g} / \mathrm{mL} \\
0.4 \mu \mathrm{g} / \mathrm{mL}\end{array}$ & RIP 2 candidate & {$[45]$} \\
\hline Arborvitae RIP & Thuja occidentalis (Cupressaceae) & n.a. & n.a. & RIP candidate & [272] \\
\hline BDA & $\begin{array}{c}\text { Bryonia cretica subsp. dioica } \\
\text { (Cucurbitaceae) }\end{array}$ & $61 \mathrm{kDa}$ & $>1500 \mathrm{~nm}$ & RIP 2-like lectin & {$[73,156]$} \\
\hline Boerhaavia inhibitor & Boerhaavia diffusa (Nyctaginaceae) & $16-20 \mathrm{kDa}$ & n.a. & RIP 1 candidate & {$[371-373]$} \\
\hline CA-SRI & Clerodendrum aculeatum (Lamiaceae) & $34 \mathrm{kDa}$ & $<0.01 \mathrm{nM}$ & RIP 1 candidate & {$[358,359]$} \\
\hline CF-RIP & Cucumis ficifolius (Cucurbitaceae) & n.a. & n.a. & RIP 1 candidate & [159] \\
\hline CIP-34 & Clerodendrum inerme (Lamiaceae) & $34 \mathrm{kDa}$ & $\begin{array}{l}87.4 \mathrm{nM} \\
3 \mu \mathrm{g} / \mathrm{mL}\end{array}$ & RIP 1 candidate & {$[360,361]$} \\
\hline CIP31 & Nicotiana tabacum (Solanaceae) & $31 \mathrm{kDa}$ & n.a. & RIP 1-like protein & [460] \\
\hline Crotin I & Croton tiglium (Euphorbiaceae) & $40 \mathrm{kDa}$ & n.a. & RIP 1 candidate & {$[273,275]$} \\
\hline Cucurmoschin & Cucurbita maxima (Cucurbitaceae) & $9 \mathrm{kDa}$ & $1.2 \mu \mathrm{M}$ & small RIP 1 candidate & {$[160]$} \\
\hline Foetidissimin & $\begin{array}{c}\text { Cucurbita foetidissima } \\
\text { (Cucurbitaceae) }\end{array}$ & $63 \mathrm{kDa}$ & $25.9 \mathrm{nM}$ & peculiar RIP 2 & [157] \\
\hline Lagenin & Lagenaria siceraria (Cucurbitaceae) & $20 \mathrm{kDa}$ & $0.21 \mathrm{nM}$ & RIP 1 candidate & [171] \\
\hline Leonurin & Leonurus japonicus (Laminariaceae) & n.a. & n.a. & RIP candidate & [362] \\
\hline Luffin-S & Luffa cylindrica (Cucurbitaceae) & $10 \mathrm{kDa}$ & $0.34 \mathrm{nM}$ & small RIP 1 candidate & {$[186]$} \\
\hline LuffinS(1) & Luffa cylindrica (Cucurbitaceae) & $8 \mathrm{kDa}$ & $130 \mathrm{nM}$ & small RIP 1 candidate & {$[187]$} \\
\hline LuffinS(2) = luffin S2 & Luffa cylindrica (Cucurbitaceae) & $7.8 \mathrm{kDa}$ & $10 \mathrm{nM}$ & small RIP 1 candidate & {$[187,188]$} \\
\hline LuffinS(3) & Luffa cylindrica (Cucurbitaceae) & $8 \mathrm{kDa}$ & $630 \mathrm{nM}$ & small RIP 1 candidate & {$[187]$} \\
\hline Malanin & Malania oleifera (Olacaceae) & $61,875 \mathrm{Da}$ & n.a. & lectin/RIP 2 candidate & [384] \\
\hline$\varepsilon$-momorcharin & Momordica charantia (Cucurbitaceae) & $24 \mathrm{kDa}$ & $170 \mathrm{nM}$ & RIP 1 candidate & [203] \\
\hline$\alpha$-moschin & Cucurbita moschata (Cucurbitaceae) & $12 \mathrm{kDa}$ & $17 \mu \mathrm{M}$ & small RIP 1 candidate & [168] \\
\hline$\beta$-moschin & Cucurbita moschata (Cucurbitaceae) & $12 \mathrm{kDa}$ & $300 \mathrm{nM}$ & small RIP 1 candidate & {$[168]$} \\
\hline Panaxagin & Panax ginseng (Araliaceae) & $52 \mathrm{kDa}$ & $0.28 \mathrm{nM}$ & $\begin{array}{c}\text { peculiar RIP } 1 \\
\text { candidate/RNase }\end{array}$ & {$[110]$} \\
\hline P. macrocarpa RIP & Phaleria macrocarpa (Thymelaceae) & n.a. & n.a. & RIP candidate & [462] \\
\hline Quinqueginsin & Panax quinquefolius (Araliaceae) & $53 \mathrm{kDa}$ & $0.26 \mathrm{nM}$ & $\begin{array}{c}\text { peculiar RIP } 1 \\
\text { candidate/RNase }\end{array}$ & [111] \\
\hline Sativin & $\begin{array}{l}\text { Pisum sativum var. macrocarpon } \\
\text { (Fabaceae) }\end{array}$ & $38 \mathrm{kDa}$ & $14 \mu \mathrm{M}$ & RIP 1 candidate & [352] \\
\hline SGSL & $\begin{array}{c}\text { Trichosanthes anguina } \\
\text { (Cucurbitaceae) }\end{array}$ & $62 \mathrm{kDa}$ & n.a. & RIP 2-like lectin & [234] \\
\hline
\end{tabular}


Table 3. Cont.

\begin{tabular}{cccccc}
\hline Protein & Source & Mw & IC $_{\mathbf{5 0}}$ & Classification & References \\
\hline SoRIP2 & Spinacia oleraceae (Amaranthaceae) & $36 \mathrm{kDa}$ & n.a. & RIP 1 candidate & {$[106,107]$} \\
\hline TCSL & $\begin{array}{c}\text { Trichosanthes cucumerina } \\
\text { (Cucurbitaceae) }\end{array}$ & $69 \mathrm{kDa}$ & n.a. & lectin/RIP 2 candidate & {$[236]$} \\
\hline TDSL & Trichosanthes dioica (Cucurbitaceae) & $55 \mathrm{kDa}$ & n.a. & lectin/RIP 2 candidate & {$[270]$} \\
\hline TKL-1 & $\begin{array}{c}\text { Trichosanthes kirilowii } \\
\text { (Cucurbitaceae) }\end{array}$ & $60 \mathrm{kDa}$ & n.a. & lectin/RIP 2 candidate & {$[260]$} \\
\hline TRIP & Nicotiana tabacum (Solanaceae) & $26 \mathrm{kDa}$ & $100 \mathrm{ng} / \mathrm{mL}$ & RIP 1 candidate & {$[461]$} \\
\hline
\end{tabular}

\subsection{RIP Candidates and RIP-Like Proteins}

There are four single chain proteins with a bigger molecular weight than the other type 1 RIPs: Jc-SCRIP from Jatropha curcas (38 kDa), $\beta$-nigritin from Sambucus nigra (40 kDa), sativin from Pisum sativum (38 $\mathrm{kDa})$, and CIP-34 from Clerodendrum inerme $(34 \mathrm{kDa})$. $\beta$-nigritin exhibits $\mathrm{N}$-glycosidase activity and, therefore, it is classified as a classic type $1 \mathrm{RIP}$, because there are no further structural peculiarities [54]. Jc-SCRIP differs not only on the basis of the molecular weight from the other type 1 RIPs, but also with regard to its $N$-terminal amino acid sequence, acidic isoelectric point, high temperature stability, and high sugar content giving this protein additional lectin properties [294]. Because of those unique molecular characteristics, it might be classified as peculiar type 1 RIP as well as b-32 and JIP60. But that would make this issue unnecessarily complicated, because Jc-SCRIP does not have such structural differences compared to other type 1 RIPs like as b-32 and JIP60. Therefore, and because of its $\mathrm{N}$-glycosidase activity, Jc-SCRIP is classified as a classical type 1 RIP. Compared with that, sativin and CIP-34 cannot be classified as classical type 1 RIPs, because, among other things, the $N$-glycosidase activity was not found, and, therefore, together with other proteins, they are referred to as "RIP candidates" or "RIP-like proteins" (Table 3). Sativin is considered to be a type 1 RIP candidate, because of its amino acid sequence similarity of $48 \%$ to $\alpha$-pisavin and $\beta$-pisavin [352], which are classified as type 1 RIPs as mentioned above. CIP-34 is the major protein of a $100 \mathrm{kDa}$ protein complex with an unknown structure [360]. In Girbés et al. [7], it is indeed classified as a classical type 1 RIP, but it might be better to assign CIP-34 to the peculiar type 1 RIPs, because it is larger than other type 1 RIPs and it consists of protein domains with an unknown structure and function. To be grouped into the RIPs, however, the $N$-glycosidase activity of CIP-34 has to be detected. Thus, it is classified as type 1 RIP candidate until further notice.

Panaxagin from Panax ginseng and quinqueginsin from Panax quinquefolius are two other proteins that differ from the classical type 1 RIPs with regard to molecular weight, structure, and functionality. Both panaxagin and quinqueginsin are homodimeric proteins with molecular weights of $52 \mathrm{kDa}$ and $53 \mathrm{kDa}$, respectively [110,111]. The amino acid sequence of panaxagin and quinqueginsin show similarities with both RNases and type 1 RIPs, and on the basis of their high translation-inhibitory activities of $0.26 \mathrm{nM}$ and $0.28 \mathrm{nM}$, respectively, they are classified as RIPs, where the authors proposed the denomination "dimeric type 1 RIP". Due to their unusual dimeric structure, they can also be considered as peculiar type 1 RIPs. As mentioned above, the $N$-glycosidase activity of a protein needs to be detected in order to be classified as an RIP, but this was not possible for either panaxagin or quinqueginsin, because they both show strong RNase activity destroying the ribosomes. Therefore, both 
panaxagin and quinqueginsin are considered as peculiar type 1 RIP candidates until the whole amino acid sequence is analyzed, which will or will not show the conserved amino acids of the active site region.

SoRIP2 from Spinacia oleraceae is a type 1 RIP candidate, because the $N$-glycosidase activity assay was not performed, but the amino acid sequence shows similarities to the shiga/ricin toxic domain [106]. Interestingly, SoRIP2 only shows low sequence similarity with SoRIP1, another protein from Spinacia oleraceae that is classified as type 1 RIP.

Boerhaavia inhibitor from Boerhaavia diffusa was described as a virus inhibitor without mentioning any more details about the inhibitory activity of rabbit reticulocyte lysate or $N$-glycosidase activity [371,372]. But the size of $16-20 \mathrm{kDa}$ and the fact that antiserum against the type 1 RIP MAP from Mirabilis jalapa giving positive reaction with Boerhaavia diffusa extract [373], led us to the conclusion to denote Boerhaavia inhibitor as a RIP 1 candidate.

CA-SRI from Clerodendrum aculeatum is like Boerhaavia inhibitor an antiviral protein that induces systemic resistance [358]. Neither the inhibition of translation of rabbit reticulocyte lysate nor the $\mathrm{N}$-glycosidase was demonstrated, but the size of $34 \mathrm{kDa}$ and the amino acid sequence homology of 54\% [359] to the type 1 RIP PAP from Phytolacca americana make CA-SRI a RIP 1 candidate.

CF-RIP is a type 1 RIP candidate from Cucumis ficifolius that was obtained by cloning and sequencing the cDNA [159]. To be classified as type 1 RIP, native CF-RIP has to be isolated as well as the $N$-glycosidase activity has to be detected. Compared with that, the enzymatic activity of $\varepsilon$-momorcharin from Momordica charantia indeed was detected, but it was not denominated as a classical type 1 RIP, because its $\mathrm{IC}_{50}$ of $170 \mathrm{nM}$ is too low. Thus, the authors supposed significant structural dissimilarities of $\varepsilon$-momorcharin from the classical type 1 RIPs [203]. Another protein showing $N$-glycosidase activity, but is not classified as type 1 RIP, is TRIP from Nicotiana tabacum, because TRIP releases less adenine compared to type 1 RIPs [461]. It shows almost all the characteristics of type 1 RIPs instead of sequence similarity with other type 1 RIPs, wherein it should be mentioned that only 15 internal amino acids were analyzed. The authors classified TRIP as a RIP-like protein, but the fact that it shows superoxide dismutase activity, that is well known for RIPs [23], led us to the proposal to classify TRIP as a type 1 RIP candidate until the whole amino acid sequence is analyzed, which will or will not show the conserved amino acids of type 1 RIPs. Another protein from Nicotiana tabacum is CIP31 that shows a distinct mechanism of action as RIPs. In addition, not only is its $N$-terminal amino acid sequence different from the RIPs, but it is also only expressed with the presence of Cinchonaglykoside C (1) [460]. Thus, it is denominated as an RIP-like protein.

Because of cleaving supercoiled DNA by a crude extract of seeds from Phaleria macrocarpa, it was assumed that at least one RIP is included in this extract [462], but there were no more details given about this assumed RIP. The same applies to arborvitae RIP, where it is only known that there is probably a RIP synthesized by arborvitae [272], but we could only find the abstract of this paper during our investigation and in the abstract it is not clarified whether it is a RIP or just an RNase. Due to a lack of any further details, we propose to denominate these assumed RIPs as RIP candidates without mentioning the more detailed denomination RIP 1 or RIP 2 candidate. The same applies to leonurin from Leonurus japonicus, for which we did not find any further information as well [362].

As mentioned in the introduction, some lectins were found from several Adenia species [45], of which the lectins from Adenia lanceolata and from Adenia stenodactyla were classified later as 
type 2 RIPs and were denominated as lanceolin and stenodactylin [391], respectively. The lectin from Adenia goetzei is a type 2 RIP as well, because it was found that it is active as glycosylase, which releases adenine from herring sperm DNA [464]. On the other hand, the lectins from Adenia ellenbeckii, Adenia glauca, Adenia keramanthus, Adenia spinosa, and Adenia venenata indeed consist of two protein chains and inhibit translation in a cell free system, but the $N$-glycosidase activity was not analyzed. Thus, they should be considered as type 2 RIP candidates.

BDA from Bryonia cretica subsp. Dioica, malanin from Malania oleifera, TCSL from Trichosanthes cucumerina, TDSL from Trichosanthes dioica, and TKL-1 from Trichosanthes kirilowii are also two-chain lectins that cannot be clearly classified as type 2 RIPs. All of them have the typical molecular weight of type 2 RIPs and consist of two protein chains resembling the structure of type 2 RIPs that was even shown by X-ray crystallography [260], but the $N$-glycosidase activity assay was not performed excluding BDA. BDA, however, was not inhibitory in the highest tested concentration ( $\mathrm{IC}_{50}>1500 \mathrm{nM}$; [73]). These samples show that proteins having both a similar molecular weight and molecular structure, but lacking $N$-glycosidase activity, cannot be classified as classical type 2 RIPs. Therefore, we propose to classify BDA as a type 2 RIP-like protein and malanin, TCSL, and TDSL as type 2 RIP candidates, because the $N$-glycosidase activity of these proteins could neither be confirmed nor excluded to date.

At this point two other proteins should be mentioned differing from the classical type 2 RIPs or two-chain lectins with regard to the molecular structure: Foetidissimin from Cucurbita foetidissima and SGSL from Trichosanthes anguina. Foetidissimin indeed inhibits translation by acting as $\mathrm{N}$-glycosidase and it consists of two protein chains, but these chains are not held together through a disulphide bridge [157]. This is hitherto unique for type 2 RIPs and, therefore, we propose to classify foetidissimin as a peculiar type 2 RIP on the basis of the denomination for the peculiar type 1 RIP b-32. The A-chain of SGSL is cleaved obtaining two non-covalently linked components $\mathrm{A}_{\alpha}$ and $\mathrm{A}_{\beta}$-S-S-B. Thus, the nucleotide and carbohydrate-binding sites of SGSL are changed and compared to cinphorin, SGSL does not show $\mathrm{N}$-glycosidase activity, which is due to the cleaved A-chain, but, as X-ray crystallography shows a very similar molecular structure compared to type 2 RIPs, SGSL is classified as a type 2 RIP-like protein. As mentioned above, cleaving processes are not unusual for RIPs, so it was shown that TrSNA-I and TrSNA-If, both lectins from Sambucus nigra, are cleaving products of the type 2 RIPs SNA-I and SNA-If, respectively. This supports the hypothesis that certain lectins and type 2 RIPs must be evolutionarily related.

\subsection{Dimeric, Tetrameric, and Octameric Type 2 RIPs and Dimeric Lectins}

Most of the dimeric, tetrameric, and octameric type 2 RIPs or dimeric lectins are synthesized by plant species belonging to the Sambucus genus, which are reviewed in Ferreras et al. [29] and Ferreras et al. [72]. In these reviews, the proteins are grouped in "heterodimeric type 2 RIPs", "tetrameric type 2 RIPs", "monomeric lectins", and "homodimeric lectins". The heterodimeric type 2 RIPs represent the classical type 2 RIPs consisting of one A-chain and one B-chain linked together through a disulphide bridge [A-s-s-B]. Tetrameric type 2 RIPs consist of four protein chains and, therefore, the proposal was made to denominate these proteins as type 4 RIPs [306]. But that would mean that there are type 1, type 2, and type 4 RIPs, but no type 3 RIPs, because they were renamed peculiar type 1 RIPs, which may lead to confusion. Thus, we agree with the term "tetrameric type 2 RIPs". These RIPs are subdivided 
into two groups. One of those consist of two [A-s-s-B]-units linked together non-covalently, which can also be considered dimeric classical type 2 RIPs ([A-s-s-B]2). It should be mentioned that the [A-s-s-B]units can be different, e.g., in RCA from Ricinus communis ([A-s-s-B $\left.]_{\alpha}[\mathrm{A}-\mathrm{s}-\mathrm{s}-\mathrm{B}]_{\beta} ;[316,323]\right)$. The other group of tetrameric type 2 RIPs includes proteins with an extra disulphide bond between the two B-chains [A-s-s-B-s-s-B-s-s-A]. In Ferreras et al. [72], SNA-I and SNA-If were grouped herein, but it was shown that both native SNA-I and native SNA-If occur as a $240 \mathrm{kDa}$ protein having the structure [A-s-s-B-s-s-B-s-s-A]2 [69]. Thus, these proteins can also be considered as dimeric tetrameric type 2 RIPs linked non-covalently, but we propose the denomination octameric type 2 RIPs. PMRIPt from Polygonatum multiflorum and abrin from Abrus precatorius are also octameric type 2 RIPs consisting of four [A-s-s-B]-units, which are linked non-covalently as well ([A-s-s-B]4; [117,328]). They can also be considered as tetrameric classical type 2 RIPs.

Dimerization or oligomerization is a common behavior of purified and concentrated proteins. To avoid any confusion, the denomination of tetrameric type 2 RIPs with the structure $[\mathrm{A}-\mathrm{s}-\mathrm{s}-\mathrm{B}]_{2}$ and octameric type 2 RIPs is not meant as a real classification, because this would separate closely related type 2 proteins such as SNAI and SSA or abrin and pulchellin. We grouped those proteins in Table 4 as an addition to Table 1 to explain the bigger molecular weights and to show their native form in which they have been detected.

Table 4. Dimeric, tetrameric, and octameric type 2 RIPs and dimeric lectins.

\begin{tabular}{|c|c|c|c|c|}
\hline Structure & Protein & Source & Mw & References \\
\hline \multirow{2}{*}{$\begin{array}{c}\text { Octameric } \\
\text { [A-s-s-B-s-s-B-s-s- } \\
\mathbf{A}]_{\mathbf{2}}\end{array}$} & SNA-I & Sambucus nigra (Adoxaceae) & $240 \mathrm{kDa}$ & {$[66,69]$} \\
\hline & SNA-If & Sambucus nigra (Adoxaceae) & $240 \mathrm{kDa}$ & [69] \\
\hline \multirow{2}{*}{$\begin{array}{l}\text { Octameric } \\
{[\mathbf{A}-\mathbf{s}-\mathbf{s}-\mathbf{B}]_{4}}\end{array}$} & Abrin & Abrus precatorius (Fabaceae) & $260 \mathrm{kDa}$ & {$[328]$} \\
\hline & PMRIPt & $\begin{array}{c}\text { Polygonatum multiflorum } \\
\text { (Asparagaceae) }\end{array}$ & $240 \mathrm{kDa}$ & [117] \\
\hline \multirow{4}{*}{$\begin{array}{c}\text { Tetrameric } \\
\text { [A-s-s-B-s-s-B-s-s-A] }\end{array}$} & SEA & Sambucus ebulus (Adoxaceae) & $135,630 \mathrm{Da}$ & {$[50]$} \\
\hline & SNAflu-I & Sambucus nigra (Adoxaceae) & $\begin{array}{l}\text { subunits of } \\
30-33 \mathrm{kDa}\end{array}$ & {$[71,72]$} \\
\hline & SRA & Sambucus sieboldiana (Adoxaceae) & $120 \mathrm{kDa}$ & [79] \\
\hline & SSA & Sambucus sieboldiana (Adoxaceae) & $160 \mathrm{kDa}$ & {$[81]$} \\
\hline \multirow{7}{*}{$\begin{array}{l}\text { Tetrameric } \\
{[\mathbf{A}-\mathbf{s}-\mathbf{s}-\mathbf{B}]_{2}}\end{array}$} & APA & Abrus precatorius (Fabaceae) & $126-134 \mathrm{kDa}$ & {$[315,341,342,345]$} \\
\hline & $\begin{array}{c}\text { Hura crepitans } \\
\text { latex lectin }\end{array}$ & Hura crepitans (Euphorbiaceae) & $112 \mathrm{kDa}$ & {$[279]$} \\
\hline & MCL & $\begin{array}{c}\text { Momordica charantia } \\
\text { (Cucurbitaceae) }\end{array}$ & $115-124 \mathrm{kDa}$ & {$[207,218-220]$} \\
\hline & ML-I & Viscum album (Santalaceae) & $115-125 \mathrm{kDa}$ & {$[445,447,450-452]$} \\
\hline & Nigrin $b$ & Sambucus nigra (Adoxaceae) & $120 \mathrm{kDa}$ & {$[58]$} \\
\hline & Nigrin $\mathrm{f}$ & Sambucus nigra (Adoxaceae) & $120 \mathrm{kDa}$ & {$[62]$} \\
\hline & SNA-I' & Sambucus nigra (Adoxaceae) & $120 \mathrm{kDa}$ & {$[67]$} \\
\hline
\end{tabular}


Table 4. Cont.

\begin{tabular}{|c|c|c|c|c|}
\hline Structure & Protein & Source & Mw & References \\
\hline $\begin{array}{c}\text { Tetrameric } \\
{[\mathbf{A}-\mathbf{s}-\mathbf{s}-\mathbf{B}]_{\boldsymbol{\alpha}}[\mathbf{A}-\mathbf{s}-\mathbf{s}-\mathbf{B}]_{\boldsymbol{\beta}}}\end{array}$ & RCA & Ricinus communis (Euphorbiaceae) & $118-130 \mathrm{kDa}$ & {$[316,323]$} \\
\hline \multirow{8}{*}{$\begin{array}{l}\text { Homodimeric lectins } \\
\qquad[\mathbf{B}]_{2}\end{array}$} & E. characias lectin & Euphorbia characias (Euphorbiaceae) & $80 \mathrm{kDa}$ & [279] \\
\hline & $\begin{array}{c}\text { Luffa acutangula } \\
\text { fruit lectin }\end{array}$ & Luffa acutangula (Cucurbitaceae) & $48 \mathrm{kDa}$ & {$[175]$} \\
\hline & Protein fraction 1 & Momordica charantia (Cucurbitaceae) & $49 \mathrm{kDa}$ & [224] \\
\hline & Protein fraction 2 & Momordica charantia (Cucurbitaceae) & $49 \mathrm{kDa}$ & [224] \\
\hline & $\begin{array}{c}\text { Sechium edule } \\
\text { fruit lectin }\end{array}$ & Sechium edule (Cucurbitaceae) & $44 \mathrm{kDa}$ & [230] \\
\hline & SELld & Sambucus ebulus (Adoxaceae) & $67,906 \mathrm{Da}$ & [52] \\
\hline & SELfd & Sambucus ebulus (Adoxaceae) & $68 \mathrm{kDa}$ & [47] \\
\hline & SNAld & Sambucus nigra (Adoxaceae) & n.a. & [63] \\
\hline
\end{tabular}

\subsection{Non-Toxic Type 2 RIPS}

For a long time, all type 2 RIPs were considered to be highly potent toxins, but, to date, there are also known type 2 RIPs, which are not or only less toxic in vivo, and therefore they are denominated as non-toxic type 2 RIPs (reviewed in [7,8], not listed in this review). Nearly all of them have lectin properties and show $\mathrm{N}$-glycosidase activity in a cell-free system, so that these characteristics cannot be the reason for the missing in vivo-toxicity. SNLRP1 from Sambucus nigra for instance is a non-toxic type 2 RIP without lectin properties. On the other hand, nigrin b from Sambucus nigra has lectin properties but is non-toxic as well, because it is degraded rapidly and excreted by cells [8]. Articulatin D from Viscum articulatum is another type 2 RIP without lectin properties, but compared to SNLRP1, articulatin D is very toxic [455]. Thus, these examples show that the reasons for the vast differences in toxicity are not clearly understood. Nevertheless, non-toxic type 2 RIPs are quite interesting for anti-cancer therapy, because they may have a lower potential of side effects.

\subsection{Demotion of Some RIPS}

At last, it should be mentioned that there are some proteins, which were first classified as RIPs, but it was later shown that they act with a different mechanism of action for inhibiting translation than $\mathrm{N}$-glycosidase. Melonin from Cucumis melo was first classified as type 1 RIP [465], but a few years later, it was found that it is a ribonuclease (RNase) that specifically degrades poly(C)- and cytidine-containing bonds [466]. Crotin I and crotin II, two proteins from Croton tiglium, were classified as type 1 RIPs as well [7], but for crotin II, it was found that it belongs to RNA hydrolases, which cleave a phosphodiester bond between $\mathrm{G}^{4325}$ and $\mathrm{A}^{4326}$ of $28 \mathrm{~S}$ rRNA [10]. That is why crotin II is not listed in Table 1. Crotin I is a $40 \mathrm{kDa}$ protein that does not fit into the type $1 \mathrm{RIP}$ classification with regard to the molecular weight and in addition, its $N$-glycosidase activity was also not detected, because the corresponding assay was not performed $[273,274]$. Thus, the $N$-glycosidase activity cannot be excluded and, therefore, crotin I should be classified as a type 1 RIP candidate. At this point, it should be mentioned that there is a type 1 RIP with $N$-glycosidase activity against bacterial rRNA [277], which was denominated as crotin 2. The denomination of crotin II and crotin 2 may lead to confusion 
particularly in Girbés et al. [7], as crotin I and crotin II are also denominated as crotin 2 and crotin 3, respectively. For that reference, however, we could not find any proof and, therefore, in Table 1, we listed crotin I and crotin 2 separately, but we did not list crotin II on the basis of the reasons mentioned above and also excluded crotin 3, because too little information exists. The question remains as to whether there are more RIPs which should be demoted.

\section{Conclusions}

Hitherto, several approaches concerning the nomenclature of RIPs were proposed. Most of the proteins were denominated by using a part of the genus or species name followed with the ending “-in", e.g., agrostin from Agrostemma githago or ocymoidin from Saponaria ocymoides. If there is more than one RIP synthesized by the same plant, the denominations are followed by an Arabic or Roman numeral, e.g., asparin 1 and asparin 2 from Asparagus officinalis or pulchellin PI, pulchellin PII, and pulchellin PIII from Abrus pulchellus. The numerals, however, can also represent the peak number, in which the proteins were eluted, e.g., agrostin 2, agrostin 5, and agrostin 6 [112]. Some proteins are denominated with additional information about their molecular weight, e.g., dianthin 29 from Dianthus barbatus with a size of $29 \mathrm{kDa}$, or the tissue they are obtained from, e.g., nigrin $\mathrm{b}$ from the bark of Sambucus nigra. There are also many proteins, which are denominated with abbreviations, mostly using the initials of the genus and species name, e.g., SEA (= Sambucus ebulus agglutinin) from Sambucus ebulus. At last, modeccin 4B and modeccin 6B from Adenia digitata were denominated by using the material for their isolation. Modeccin 4B was isolated by affinity chromatography on Sepharose 4B and modeccin 6B was isolated by affinity chromatography on acid-treated Sepharose 6B [390].

In 1996, an unambiguous nomenclature was already demanded [58], but today there is still not a uniform classification existing for RIPs. This may be due to the fact that there are several exceptions of RIPs and RIP related proteins, which cannot be grouped into the classical type 1 or type 2 RIPs concerning the structure and/or function of these proteins. Besides the small RIPs, which were already designated in 1996 [205], we propose the term "RIP candidate" for those proteins, which are structurally related to the classical type 1 and type 2 RIPs and/or inhibit translation, but were not analyzed with regard to their $N$-glyosidase activity. On the other hand, $\varepsilon$-momorcharin is also a RIP candidate [203], which is indeed active as $N$-glycosidase but shows significant structural dissimilarities from the classical RIPs. These "RIP candidates" can be subdivided into small type 1 RIP (e.g., cucurmoschin), type 1 RIP (e.g., sativin) or type 2 RIP candidates (e.g., malanin) concerning the molecular weight and structure.

For the denomination of those proteins which cannot be grouped into the classic small RIPs, type 1 RIPs or type 2 RIPs due to their unusual structure, but act as $N$-glycosidase (b-32 and JIP60), we agree with the term "peculiar RIP" [7,8], and, therefore, we add the peculiar type 2 RIP foetidissimin, which lacks the disulphide bridge between the A-chain and B-chain. Because of the dimeric structure of panaxagin and quinqueginsin, they should be considered as peculiar type 1 RIPs, or, more precisely, as peculiar type 1 RIP candidates, because the $N$-glycosidase activity could not be analyzed, but they show amino acid sequence similarities with other type 1 RIPs.

All other proteins, which are structurally related to RIPs but lack $N$-glycosidase activity, should be referred to as RIP 1-like or RIP 2-like proteins/lectins. 


\section{Author Contributions}

J.S. designed and wrote the review. A.W. and M.F.M. designed and proofread the review.

\section{Conflicts of Interest}

The authors declare no conflict of interest.

\section{References}

1. Endo, Y.; Mitsui, K.; Motizuki, M.; Tsurugi, K. The mechanism of action of ricin and related toxic lectins on eukaryotic ribosomes. The site and the characteristics of the modification in $28 \mathrm{~S}$ ribosomal RNA caused by the toxins. J. Biol. Chem. 1987, 262, 5908-5912.

2. Barbieri, L.; Valbonesi, P.; Bondioli, M.; Alvarez, M.L.; dal Monte, P.; Landini, M.P.; Stirpe, F. Adenine glycosylase activity in mammalian tissues: An equivalent of ribosome-inactivating proteins. FEBS Lett. 2001, 505, 196-197.

3. Kurinov, I.V.; Rajamohan, F.; Venkatachalam, T.K.; Uckun, F.M. X-ray crystallographic analysis of the structural basis for the interaction of pokeweed antiviral protein with guanine residues of ribosomal RNA. Protein Sci. 1999, 8, 2399-2405.

4. Walsh, T.A.; Morgan, A.E.; Hey, T.D. Characterization and molecular cloning of a proenzyme form of a ribosome-inactivating protein from maize. Novel mechanism of proenzyme activation by proteolytic removal of a 2.8-kilodalton internal peptide segment. J. Biol. Chem. 1991, 266, 23422-23427.

5. Reinbothe, S.; Reinbothe, C.; Lehmann, J.; Becker, W.; Apel, K.; Parthier, B. Jip60, a methyl jasmonate-induced ribosome-inactivating protein involved in plant stress reactions. Proc. Natl. Acad. Sci. USA 1994, 91, 7012-7016.

6. Rustgi, S.; Pollmann, S.; Buhr, F.; Springer, A.; Reinbothe, C.; von Wettstein, D.; Reinbothe, S. Jip60-Mediated, jasmonate- and senescence-induced molecular switch in translation toward stress and defense protein synthesis. Proc. Natl. Acad. Sci. USA 2014, 111, 14181-14186.

7. Girbés, J.T.; Ferreras, J.M.; Arias, F.J.; Stirpe, F. Description, distribution, activity and phylogenetic relationship of ribosome-inactivating proteins in plants, fungi and bacteria. Mini Rev. Med. Chem. 2004, 4, 461-476.

8. Stirpe, F. Ribosome-inactivating proteins. Toxicon 2004, 44, 371-383.

9. Zhang, J.-S.; Liu, W.-Y. Progress in topography of ribosomal RNA and RNA $N$-glycosidase research (ii). Prog. Biochem. Biophys. 1994, 21, 113-117.

10. Zhou, K.-J.; Fu, Z.-J.; Chen, M.-H.; Qiu, W.; Pan, K.-Z. Crystal structure of crotin ii at 2.5 å resolution. Chin. J. Struct. Chem. 1997, 21, 23-27.

11. Stirpe, F. Ribosome-inactivating proteins: From toxins to useful proteins. Toxicon 2013, 67, 12-16.

12. Jiang, S.-Y.; Ramamoorthy, R.; Bhalla, R.; Luan, H.-F.; Venkatesh, P.N.; Cai, M.; Ramachandran, S. Genome-wide survey of the rip domain family in oryza sativa and their expression profiles under various abiotic and biotic stresses. Plant Mol. Biol. 2008, 67, 603-614. 
13. Liu, R.S.; Yang, J.H.; Liu, W.Y. Isolation and enzymatic characterization of lamjapin, the first ribosome-inactivating protein from cryptogamic algal plant (Laminaria japonica a). Eur. J. Biochem. 2002, 269, 4746-4752.

14. Wang, H.X.; Ng, T.B. Isolation of pleuturegin, a novel ribosome-inactivating protein from fresh sclerotia of the edible mushroom pleurotus tuber-regium. Biochem. Biophys. Res. Commun. 2001, 288, 718-721.

15. Lam, S.K.; Ng, T.B. First simultaneous isolation of a ribosome inactivating protein and an antifungal protein from a mushroom (Lyophyllum shimeji) together with evidence for synergism of their antifungal effects. Arch. Biochem. Biophys. 2001, 393, 271-280.

16. Lam, S.K.; Ng, T.B. Hypsin, a novel thermostable ribosome-inactivating protein with antifungal and antiproliferative activities from fruiting bodies of the edible mushroom hypsizigus marmoreus. Biochem. Biophys. Res. Commun. 2001, 285, 1071-1075.

17. Wang, H.X.; Ng, T.B. Flammulin: A novel ribosome-inactivating protein from fruiting bodies of the winter mushroom flammulina velutipes. Biochem. Cell Biol. 2000, 78, 699-702.

18. Wong, J.H.; Wang, H.X.; Ng, T.B. Marmorin, a new ribosome inactivating protein with antiproliferative and HIV-1 reverse transcriptase inhibitory activities from the mushroom Hypsizigus marmoreus. Appl. Microbiol. Biotechnol. 2008, 81, 669-674.

19. Yao, Q.Z.; Yu, M.M.; Ooi, L.S.; Ng, T.B.; Chang, S.T.; Sun, S.S.; Ooi, V.E. Isolation and characterization of a type 1 ribosome-inactivating protein from fruiting bodies of the edible mushroom (Volvariella volvacea). J. Agric. Food Chem. 1998, 46, 788-792.

20. Brown, J.E.; Ussery, M.A.; Leppla, S.H.; Rothman, S.W. Inhibition of protein synthesis by shiga toxin: Activation of the toxin and inhibition of peptide elongation. FEBS Lett. 1980, 117, 84-88.

21. Hauf, N.; Chakraborty, T. Suppression of nf-kappa b activation and proinflammatory cytokine expression by shiga toxin-producing Escherichia coli. J. Immunol. 2003, 170, 2074-2082.

22. Shih, N.R.; McDonald, K.A.; Jackman, A.P.; Girbés, T.; Iglesias, R. Bifunctional plant defence enzymes with chitinase and ribosome inactivating activities from Trichosanthes kirilowii cell cultures. Plant Sci. 1997, 130, 145-150.

23. Li, X.D.; Chen, W.F.; Liu, W.Y.; Wang, G.H. Large-scale preparation of two new ribosome-inactivating proteins - Cinnamomin and camphorin from the seeds of Cinnamomum camphora. Protein Expr. Purif. 1997, 10, 27-31.

24. Ruggiero, A.; Chambery, A.; di Maro, A.; Mastroianni, A.; Parente, A.; Berisio, R. Crystallization and preliminary X-ray diffraction analysis of pd-11, a highly glycosylated ribosome inactivating protein with dnase activity. Protein Pept. Lett. 2007, 14, 407-409.

25. Lombard, S.; Helmy, M.E.; Pieroni, G. Lipolytic activity of ricin from ricinus sanguineus and ricinus communis on neutral lipids. Biochem. J. 2001, 358, 773-781.

26. Barbieri, L.; Battelli, M.G.; Stirpe, F. Ribosome-inactivating proteins from plants. Biochim. Biophys. Acta 1993, 1154, 237-282.

27. Stirpe, F.; Barbieri, L.; Gorini, P.; Valbonesi, P.; Bolognesi, A.; Polito, L. Activities associated with the presence of ribosome-inactivating proteins increase in senescent and stressed leaves. FEBS Lett. 1996, 382, 309-312. 
28. Jiang, S.Y.; Bhalla, R.; Ramamoorthy, R.; Luan, H.F.; Venkatesh, P.N.; Cai, M.; Ramachandran, S. Over-expression of osrip18 increases drought and salt tolerance in transgenic rice plants. Transgenic Res. 2012, 21, 785-795.

29. Ferreras, J.M.; Citores, L.; Iglesias, R.; Jiménez, P.; Girbés, T. Sambucus ribosome-inactivating proteins and lectins. In Toxic Plant Proteins; Lord, J.M., Hartley, M.R., Eds.; Springer: Berlin, Heidelberg, Germany, 2010; Volume 18, pp. 107-131.

30. Byers, V.S.; Levin, A.S.; Waites, L.A.; Starrett, B.A.; Mayer, R.A.; Clegg, J.A.; Price, M.R.; Robins, R.A.; Delaney, M.; Baldwin, R.W.; et al. A phase i/ii study of trichosanthin treatment of HIV disease. Aids 1990, 4, 1189-1196.

31. Fracasso, G.; Bellisola, G.; Castelletti, D.; Tridente, G.; Colombatti, M. Immunotoxins and other conjugates: Preparation and general characteristics. Mini Rev. Med. Chem. 2004, 4, 545-562.

32. Kreitman, R.J. Immunotoxins for targeted cancer therapy. AAPS J. 2006, 8, E532-E551.

33. Gilabert-Oriol, R.; Weng, A.; von Mallinckrodt, B.; Melzig, M.F.; Fuchs, H.; Thakur, M. Immunotoxins constructed with ribosome-inactivating proteins and their enhancers: A lethal cocktail with tumor specific efficacy. Curr. Pharm. Des. 2014, 20, 6584-6643.

34. Hebestreit, P.; Weng, A.; Bachran, C.; Fuchs, H.; Melzig, M.F. Enhancement of cytotoxicity of lectins by saponinum album. Toxicon 2006, 47, 330-335.

35. Heisler, I.; Sutherland, M.; Bachran, C.; Hebestreit, P.; Schnitger, A.; Melzig, M.F.; Fuchs, H. Combined application of saponin and chimeric toxins drastically enhances the targeted cytotoxicity on tumor cells. J. Control. Release 2005, 106, 123-137.

36. Bachran, C.; Durkop, H.; Sutherland, M.; Bachran, D.; Muller, C.; Weng, A.; Melzig, M.F.; Fuchs, H. Inhibition of tumor growth by targeted toxins in mice is dramatically improved by saponinum album in a synergistic way. J. Immunother. 2009, 32, 713-725.

37. Bottger, S.; Westhof, E.; Siems, K.; Melzig, M.F. Structure-activity relationships of saponins enhancing the cytotoxicity of ribosome-inactivating proteins type i (rip-i). Toxicon 2013, 73, $144-150$.

38. Weng, A.; Jenett-Siems, K.; Gorick, C.; Melzig, M.F. Enhancement of cytotoxicity of ribosome-inactivating-protein type $\mathrm{i}$ by saponinum album is not based on stimulation of phagocytosis. J. Pharm. Pharmacol. 2008, 60, 925-930.

39. Weng, A.; Bachran, C.; Fuchs, H.; Melzig, M.F. Soapwort saponins trigger clathrin-mediated endocytosis of saporin, a type I ribosome-inactivating protein. Chem. Biol. Interact. 2008, 176, 204-211.

40. Weng, A.; Thakur, M.; von Mallinckrodt, B.; Beceren-Braun, F.; Gilabert-Oriol, R.; Wiesner, B.; Eichhorst, J.; Bottger, S.; Melzig, M.F.; Fuchs, H.; et al. Saponins modulate the intracellular trafficking of protein toxins. J. Control. Release 2012, 164, 74-86.

41. Nielsen, K.; Boston, R.S. Ribosome-inactivating proteins: A plant perspective. Annu. Rev. Plant Physiol. Plant Mol. Biol. 2001, 52, 785-816.

42. Peumans, W.J.; Hao, Q.; van Damme, E.J. Ribosome-inactivating proteins from plants: More than RNA $N$-glycosidases? FASEB J. 2001, 15, 1493-1506.

43. Stirpe, F.; Battelli, M.G. Ribosome-inactivating proteins: Progress and problems. Cell. Mol. Life Sci. 2006, 63, 1850-1866. 
44. Puri, M.; Kaur, I.; Perugini, M.A.; Gupta, R.C. Ribosome-inactivating proteins: Current status and biomedical applications. Drug Discov. Today 2012, 17, 774-783.

45. Pelosi, E.; Lubelli, C.; Polito, L.; Barbieri, L.; Bolognesi, A.; Stirpe, F. Ribosome-inactivating proteins and other lectins from Adenia (passifloraceae). Toxicon 2005, 46, 658-663.

46. De Benito, F.M.; Citores, L.; Iglesias, R.; Ferreras, J.M.; Soriano, F.; Arias, J.; Mendez, E.; Girbes, T. Ebulitins: A new family of type 1 ribosome-inactivating proteins (rRNA $N$-glycosidases) from leaves of Sambucus ebulus L. That coexist with the type 2 ribosome-inactivating protein ebulin 1. FEBS Lett. 1995, 360, 299-302.

47. Citores, L.; de Benito, F.M.; Iglesias, R.; Ferreras, J.M.; Argueso, P.; Jimenez, P.; Mendez, E.; Girbes, T. Presence of polymerized and free forms of the non-toxic type 2 ribosome-inactivating protein ebulin and a structurally related new homodimeric lectin in fruits of Sambucus ebulus L. Planta 1998, 204, 310-319.

48. Pascal, J.M.; Day, P.J.; Monzingo, A.F.; Ernst, S.R.; Robertus, J.D.; Iglesias, R.; Perez, Y.; Ferreras, J.M.; Citores, L.; Girbes, T.; et al. 2.8-a crystal structure of a nontoxic type-ii ribosome-inactivating protein, ebulin 1. Proteins 2001, 43, 319-326.

49. Citores, L.; de Benito, F.M.; Iglesias, R.; Ferreras, J.M.; Argueso, P.; Jimenez, P.; Testera, A.; Camafeita, E.; Mendez, E.; Girbes, T.; et al. Characterization of a new non-toxic two-chain ribosome-inactivating protein and a structurally-related lectin from rhizomes of dwarf elder (Sambucus ebulus L.). Cell. Mol. Biol. 1997, 43, 485-499.

50. Iglesias, R.; Citores, L.; Ferreras, J.M.; Perez, Y.; Jimenez, P.; Gayoso, M.J.; Olsnes, S.; Tamburino, R.; di Maro, A.; Parente, A.; et al. Sialic acid-binding dwarf elder four-chain lectin displays nucleic acid $N$-glycosidase activity. Biochimie 2010, 92, 71-80.

51. Benitez, J.; Rojo, M.A.; Munoz, R.; Ferreras, J.M.; Jiménez, P.; Girbés, T. Design and cytotoxicity analysis of a conjugate containing the new dgalactose-binding lectin selld and the non-toxic type 2 ribosome-inactivating protein nigrin b. Lett. Drug Des. Discov. 2004, 1, 361-367.

52. Rojo, M.A.; Citores, L.; Arias, F.J.; Ferreras, J.M.; Jimenez, P.; Girbes, T. Cdna molecular cloning and seasonal accumulation of an ebulin 1-related dimeric lectin of dwarf elder (Sambucus ebulus L.) leaves. Int. J. Biochem. Cell Biol. 2003, 35, 1061-1065.

53. Citores, L.; Rojo, M.A.; Jimenez, P.; Ferreras, J.M.; Iglesias, R.; Aranguez, I.; Girbes, T. Transient occurrence of an ebulin-related D-galactose-lectin in shoots of Sambucus ebulus L. Phytochemistry 2008, 69, 857-864.

54. Girbés, J.T.; de Benito, F.M.; Citores, L.; Iglesias, R.; Ferreras, J.M. Alpha-, Beta- and Gamma-Nigritins, Their Purification from sambucus nigra, and Their Use for Inhibition of Ribosomes. Patent No. Es 2095190 a1, 1 February 1997.

55. De Benito, F.M.; Iglesias, R.; Ferreras, J.M.; Citores, L.; Camafeita, E.; Mendez, E.; Girbes, T. Constitutive and inducible type 1 ribosome-inactivating proteins (rips) in elderberry (Sambucus nigra L.). FEBS Lett. 1998, 428, 75-79.

56. De Benito, F.M.; Citores, L.; Iglesias, R.; Ferreras, J.M.; Camafeita, E.; Mendez, E.; Girbes, T. Isolation and partial characterization of a novel and uncommon two-chain 64-kda ribosome-inactivating protein from the bark of elder (Sambucus nigra L.). FEBS Lett. 1997, 413, 85-91. 
57. Girbés, J.T.; Citores, L.; Ferreras, J.M.; Rojo, M.A.; Iglesias, R.; Munoz, R.; Arias, F.J.; Calonge, M.; Garcia, J.R.; Mendez, E.; et al. Isolation and partial characterization of nigrin b, a non-toxic novel type 2 ribosome-inactivating protein from the bark of Sambucus nigra L. Plant Mol. Biol. 1993, 22, 1181-1186.

58. Van Damme, E.J.; Barre, A.; Rouge, P.; van Leuven, F.; Peumans, W.J. Characterization and molecular cloning of sambucus nigra agglutinin $\mathrm{v}$ (nigrin b), a galnac-specific type-2 ribosome-inactivating protein from the bark of elderberry (Sambucus nigra). Eur. J. Biochem. 1996, 237, 505-513.

59. Battelli, M.G.; Citores, L.; Buonamici, L.; Ferreras, J.M.; de Benito, F.M.; Stirpe, F.; Girbes, T. Toxicity and cytotoxicity of nigrin b, a two-chain ribosome-inactivating protein from Sambucus nigra: Comparison with ricin. Arch. Toxicol. 1997, 71, 360-364.

60. Citores, L.; de Benito, F.M.; Iglesias, R.; Ferreras, J.M.; Jiménez, P.; Argüeso, P.; Farias, G.; Méndez, E.; Girbés, T. Isolation and characterization of a new non-toxic two-chain ribosomeinactivating protein from fruits of elder (Sambucus nigra L.). J. Exp. Bot. 1996, 47, 1577-1585.

61. Girbés, T.; Citores, L.; de Benito, F.M.; Iglesias, R.; Ferreras, J.M. A non-toxic two-chain ribosome-inactivating protein co-exists with a structure-related monomeric lectin (sna iii) in elder (Sambucus nigra) fruits. Biochem. J. 1996, 315, 343-344.

62. Van Damme, E.J.; Roy, S.; Barre, A.; Rouge, P.; van Leuven, F.; Peumans, W.J. The major elderberry (Sambucus nigra) fruit protein is a lectin derived from a truncated type 2 ribosome-inactivating protein. Plant J. 1997, 12, 1251-1260.

63. Ferreras, J.M.; Citores, L.; de Benito, F.M.; Arias, F.J.; Rojo, M.A.; Munoz, R.; Iglesias, R. Ribosome-inactivating proteins and lectins from Sambucus. Curr. Top. Phytochem. 2000, 3, $113-128$.

64. Citores, L.; Iglesias, R.; Muñoz, R.; Ferreras, J.M.; Jimenez, P.; Girbes, T. Elderberry (Sambucus nigra L.) seed proteins inhibit protein synthesis and display strong immunoreactivity with rabbit polyclonal antibodies raised against the type 2 ribosome-inactivating protein nigrin b. J. Exp. Bot. 1994, 45, 513-516.

65. Broekaert, W.F.; Nsimba-Lubaki, M.; Peeters, B.; Peumans, W.J. A lectin from elder (Sambucus nigra L.) bark. Biochem. J. 1984, 221, 163-169.

66. Van Damme, E.J.; Barre, A.; Rouge, P.; van Leuven, F.; Peumans, W.J. The neuac(alpha-2,6)-gal/galnac-binding lectin from elderberry (Sambucus nigra) bark, a type-2 ribosome-inactivating protein with an unusual specificity and structure. Eur. J. Biochem. 1996, $235,128-137$.

67. Van Damme, E.J.; Roy, S.; Barre, A.; Citores, L.; Mostafapous, K.; Rouge, P.; van Leuven, F.; Girbes, T.; Goldstein, I.J.; Peumans, W.J.; et al. Elderberry (Sambucus nigra) bark contains two structurally different neu5ac(alpha2,6)gal/galnac-binding type 2 ribosome-inactivating proteins. Eur. J. Biochem. 1997, 245, 648-655.

68. Shahidi-Noghabi, S.; van Damme, E.J.; de Vos, W.H.; Smagghe, G. Internalization of Sambucus nigra agglutinins i and ii in insect midgut cf-203 cells. Arch. Insect Biochem. Physiol. 2011, 76, 211-222.

69. Chen, Y.; Peumans, W.J.; van Damme, E.J. The sambucus nigra type-2 ribosome-inactivating protein sna-I' exhibits in planta antiviral activity in transgenic tobacco. FEBS Lett. 2002, 516, 27-30. 
70. Peumans, W.J.; Roy, S.; Barre, A.; Rouge, P.; van Leuven, F.; van Damme, E.J. Elderberry (Sambucus nigra) contains truncated neu5ac(alpha-2,6)gal/galnac-binding type 2 ribosome-inactivating proteins. FEBS Lett. 1998, 425, 35-39.

71. Karpova, I.S.; Korets'ka, N.V.; Pal'chykovs'ka, L.H.; Nehruts'ka, V.V. Lectins from Sambucus nigra L. inflorescences: Isolation and investigation of biological activity using procaryotic test-systems. Ukr. Biokhim. Zh. 2007, 79, 145-152.

72. Ferreras, J.M.; Citores, L.; Iglesias, R.; Jimenez, P.; Girbes, T. Use of ribosome-inactivating proteins from Sambucus for the construction of immunotoxins and conjugates for cancer therapy. Toxins 2011, 3, 420-441.

73. Battelli, M.G.; Barbieri, L.; Bolognesi, A.; Buonamici, L.; Valbonesi, P.; Polito, L.; van Damme, E.J.; Peumans, W.J.; Stirpe, F. Ribosome-inactivating lectins with polynucleotide: Adenosine glycosidase activity. FEBS Lett. 1997, 408, 355-359.

74. Van Damme, E.J.; Barre, A.; Rouge, P.; van Leuven, F.; Peumans, W.J. Isolation and molecular cloning of a novel type 2 ribosome-inactivating protein with an inactive $\mathrm{b}$ chain from elderberry (Sambucus nigra) bark. J. Biol. Chem. 1997, 272, 8353-8360.

75. Kaku, H.; Peumans, W.J.; Goldstein, I.J. Isolation and characterization of a second lectin (sna-ii) present in elderberry (Sambucus nigra L.) bark. Arch. Biochem. Biophys. 1990, 277, 255-262.

76. Peumans, W.J.; Kellens, J.T.; Allen, A.K.; van Damme, E.J. Isolation and characterization of a seed lectin from elderberry (Sambucus nigra L.) and its relationship to the bark lectins. Carbohydr. Res. 1991, 213, 7-17.

77. Mach, L.; Scherf, W.; Ammann, M.; Poetsch, J.; Bertsch, W.; Marz, L.; Glossl, J. Purification and partial characterization of a novel lectin from elder (Sambucus nigra L.) fruit. Biochem. J. 1991, 278 Pt 3, 667-671.

78. Mach, L.; Kerschbaumer, R.; Schwihla, H.; Gloss1, J. Elder (Sambucus nigra L.)-fruit lectin (sna-iv) occurs in monomeric, dimeric and oligomeric isoforms. Biochem. J. 1996, 315 Pt 3, 1061.

79. Nsimba-Lubaki, M.; Peumans, W.J.; Allen, A.K. Isolation and characterization of glycoprotein lectins from the bark of three species of elder, sambucus ebulus, S. Nigra and S. Racemosa. Planta 1986, 168, 113-118.

80. Rojo, M.A.; Citores, L.; Jimenez, P.; Ferreras, J.M.; Arias, F.J.; Mendez, E.; Girbes, T. Isolation and characterization of a new D-galactose-binding lectin from Sambucus racemosa L. Protein Pept. Lett. 2003, 10, 287-293.

81. Tazaki, K.; Shibuya, N. Purification and partial characterization of a lectin from the bark of Japanese elderberry (Sambucus sieboldiana). Plant Cell Physiol. 1989, 30, 899-903.

82. Kaku, H.; Tanaka, Y.; Tazaki, K.; Minami, E.; Mizuno, H.; Shibuya, N. Sialylated oligosaccharide-specific plant lectin from japanese elderberry (Sambucus sieboldiana) bark tissue has a homologous structure to type ii ribosome-inactivating proteins, ricin and abrin. cDNA cloning and molecular modeling study. J. Biol. Chem. 1996, 271, 1480-1485.

83. Rojo, M.A.; Kaku, H.; Ishii-Minami, N.; Minami, E.; Yato, M.; Hisajima, S.; Yamaguchi, T.; Shibuya, N. Characterization and cDNA cloning of monomeric lectins that correspond to the b-chain of a type 2 ribosome-inactivating protein from the bark of Japanese elderberry (Sambucus sieboldiana). J. Biochem. 2004, 135, 509-516. 
84. Rojo, M.A.; Yato, M.; Ishii-Minami, N.; Minami, E.; Kaku, H.; Citores, L.; Girbes, T.; Shibuya, N. Isolation, cdna cloning, biological properties, and carbohydrate binding specificity of sieboldin-b, a type ii ribosome-inactivating protein from the bark of Japanese elderberry (Sambucus sieboldiana). Arch. Biochem. Biophys. 1997, 340, 185-194.

85. Rippmann, J.F.; Michalowski, C.B.; Nelson, D.E.; Bohnert, H.J. Induction of a ribosomeinactivating protein upon environmental stress. Plant Mol. Biol. 1997, 35, 701-709.

86. Rinderle, S.J.; Goldstein, I.J.; Matta, K.L.; Ratcliffe, R.M. Isolation and characterization of amaranthin, a lectin present in the seeds of Amaranthus caudatus, that recognizes the t-(or cryptic t)-antigen. J. Biol. Chem. 1989, 264, 16123-16131.

87. Rinderle, S.J.; Goldstein, I.J.; Remsen, E.E. Physicochemical properties of amaranthin, the lectin from Amaranthus caudatus seeds. Biochemistry 1990, 29, 10555-10561.

88. Boland, C.R.; Chen, Y.F.; Rinderle, S.J.; Resau, J.H.; Luk, G.D.; Lynch, H.T.; Goldstein, I.J. Use of the lectin from Amaranthus caudatus as a histochemical probe of proliferating colonic epithelial cells. Cancer Res. 1991, 51, 657-665.

89. Koeppe, S.J.; Rupnow, J.H. Purification and characterization of a lectin from the seeds of Amaranth (Amaranthus cruentus). J. Food Sci. 1988, 53, 1412-1417.

90. Zenteno, E.; Ochoa, J.-L. Purification of a lectin from Amaranthus leucocarpus by affinity chromatography. Phytochemistry 1988, 27, 313-317.

91. Chen, M.-H.; Wang, Y.-Q.; Wang, Z. Amaramangin Isolated from Plant Seed as Ribosome Inactivating Protein and Uses in Therapy. Patent No. Cn 1491961 a, 28 April 2004.

92. Roy, S.; Sadhana, P.; Begum, M.; Kumar, S.; Lodha, M.L.; Kapoor, H.C. Purification, characterization and cloning of antiviral/ribosome inactivating protein from Amaranthus tricolor leaves. Phytochemistry 2006, 67, 1865-1873.

93. Kwon, S.Y.; An, C.S.; Liu, J.R.; Paek, K.H. A ribosome-inactivating protein from Amaranthus viridis. Biosci. Biotechnol. Biochem. 1997, 61, 1613-1614.

94. Kwon, S.Y.; An, C.S.; Liu, J.R.; Kwak, S.S.; Lee, H.S.; Kim, J.K.; Paek, K.H. Molecular cloning of a cdna encoding ribosome inactivating protein from Amaranthus viridis and its expression in E. Coli. Mol. Cells 2000, 10, 8-12.

95. Girbés, T.; de Torre, C.; Iglesias, R.; Ferreras, J.M.; Méndez, E. Rip for viruses. Nature 1996, 379, $777-778$.

96. Girbés, J.T.; Citores, L.; de Benito, F.M.; Iglesias, R.; Ferreras, J.M. Ribosome-Inactivating Proteins Beetin-27 and Beetin-29 and Their Use as Antivirals in Mammals and Plants. Patent No. Es 2115520 a1, 16 June 1998.

97. Iglesias, R.; Perez, Y.; de Torre, C.; Ferreras, J.M.; Antolin, P.; Jimenez, P.; Rojo, M.A.; Mendez, E.; Girbes, T. Molecular characterization and systemic induction of single-chain ribosome-inactivating proteins (rips) in sugar beet (beta vulgaris) leaves. J. Exp. Bot. 2005, 56, 1675-1684.

98. Hornung, E.; Wajant, H.; Jeske, H.; Mundry, K.W. Cloning of a cdna encoding a new ribosome-inactivating protein from beta Vulgaris vulgaris (mangold). Gene 1996, 170, 233-236.

99. Balasubrahmanyam, A.; Baranwal, V.K.; Lodha, M.L.; Varma, A.; Kapoor, H.C. Purification and properties of growth stage-dependent antiviral proteins from the leaves of Celosia cristata. Plant Sci. 2000, 154, 13-21. 
100. Gholizadeh, A.; Kapoor, H.C. Modifications in the purification protocol of Celosia cristata antiviral proteins lead to protein that can be $N$-terminally sequenced. Protein Pept. Lett. 2004, 11, 551-561.

101. Begam, M.; Kumar, S.; Roy, S.; Campanella, J.J.; Kapoor, H.C. Molecular cloning and functional identification of a ribosome inactivating/antiviral protein from leaves of post-flowering stage of Celosia cristata and its expression in E. Coli. Phytochemistry 2006, 67, 2441-2449.

102. Cho, K.-J.; Lee, S.-M.; Kim, Y.-T.; Hwang, Y.-S. Purification and characterization of an antiviral ribosome-inactivating protein from Chenopodium album L. Agric. Chem. Biotechnol. 2000, 43, 125-130.

103. Park, J.S.; Hwang, D.J.; Lee, S.M.; Kim, Y.T.; Choi, S.B.; Cho, K.J. Ribosome-inactivating activity and cDNA cloning of antiviral protein isoforms of Chenopodium album. Mol. Cells 2004, $17,73-80$.

104. Prestle, J.; Schonfelder, M.; Adam, G.; Mundry, K.W. Type 1 ribosome-inactivating proteins depurinate plant 25s rRNA without species specificity. Nucleic Acids Res. 1992, 20, 3179-3182.

105. Ishizaki, T.; Megumi, C.; Komai, F.; Masuda, K.; Oosawa, K. Accumulation of a 31-kDa glycoprotein in association with the expression of embryogenic potential by spinach callus in culture. Physiol. Plant. 2002, 114, 109-115.

106. Kawade, K.; Ishizaki, T.; Masuda, K. Differential expression of ribosome-inactivating protein genes during somatic embryogenesis in spinach (Spinacia oleracea). Physiol. Plant. 2008, 134, 270-281.

107. Kawade, K.; Masuda, K. Transcriptional control of two ribosome-inactivating protein genes expressed in spinach (Spinacia oleracea) embryos. Plant Physiol. Biochem. 2009, 47, 327-334.

108. Tomatsu, M.; Ohnishi-Kameyama, M.; Shibamoto, N. Aralin, a new cytotoxic protein from Aralia elata, inducing apoptosis in human cancer cells. Cancer Lett. 2003, 199, 19-25.

109. Tomatsu, M.; Kondo, T.; Yoshikawa, T.; Komeno, T.; Adachi, N.; Kawasaki, Y.; Ikuta, A.; Tashiro, F. An apoptotic inducer, aralin, is a novel type ii ribosome-inactivating protein from Aralia elata. Biol. Chem. 2004, 385, 819-827.

110. Ng, T.B.; Wang, H. Panaxagin, a new protein from Chinese ginseng possesses anti-fungal, anti-viral, translation-inhibiting and ribonuclease activities. Life Sci. 2001, 68, 739-749.

111. Wang, H.X.; Ng, T.B. Quinqueginsin, a novel protein with anti-human immunodeficiency virus, antifungal, ribonuclease and cell-free translation-inhibitory activities from American ginseng roots. Biochem. Biophys. Res. Commun. 2000, 269, 203-208.

112. Stirpe, F.; Gasperi-Campani, A.; Barbieri, L.; Falasca, A.; Abbondanza, A.; Stevens, W.A. Ribosome-inactivating proteins from the seeds of Saponaria officinalis L. (soapwort), of Agrostemma githago L. (corn cockle) and of Asparagus officinalis L. (asparagus), and from the latex of Hura crepitans L. (sandbox tree). Biochem. J. 1983, 216, 617-625.

113. Bolognesi, A.; Barbieri, L.; Abbondanza, A.; Falasca, A.I.; Carnicelli, D.; Battelli, M.G.; Stirpe, F. Purification and properties of new ribosome-inactivating proteins with rna $N$-glycosidase activity. Biochim. Biophys. Acta 1990, 1087, 293-302. 
114. Touloupakis, E.; Gessmann, R.; Kavelaki, K.; Christofakis, E.; Petratos, K.; Ghanotakis, D.F. Isolation, characterization, sequencing and crystal structure of charybdin, a type 1 ribosome-inactivating protein from charybdis maritima agg. FEBS J. 2006, 273, 2684-2692.

115. Arias, F.J.; Antolin, P.; de Torre, C.; Barriuso, B.; Iglesias, R.; Rojo, M.A.; Ferreras, J.M.; Benvenuto, E.; Mendez, E.; Girbes, T.; et al. Musarmins: Three single-chain ribosome-inactivating protein isoforms from bulbs of Muscari armeniacum L. And miller. Int. J. Biochem. Cell Biol. 2003, 35, 61-78.

116. Girbés, J.T.; Barriuso, B.; Antolin, P.; Arias, F.J.; Munoz, R. Muscari Ribosome-Inactivating Protein Musarmin 4, Its Production in Bacterial and Plant Systems, and Its Uses in Therapy. Patent No. Wo 2004106522 a1, 9 December 2004.

117. Van Damme, E.J.; Hao, Q.; Charels, D.; Barre, A.; Rouge, P.; van Leuven, F.; Peumans, W.J. Characterization and molecular cloning of two different type 2 ribosome-inactivating proteins from the monocotyledonous plant Polygonatum multiflorum. Eur. J. Biochem. 2000, 267, 2746-2759.

118. Osawa, N.; Hiramatsu, A. Purification and chemical properties of an inhibitor of plant virus infection from leaves of Yucca recurvifolia salisb. Agric. Biol. Chem. 1987, 51, 891-896.

119. Hayashi, K.; Nishino, H.; Niwayama, S.; Shiraki, K.; Hiramatsu, A. Yucca leaf protein (ylp) stops the protein synthesis in hsv-infected cells and inhibits virus replication. Antivir. Res. 1992, 17, 323-333.

120. Bolognesi, A.; Polito, L.; Olivieri, F.; Valbonesi, P.; Barbieri, L.; Battelli, M.G.; Carusi, M.V.; Benvenuto, E.; del Vecchio Blanco, F.; di Maro, A.; et al. New ribosome-inactivating proteins with polynucleotide: Adenosine glycosidase and antiviral activities from Basella rubra L. And bougainvillea spectabilis willd. Planta 1997, 203, 422-429.

121. Takayama, S.; Misawa, M.; Ko, K.; Misato, T. Effect of cullural conditions on the growth of Agrostemma githago cells in suspension culture and the concomitant production of an anti-plant virus substance. Physiol. Plant. 1977, 41, 313-320.

122. Stirpe, F.; Barbieri, L. Ribosome-inactivating proteins up to date. FEBS Lett. 1986, 195, 1-8.

123. Hebestreit, P.; Melzig, M.F. Cytotoxic activity of the seeds from Agrostemma githago var. Githago. Planta Med. 2003, 69, 921-925.

124. Prestle, J.; Hornung, E.; Schonfelder, M.; Mundry, K.W. Mechanism and site of action of a ribosome-inactivating protein type 1 from dianthus barbatus which inactivates Escherichia coli ribosomes. FEBS Lett. 1992, 297, 250-252.

125. Stirpe, F.; Williams, D.G.; Onyon, L.J.; Legg, R.F.; Stevens, W.A. Dianthins, ribosome-damaging proteins with anti-viral properties from Dianthus caryophyllus L. (carnation). Biochem. J. 1981, 195, 399-405.

126. Falasca, A.; Gasperi-Campani, A.; Abbondanza, A.; Barbieri, L.; Stirpe, F. Properties of the ribosome-inactivating proteins gelonin, Momordica charantia inhibitor, and dianthins. Biochem. J. 1982, 207, 505-509.

127. Cho, H.J.; Lee, S.J.; Kim, S.; Kim, B.D. Isolation and characterization of cDNAs encoding ribosome inactivating protein from Dianthus sinensis L. Mol. Cells 2000, 10, 135-141. 
128. Yoshinari, S.; Koresawa, S.; Yokota, S.; Sawamoto, H.; Tamura, M.; Endo, Y. Gypsophilin, a new type 1 ribosome-inactivating protein from gypsophila elegans: Purification, enzymatic characterization, and subcellular localization. Biosci. Biotechnol. Biochem. 1997, 61, 324-331.

129. Fermani, S.; Tosi, G.; Farini, V.; Polito, L.; Falini, G.; Ripamonti, A.; Barbieri, L.; Chambery, A.; Bolognesi, A. Structure/function studies on two type 1 ribosome inactivating proteins: Bouganin and lychnin. J. Struct. Biol. 2009, 168, 278-287.

130. Chambery, A.; de Donato, A.; Bolognesi, A.; Polito, L.; Stirpe, F.; Parente, A. Sequence determination of lychnin, a type 1 ribosome-inactivating protein from Lychnis chalcedonica seeds. Biol. Chem. 2006, 387, 1261-1266.

131. Arias, F.J.; Rojo, M.A.; Ferreras, J.M.; Iglesias, R.; Munoz, R.; Soriano, F.; Mendez, E.; Barbieri, L.; Girbes, T. Isolation and characterization of two new $N$-glycosidase type- 1 ribosome-inactivating proteins, unrelated in amino-acid sequence, from petrocoptis species. Planta 1994, 194, 487-491.

132. Arias, F.J.; Rojo, M.A.; Ferreras, J.M.; Iglesias, R.; Munoz, R.; Rocher, A.; Mendez, E.; Barbieri, L.; Girbes, T. Isolation and partial characterization of a new ribosome-inactivating protein from Petrocoptis glaucifolia (lag.) boiss. Planta 1992, 186, 532-540.

133. Bolognesi, A.; Olivieri, F.; Battelli, M.G.; Barbieri, L.; Falasca, A.I.; Parente, A.; del Vecchio Blanco, F.; Stirpe, F. Ribosome-inactivating proteins (RNA $N$-glycosidases) from the seeds of Saponaria ocymoides and Vaccaria pyramidata. Eur. J. Biochem. 1995, 228, 935-940.

134. Di Massimo, A.M.; di Loreto, M.; Pacilli, A.; Raucci, G.; D’Alatri, L.; Mele, A.; Bolognesi, A.; Polito, L.; Stirpe, F.; de Santis, R.; et al. Immunoconjugates made of an anti-egf receptor monoclonal antibody and type 1 ribosome-inactivating proteins from Saponaria ocymoides or Vaccaria pyramidata. Br. J. Cancer 1997, 75, 822-828.

135. Ferreras, J.M.; Barbieri, L.; Girbes, T.; Battelli, M.G.; Rojo, M.A.; Arias, F.J.; Rocher, M.A.; Soriano, F.; Mendez, E.; Stirpe, F.; et al. Distribution and properties of major ribosome-inactivating proteins (28 s rRNA $N$-glycosidases) of the plant Saponaria officinalis L. (caryophyllaceae). Biochim. Biophys. Acta 1993, 1216, 31-42.

136. Barbieri, L.; Gorini, P.; Valbonesi, P.; Castiglioni, P.; Stirpe, F. Unexpected activity of saporins. Nature 1994, 372, 624.

137. Ho, M.C.; Sturm, M.B.; Almo, S.C.; Schramm, V.L. Transition state analogues in structures of ricin and saporin ribosome-inactivating proteins. Proc. Natl. Acad. Sci. USA 2009, 106, 20276-20281.

138. Sturm, M.B.; Tyler, P.C.; Evans, G.B.; Schramm, V.L. Transition state analogues rescue ribosomes from saporin-11 ribosome inactivating protein. Biochemistry 2009, 48, 9941-9948.

139. Soria, M.R.; Benatti, L.; Nitti, G.; Ceriotti, A.; Solinas, M.; Lappi, D.A.; Lorenzetti, R. Studies on ribosome-inactivating proteins from saponaria officinalis. Target. Diagn. Ther. 1992, 7, $193-212$.

140. Yang, Y.-D.; Zhou, K.-J.; Pan, K.-Z.; Zhang, R.-Z.; Chen, R.-M.; Rao, P.-F. Purification and characterization of saporins. Prog. Biochem. Biophys. 2000, 27, 57-61.

141. Ghosh, P.; Batra, J.K. The differential catalytic activity of ribosome-inactivating proteins saporin 5 and 6 is due to a single substitution at position 162. Biochem. J. 2006, 400, 99-104. 
142. Lappi, D.A.; Esch, F.S.; Barbieri, L.; Stirpe, F.; Soria, M. Characterization of a Saponaria officinalis seed ribosome-inactivating protein: Immunoreactivity and sequence homologies. Biochem. Biophys. Res. Commun. 1985, 129, 934-942.

143. Benatti, L.; Nitti, G.; Solinas, M.; Valsasina, B.; Vitale, A.; Ceriotti, A.; Soria, M.R. A saporin-6 cdna containing a precursor sequence coding for a carboxyl-terminal extension. FEBS Lett. 1991, 291, 285-288.

144. De Angelis, F.; di Tullio, A.; Spano, L.; Tucci, A. Mass spectrometric study of different isoforms of the plant toxin saporin. J. Mass Spectrom. 2001, 36, 1237-1239.

145. Lombardi, A.; Marshall, R.S.; Savino, C.; Fabbrini, M.S.; Ceriotti, A. Toxic Plant Proteins, Plant Cell Monographs; Springer Verlag: Heidelberg, Germany, 2010; Volume 18, pp. 55-78.

146. Di Maro, A.; Ferranti, P.; Mastronicola, M.; Polito, L.; Bolognesi, A.; Stirpe, F.; Malorni, A.; Parente, A. Reliable sequence determination of ribosome- inactivating proteins by combining electrospray mass spectrometry and edman degradation. J. Mass Spectrom. 2001, 36, 38-46.

147. Fabbrini, M.S.; Rappocciolo, E.; Carpani, D.; Solinas, M.; Valsasina, B.; Breme, U.; Cavallaro, U.; Nykjaer, A.; Rovida, E.; Legname, G.; et al. Characterization of a saporin isoform with lower ribosome-inhibiting activity. Biochem. J. 1997, 322 Pt 3, 719-727.

148. Yoshinari, S.; Tamura, M.; Endo, Y. A new type-1 ribosome-inactivating protein from the leaves of Stellaria aquatica: Purification and characterization. Viva Orig. 1996, 24, 225-236.

149. Zheng, Y.-H.; Zhao, H.-G.; Shan, Y.; Zhou, J.-J.; He, S.-I. Cloning and sequence analysis of ribosome inactivating protein gene from Stellaria media. Acta Bot. Boreali-Occident. Sin. 2010, 1, 14-20.

150. Ng, T.B.; Parkash, A. Hispin, a novel ribosome inactivating protein with antifungal activity from hairy melon seeds. Protein Expr. Purif. 2002, 26, 211-217.

151. Ng, T.B.; Parkash, A.; Tso, W.W. Purification and characterization of alpha- and beta-benincasins, arginine/glutamate-rich peptides with translation-inhibiting activity from wax gourd seeds. Peptides 2003, 24, 11-16.

152. Stirpe, F.; Barbieri, L.; Battelli, M.G.; Falasca, A.I.; Abbondanza, A.; Lorenzoni, E.; Stevens, W.A. Bryodin, a ribosome-inactivating protein from the roots of Bryonia dioica L. (white bryony). Biochem. J. 1986, 240, 659-665.

153. Siegall, C.B.; Gawlak, S.L.; Chace, D.; Wolff, E.A.; Mixan, B.; Marquardt, H. Characterization of ribosome-inactivating proteins isolated from bryonia dioica and their utility as carcinoma-reactive immunoconjugates. Bioconjug. Chem. 1994, 5, 423-429.

154. Montecucchi, P.C.; Lazzarini, A.M.; Barbieri, L.; Stirpe, F.; Soria, M.; Lappi, D. N-Terminal sequence of some ribosome-inactivating proteins. Int. J. Pept. Protein Res. 1989, 33, 263-267.

155. Barbieri, L.; Polito, L.; Bolognesi, A.; Ciani, M.; Pelosi, E.; Farini, V.; Jha, A.K.; Sharma, N.; Vivanco, J.M.; Chambery, A.; et al. Ribosome-inactivating proteins in edible plants and purification and characterization of a new ribosome-inactivating protein from Cucurbita moschata. Biochim. Biophys. Acta 2006, 1760, 783-792.

156. Peumans, W.J.; Nsimba-Lubaki, M.; Carlier, A.R.; van Driessche, E. A lectin from Bryonia dioica root stocks. Planta 1984, 160, 222-228.

157. Zhang, D.; Halaweish, F.T. Isolation and identification of foetidissimin: A novel ribosome-inactivating protein from Cucurbita foetidissima. Plant Sci. 2003, 164, 387-393. 
158. Zhang, D.; Halaweish, F.T. Isolation and characterization of ribosome-inactivating proteins from Cucurbitaceae. Chem. Biodivers. 2007, 4, 431-442.

159. Yamada, T.; Ohki, S.T.; Osaki, T. Cloning and analysis of a cdna coding a putative ribosome-inactivating protein from Cucumis figarei. Plant Biotechnol. 2000, 17, 337-340.

160. Wang, H.X.; $\mathrm{Ng}$, T.B. Isolation of cucurmoschin, a novel antifungal peptide abundant in arginine, glutamate and glycine residues from black pumpkin seeds. Peptides 2003, 24, 969-972.

161. Chen, M.; Ye, X.; Cai, J.; Lin, Y. Crystallization and preliminary crystallographic study of cucurmosin, a ribosome-inactivating protein from the sarcocarp of Cucurbita moschata. Acta Crystallogr. D Biol. Crystallogr. 2000, 56, 665-666.

162. Shi, X.-L.; Zhou, E.X.; Ye, X.-M.; Meehan, E.J.; Chen, M.-H.; Liqing, C. Molecular replacement studies of cucurmosin from Cucurbita moschata: Structure homology with trichosanthin. Chin. J. Struct. Chem. 2003, 22, 165-168.

163. Hou, X.; Meehan, E.J.; Xie, J.; Huang, M.; Chen, M.; Chen, L. Atomic resolution structure of cucurmosin, a novel type 1 ribosome-inactivating protein from the sarcocarp of Cucurbita moschata. J. Struct. Biol. 2008, 164, 81-87.

164. Hou, X.-M.; Chen, M.-H.; Xie, J.-M.; Peng, Q.; Chen, L.-Q.; Huang, M.-D. Crystallization and preliminary crystallographic studies of cucurmosin 2, a ribosome-inactivating protein from the sarcocarp of Cucurbita moschata. Chin. J. Struct. Chem. 2009, 28, 215-217.

165. Chen, M.-H. Cucurmosin 2 from Cucurbita Moschata Melon Pulp and Its Application to Prepare the Medical Preparations as Antitumor Agent or Anti Aids Agent. Patent No. Cn 101386644 a, 18 March 2009.

166. Xia, H.C.; Li, F.; Li, Z.; Zhang, Z.C. Purification and characterization of moschatin, a novel type i ribosome-inactivating protein from the mature seeds of pumpkin (Cucurbita moschata), and preparation of its immunotoxin against human melanoma cells. Cell Res. 2003, 13, 369-374.

167. Cho, K.-J.; Lee, S.-M.; Kim, Y.-T.; Hwang, Y.-S. Purification and properties of ribosome-inactivating proteins from the leaves of Cucurbita moschata duchesne. J. Korean Agric. Chem. Soc. 1997, 40, 375-379.

168. Ng, T.B.; Parkash, A.; Tso, W.W. Purification and characterization of moschins, arginine-glutamate-rich proteins with translation-inhibiting activity from brown pumpkin (Cucurbita moschata) seeds. Protein Expr. Purif. 2002, 26, 9-13.

169. Yoshinari, S.; Yokota, S.; Sawamoto, H.; Koresawa, S.; Tamura, M.; Endo, Y. Purification, characterization and subcellular localization of a type-1 ribosome-inactivating protein from the sarcocarp of Cucurbita pepo. Eur. J. Biochem. 1996, 242, 585-591.

170. Lin, Y.; Chen, G.-Q.; Wu, Z.-J.; Lin, Q.-Y.; Xie, L.-H. Purification of a novel anti-tmv protein from Gynostemma pentaphyllum and sequence analysis of its partial DNA coding region. J. Agric. Biotechnol. 2003, 4, 365-369.

171. Wang, H.X.; Ng, T.B. Lagenin, a novel ribosome-inactivating protein with ribonucleolytic activity from bottle gourd (Lagenaria siceraria) seeds. Life Sci. 2000, 67, 2631-2638.

172. Yeung, H.W.; Li, W.W.; Ng, T.B. Isolation of a ribosome-inactivating and abortifacient protein from seeds of Luffa acutangula. Int. J. Pept. Protein Res. 1991, 38, 15-19. 
173. Lin, J.-K.; Chen, M.-H.; Xie, J.-M.; Zhao, R.; Ye, X.-M.; Shi, X.-L.; Wang, Z.-R. Purification and characterization of two luffaculins, ribosome-inactivating proteins from seeds of Luffa acutangula. Chin. J. Biochem. Mol. Biol. 2002, 18, 609-613.

174. Wang, H.; Ng, T.B. Luffangulin, a novel ribosome inactivating peptide from ridge gourd (Luffa acutangula) seeds. Life Sci. 2002, 70, 899-906.

175. Anantharam, V.; Patanjali, S.R.; Swamy, M.J.; Sanadi, A.R.; Goldstein, I.J.; Surolia, A. Isolation, macromolecular properties, and combining site of a chito-oligosaccharide-specific lectin from the exudate of ridge gourd (Luffa acutangula). J. Biol. Chem. 1986, 261, 14621-14627.

176. Kishida, K.; Masuho, Y.; Hara, T. Protein-synthesis inhibitory protein from seeds of Luffa cylindria roem. FEBS Lett. 1983, 153, 209-212.

177. Kamenosono, M.; Nishida, H.; Funatsu, G. Isolation and characterization of two luffins, protein-biosynthesis inhibitory proteins from the seeds of Luffa cylindrica. Agric. Biol. Chem. 1988, 52, 1223-1227.

178. Ng, T.B.; Wong, R.N.; Yeung, H.W. Two proteins with ribosome-inactivating, cytotoxic and abortifacient activities from seeds of Luffa cylindrica roem (cucurbitaceae). Biochem. Int. 1992, 27, 197-207.

179. Kataoka, J.; Habuka, N.; Miyano, M.; Masuta, C.; Koiwai, A. Nucleotide sequence of cdna encoding alpha-luffin, a ribosome-inactivating protein from Luffa cylindrica. Plant Mol. Biol. 1992, 18, 1199-1202.

180. Guo, F.; Liu, D. Isolation and purification of alpha- and beta-luffins, ribosome inactivating protein from seeds of Luffa cylindrica. Prog. Biochem. Biophys. 1995, 22, 464-468.

181. Liu, L.; Wang, R.; He, W.; He, F.; Huang, G. Cloning and soluble expression of mature alpha-luffin from Luffa cylindrica and its antitumor activities in vitro. Acta Biochim. Biophys. Sin. 2010, 42, 585-592.

182. Kataoka, J.; Habuka, N.; Miyano, M.; Masuta, C.; Koiwai, A. Nucleotide sequence of cdna encoding beta-luffin, another ribosome-inactivating protein from Luffa cylindrica. Plant Mol. Biol. 1992, 19, 887-889.

183. Ramakrishnan, S.; Enghlid, J.J.; Bryant, H.L., Jr.; Xu, F.J. Characterization of a translation inhibitory protein from Luffa aegyptiaca. Biochem. Biophys. Res. Commun. 1989, 160, 509-516.

184. Parkash, A.; Ng, T.B.; Tso, W.W. Isolation and characterization of luffacylin, a ribosome inactivating peptide with anti-fungal activity from sponge gourd (Luffa cylindrica) seeds. Peptides 2002, 23, 1019-1024.

185. Li, F.; Yang, X.X.; Xia, H.C.; Zeng, R.; Hu, W.G.; Li, Z.; Zhang, Z.C. Purification and characterization of luffin $\mathrm{p} 1$, a ribosome-inactivating peptide from the seeds of Luffa cylindrica. Peptides 2003, 24, 799-805.

186. Gao, W.; Ling, J.; Zhong, X.; Liu, W.; Zhang, R.; Yang, H.; Cao, H.; Zhang, Z. Luffin-s-A small novel ribosome-inactivating protein from Luffa cylindrica. Characterization and mechanism studies. FEBS Lett. 1994, 347, 257-260.

187. Xiong, C.Y.; Zhang, Z.C. Isolation, purification and characterization of a group of novel small molecular ribosome inactivating protein-Luffins from seeds of Luffa cylindrica. Acta Biochim. Biophys. Sin. 1998, 30, 142-146. 
188. Li, F.; Hu, W.; Tai, N.; Zhang, Z. Gene Cloning of Luffin s2, a New Small Ribosome-Inactivating Protein from Seeds of Luffa cylindrica, and Expression in Escherichia coli. Available online: http://www.uniprot.org/uniprot/Q7XBB8 (accessed on 1 October 2003).

189. Shih, N.J.; McDonald, K.A.; Girbes, T.; Iglesias, R.; Kohlhoff, A.J.; Jackman, A.P. Ribosome-inactivating proteins (rips) of wild oregon cucumber (marah oreganus). Biol. Chem. 1998, 379, 721-725.

190. Kaur, I.; Yadav, S.K.; Hariprasad, G.; Gupta, R.C.; Srinivasan, A.; Batra, J.K.; Puri, M. Balsamin, a novel ribosome-inactivating protein from the seeds of balsam apple Momordica balsamina. Amino Acids 2012, 43, 973-981.

191. Kushwaha, G.S.; Pandey, N.; Sinha, M.; Singh, S.B.; Kaur, P.; Sharma, S.; Singh, T.P. Crystal structures of a type-1 ribosome inactivating protein from Momordica balsamina in the bound and unbound states. Biochim. Biophys. Acta 2012, 1824, 679-691.

192. Kushwaha, G.S.; Yamini, S.; Kumar, M.; Sinha, M.; Kaur, P.; Sharma, S.; Singh, T.P. First structural evidence of sequestration of mRNA cap structures by type 1 ribosome inactivating protein from Momordica balsamina. Proteins 2013, 81, 896-905.

193. Ortigao, M.; Better, M. Momordin ii, a ribosome inactivating protein from Momordica balsamina, is homologous to other plant proteins. Nucleic Acids Res. 1992, 20, 4662.

194. Lee-Huang, S.; Huang, P.L.; Nara, P.L.; Chen, H.C.; Kung, H.F.; Huang, P.; Huang, H.I.; Huang, P.L. Map 30: A new inhibitor of hiv-1 infection and replication. FEBS Lett. 1990, 272, 12-18.

195. Lee-Huang, S.; Huang, P.L.; Chen, H.C.; Huang, P.L.; Bourinbaiar, A.; Huang, H.I.; Kung, H.F. Anti-hiv and anti-tumor activities of recombinant map30 from bitter melon. Gene 1995, 161, 151-156.

196. Yeung, H.W.; Li, W.W.; Chan, W.Y.; Law, L.K.; Ng, T.B. Alpha and beta momorcharins. Int. J. Pept. Protein Res. 1986, 28, 518-524.

197. Yeung, H.W.; Ng, T.B.; Li, W.W.; Cheung, W.K. Partial chemical characterization of alpha- and beta-momorcharins. Planta Med. 1987, 53, 164-166.

198. Yeung, H.W.; Li, W.W.; Feng, Z.; Barbieri, L.; Stirpe, F. Trichosanthin, alpha-momorcharin and beta-momorcharin: Identity of abortifacient and ribosome-inactivating proteins. Int. J. Pept. Protein Res. 1988, 31, 265-268.

199. Feng, Z.; Li, W.W.; Yeung, H.W.; Chen, S.Z.; Wang, Y.P.; Lin, X.Y.; Dong, Y.C.; Wang, J.H. Crystals of alpha-momorcharin. A new ribosome-inactivating protein. J. Mol. Biol. 1990, 214, 625-626.

200. Ng, T.B.; Chan, W.Y.; Yeung, H.W. Proteins with abortifacient, ribosome inactivating, immunomodulatory, antitumor and anti-aids activities from cucurbitaceae plants. Gen. Pharmacol. 1992, 23, 579-590.

201. Fong, W.P.; Poon, Y.T.; Wong, T.M.; Mock, J.W.; Ng, T.B.; Wong, R.N.; Yao, Q.Z.; Yeung, H.W. A highly efficient procedure for purifying the ribosome-inactivating proteins alpha- and beta-momorcharins from Momordica charantia seeds, $N$-terminal sequence comparison and establishment of their $N$-glycosidase activity. Life Sci. 1996, 59, 901-909.

202. Ye, G.-J.; Qian, R.-Q.; Lu, B.-Y.; Gu, Z.-W.; Jin, S.-W.; Wang, Y. Isolation and characterization of alpha-, beta-momorcharins. Acta Chim. Sin. 1998, 56, 1135-1144. 
203. Tse, P.M.F.; Ng, T.B.; Fong, W.P.; Wong, R.N.S.; Wan, C.C.; Mak, N.K.; Yeung, H.W. New ribosome-inactivating proteins from seeds and fruits of the bitter gourd Momordica charantia. Int. J. Biochem. Cell Biol. 1999, 31, 895-901.

204. Zhu, F.; Zhang, P.; Meng, Y.F.; Xu, F.; Zhang, D.W.; Cheng, J.; Lin, H.H.; Xi, D.H. Alpha-momorcharin, a rip produced by bitter melon, enhances defense response in tobacco plants against diverse plant viruses and shows antifungal activity in vitro. Planta 2013, 237, 77-88.

205. Pu, Z.; Lu, B.Y.; Liu, W.Y.; Jin, S.W. Characterization of the enzymatic mechanism of gamma-momorcharin, a novel ribosome-inactivating protein with lower molecular weight of 11,500 purified from the seeds of bitter gourd (Momordica charantia). Biochem. Biophys. Res. Commun. 1996, 229, 287-294.

206. Endo, Y.; Tsurugi, K.; Lambert, J.M. The site of action of six different ribosome-inactivating proteins from plants on eukaryotic ribosomes: The RNA $N$-glycosidase activity of the proteins. Biochem. Biophys. Res. Commun. 1988, 150, 1032-1036.

207. Barbieri, L.; Zamboni, M.; Lorenzoni, E.; Montanaro, L.; Sperti, S.; Stirpe, F. Inhibition of protein synthesis in vitro by proteins from the seeds of Momordica charantia (bitter pear melon). Biochem. J. 1980, 186, 443-452.

208. Takemoto, D.J.; Jilka, C.; Rockenbach, S.; Hughes, J.V. Purification and characterization of a cytostatic factor with anti-viral activity from the bitter melon. Prep. Biochem. 1983, 13, 371-393.

209. Stirpe, F.; Bailey, S.; Miller, S.P.; Bodley, J.W. Modification of ribosomal RNA by ribosome-inactivating proteins from plants. Nucleic Acids Res. 1988, 16, 1349-1357.

210. Cunnick, J.E.; Sakamoto, K.; Chapes, S.K.; Fortner, G.W.; Takemoto, D.J. Induction of tumor cytotoxic immune cells using a protein from the bitter melon (Momordica charantia). Cell. Immunol. 1990, 126, 278-289.

211. Husain, J.; Tickle, I.J.; Wood, S.P. Crystal structure of momordin, a type i ribosome inactivating protein from the seeds of Momordica charantia. FEBS Lett. 1994, 342, 154-158.

212. Wang, Q.-H.; Ren, H.; Yu, C. Studies on ribosome inactivating protein of Momordica charantia L. Chin. Tradit. Herb. Drugs 1996, 27, 441-442.

213. Valbonesi, P.; Barbieri, L.; Bolognesi, A.; Bonora, E.; Polito, L.; Stirpe, F. Preparation of highly purified momordin ii without ribonuclease activity. Life Sci. 1999, 65, 1485-1491.

214. Minami, Y.; Nakahara, Y.; Funatsu, G. Isolation and characterization of two momordins, ribosome-inactivating proteins from the seeds of bitter gourd (Momordica charantia). Biosci. Biotechnol. Biochem. 1992, 56, 1470-1471.

215. Minami, Y.; Funatsu, G. The complete amino acid sequence of momordin-a, a ribosome-inactivating protein from the seeds of bitter gourd (Momordica charantia). Biosci. Biotechnol. Biochem. 1993, 57, 1141-1144.

216. Parkash, A.; Ng, T.B.; Tso, W.W. Purification and characterization of charantin, a napin-like ribosome-inactivating peptide from bitter gourd (Momordica charantia) seeds. J. Pept. Res. 2002, 59, 197-202.

217. Wang, H.; Ng, T.B. Ribosome inactivating protein and lectin from bitter melon (Momordica charantia) seeds: Sequence comparison with related proteins. Biochem. Biophys. Res. Commun. 1998, 253, 143-146. 
218. Barbieri, L.; Lorenzoni, E.; Stirpe, F. Inhibition of protein synthesis in vitro by a lectin from Momordica charantia and by other haemagglutinins. Biochem. J. 1979, 182, 633-635.

219. Ng, T.B.; Wong, C.M.; Li, W.W.; Yeung, H.W. Isolation and characterization of a galactose binding lectin with insulinomimetic activities. From the seeds of the bitter gourd Momordica charantia (family cucurbitaceae). Int. J. Pept. Protein Res. 1986, 28, 163-172.

220. Sultan, N.A.; Swamy, M.J. Energetics of carbohydrate binding to Momordica charantia (bitter gourd) lectin: An isothermal titration calorimetric study. Arch. Biochem. Biophys. 2005, 437, 115-125.

221. Tanaka, H.; Toyama, J.; Akashi, R. Molecular characterization of a galactose-binding lectin from Momordica charantia seeds and its expression in tobacco cells. Asian J. Plant Sci. 2009, 8, $544-550$.

222. Toyama, J.; Tanaka, H.; Horie, A.; Uchiyama, T.; Akashi, R. Purification and characterization of anti-h lectin from the seed of Momordica charantia and the inter-specific differences of hemagglutinating activity in cucurbitaceae. Asian J. Plant Sci. 2008, 7, 647-653.

223. Lin, J.Y.; Hou, M.J.; Chen, Y.C. Isolation of toxic and non-toxic lectins from the bitter pear melon Momordica charantia linn. Toxicon 1978, 16, 653-660.

224. Li, S.S. Purification and partial characterization of two lectins from Momordica charantia. Experientia 1980, 36, 524-527.

225. Chuethong, J.; Oda, K.; Sakurai, H.; Saiki, I.; Leelamanit, W. Cochinin b, a novel ribosome-inactivating protein from the seeds of Momordica cochinchinensis. Biol. Pharm. Bull. 2007, 30, 428-432.

226. Yeung, H.W.; Ng, T.B.; Wong, N.S.; Li, W.W. Isolation and characterization of an abortifacient protein, momorcochin, from root tubers of Momordica cochinchinensis (family cucurbitaceae). Int. J. Pept. Protein Res. 1987, 30, 135-140.

227. Bolognesi, A.; Barbieri, L.; Carnicelli, D.; Abbondanza, A.; Cenini, P.; Falasca, A.I.; Dinota, A.; Stirpe, F. Purification and properties of a new ribosome-inactivating protein with RNA $N$-glycosidase activity suitable for immunotoxin preparation from the seeds of Momordica cochinchinensis. Biochim. Biophys. Acta 1989, 993, 287-292.

228. Tsang, K.Y.; Ng, T.B. Isolation and characterization of a new ribosome inactivating protein, momorgrosvin, from seeds of the monk's fruit Momordica grosvenorii. Life Sci. 2001, 68, $773-784$.

229. Wu, T.H.; Chow, L.P.; Lin, J.Y. Sechiumin, a ribosome-inactivating protein from the edible gourd, sechium edule swartz-Purification, characterization, molecular cloning and expression. Eur. J. Biochem. 1998, 255, 400-408.

230. Vozari-Hampe, M.M.; Viegas, C.; Saucedo, C.; Rosseto, S.; Manica, G.G.; Hampe, O.G. A lectin from Sechium edule fruit exudate. Phytochemistry 1992, 31, 1477-1480.

231. Chow, L.P.; Chou, M.H.; Ho, C.Y.; Chuang, C.C.; Pan, F.M.; Wu, S.H.; Lin, J.Y. Purification, characterization and molecular cloning of trichoanguin, a novel type i ribosome-inactivating protein from the seeds of Trichosanthes anguina. Biochem. J. 1999, 338 Pt 1, 211-219.

232. Komath, S.S.; Nadimpalli, S.K.; Swamy, M.J. Purification in high yield and characterisation of the galactose-specific lectin from the seeds of snake gourd (Trichosanthes anguina). Biochem. Mol. Biol. Int. 1996, 39, 243-252. 
233. Manoj, N.; Jeyaprakash, A.A.; Pratap, J.V.; Komath, S.S.; Kenoth, R.; Swamy, M.J.; Vijayan, M. Crystallization and preliminary X-ray studies of snake gourd lectin: Homology with type ii ribosome-inactivating proteins. Acta Crystallogr. D Biol. Crystallogr. 2001, 57, 912-914.

234. Sharma, A.; Pohlentz, G.; Bobbili, K.B.; Jeyaprakash, A.A.; Chandran, T.; Mormann, M.; Swamy, M.J.; Vijayan, M. The sequence and structure of snake gourd (Trichosanthes anguina) seed lectin, a three-chain nontoxic homologue of type ii rips. Acta Crystallogr. D Biol. Crystallogr. 2013, 69, 1493-1503.

235. Sultan, N.A.; Kavitha, M.; Swamy, M.J. Purification and physicochemical characterization of two galactose-specific isolectins from the seeds of Trichosanthes cordata. IUBMB Life 2009, 61, 457-469.

236. Padma, P.; Komath, S.S.; Nadimpalli, S.K.; Swamy, M.J. Purification in high yield and characterization of a new galactose-specific lectin from the seeds of Trichosanthes cucumerina. Phytochemistry 1999, 50, 363-371.

237. Yeung, H.W.; Li, W.W. Beta-trichosanthin: A new abortifacient protein from the Chinese drug, wangua, Trichosanthes cucumeroides. Int. J. Pept. Protein Res. 1987, 29, 289-292.

238. Ng, T.B.; Feng, Z.; Li, W.W.; Yeung, H.W. Improved isolation and further characterization of beta-trichosanthin, a ribosome-inactivating and abortifacient protein from tubers of Trichosanthes cucumeroides (cucurbitaceae). Int. J. Biochem. 1991, 23, 561-567.

239. Wong, R.N.; Dong, T.X.; Ng, T.B.; Choi, W.T.; Yeung, H.W. Alpha-kirilowin, a novel ribosome-inactivating protein from seeds of Trichosanthes kirilowii (family cucurbitaceae): A comparison with beta-kirilowin and other related proteins. Int. J. Pept. Protein Res. 1996, 47, $103-109$.

240. Dong, T.X.; Ng, T.B.; Yeung, H.W.; Wong, R.N. Isolation and characterization of a novel ribosome-inactivating protein, beta-kirilowin, from the seeds of Trichosanthes kirilowii. Biochem. Biophys. Res. Commun. 1994, 199, 387-393.

241. Lee-Huang, S.; Huang, P.L.; Kung, H.F.; Li, B.Q.; Huang, P.L.; Huang, P.; Huang, H.I.; Chen, H.C. Tap 29: An anti-human immunodeficiency virus protein from Trichosanthes kirilowii that is nontoxic to intact cells. Proc. Natl. Acad. Sci. USA 1991, 88, 6570-6574.

242. Thorup, J.E.; McDonald, K.A.; Jackman, A.P.; Bhatia, N.; Dandekar, A.M. Ribosome-inactivating protein production from Trichosanthes kirilowii plant cell cultures. Biotechnol. Prog. 1994, 10, 345-352.

243. Remi Shih, N.J.; McDonald, K.A.; Dandekar, A.M.; Girbés, T.; Iglesias, R.; Jackman, A.P. A novel type-1 ribosome-inactivating protein isolated from the supernatant of transformed suspension cultures of Trichosanthes kirilowii. Plant Cell Rep. 1998, 17, 531-537.

244. Jin, S.-W.; Xiang, B.-P.; Cao, B.-X.; Wang, Y. Trichobitacin-A new ribosome-inactivating protein $\mathrm{i}$. The isolation, physicochemical and biological properties of trichobitacin. Chin. J. Chem. 1997, 15, 160-168.

245. Xiang, B.-P.; Jin, S.-W.; Cao, B.-X.; Fu, G.-X.; Wang, Y. Trichobitacin ii. Determination of the partial primary structure of trichobitacin. Acta Chim. Sin. 1998, 56, 302-307.

246. Zheng, Y.T.; Ben, K.L.; Jin, S.W. Anti-hiv-1 activity of trichobitacin, a novel ribosome-inactivating protein. Acta Pharmacol. Sin. 2000, 21, 179-182. 
247. Casellas, P.; Dussossoy, D.; Falasca, A.I.; Barbieri, L.; Guillemot, J.C.; Ferrara, P.; Bolognesi, A.; Cenini, P.; Stirpe, F. Trichokirin, a ribosome-inactivating protein from the seeds of trichosanthes kirilowii maximowicz. Purification, partial characterization and use for preparation of immunotoxins. Eur. J. Biochem. 1988, 176, 581-588.

248. Mi, S.L.; An, C.C.; Wang, Y.; Chen, J.Y.; Che, N.Y.; Gao, Y.; Chen, Z.L. Trichomislin, a novel ribosome-inactivating protein, induces apoptosis that involves mitochondria and caspase-3. Arch. Biochem. Biophys. 2005, 434, 258-265.

249. Gu, Z.-W.; Jin, S.-W.; Qian, W.-W.; Zhang, X.-L.; Cao, B.-X.; Wang, Q.-H.; Fu, Y.-H.; Xu, S.-Z.; Yao, Y.-Z.; Liu, Y.-F.; et al. Chemistry of trichosanthin iii: Amino acid sequence of cnbr degradation fragment cba. Acta Chim. Sin. 1983, 41, 1190-1192.

250. Gu, Z.-W.; Qian, R.-R.; Jin, S.-W.; Qian, W.-W.; Liu, Y.-F.; Zhu, S.-Q.; Cao, B.-S.; Wang, S.-F.; $\mathrm{Xu}$, S.-Z.; Zhang, L.-Q.; et al. Chemistry of trichosanthin iv: The principal structure of trichosanthin. Acta Chim. Sin. 1984, 42, 943-945.

251. McGrath, M.S.; Hwang, K.M.; Caldwell, S.E.; Gaston, I.; Luk, K.C.; Wu, P.; Ng, V.L.; Crowe, S.; Daniels, J.; Marsh, J.; et al. Glq223: An inhibitor of human immunodeficiency virus replication in acutely and chronically infected cells of lymphocyte and mononuclear phagocyte lineage. Proc. Natl. Acad. Sci. USA 1989, 86, 2844-2848.

252. Collins, E.J.; Robertus, J.D.; LoPresti, M.; Stone, K.L.; Williams, K.R.; Wu, P.; Hwang, K.; Piatak, M. Primary amino acid sequence of alpha-trichosanthin and molecular models for abrin A-chain and alpha-trichosanthin. J. Biol. Chem. 1990, 265, 8665-8669.

253. Shaw, P.C.; Chan, W.L.; Yeung, H.W.; Ng, T.B. Minireview: Trichosanthin-A protein with multiple pharmacological properties. Life Sci. 1994, 55, 253-262.

254. Bhatia, N.; McDonald, K.A.; Jackman, A.P.; Dandekar, A.M. A simplified procedure for the purification of trichosanthin (a type 1 ribosome inactivating protein) from Trichosanthes kirilowii root tubers. Protein Expr. Purif. 1996, 7, 143-146.

255. Narayanan, P.; Mak, N.K.; Luong, P.B.; Wong, R.N.S. Isolation and characterization of new isoforms of trichosanthin from Trichosanthes kirilowii. Plant Sci. 2002, 162, 79-85.

256. Shu, S.H.; Xie, G.Z.; Guo, X.L.; Wang, M. Purification and characterization of a novel ribosome-inactivating protein from seeds of Trichosanthes kirilowii maxim. Protein Expr. Purif. 2009, 67, 120-125.

257. Maraganore, J.M.; Joseph, M.; Bailey, M.C. Purification and characterization of trichosanthin. Homology to the ricin a chain and implications as to mechanism of abortifacient activity. J. Biol. Chem. 1987, 262, 11628-11633.

258. Li, F.; Yang, X.X.; Hu, W.G.; Xia, H.C.; Li, Z.; Zhang, Z.C. Purification and characterization of trichokirin-s1, a novel ribosome-inactivating peptide from seeds of Trichosanthes kirilowii. Acta Biochim. Biophys. Sin. 2003, 35, 841-846.

259. Tai, N.W.; Li, F.; Li, Z.; Zhuang, D.H.; Zhang, Z.C. Purification and partial characterization of s-trichokirin, a new small ribosome-inactivating protein, from seeds of Trichosanthes kirilowii. Acta Biochim. Biophys. Sin. (Shanghai) 2000, 32, 495-498.

260. Li, M.; Wang, Y.P.; Chai, J.J.; Wang, K.Y.; Bi, R.C. Molecular-replacement studies of Trichosanthes kirilowii lectin 1: A structure belonging to the family of type 2 ribosome-inactivating proteins. Acta Crystallogr. D Biol. Crystallogr. 2000, 56, 1073-1075. 
261. Li, M.; Chai, J.-J.; Wang, X.-P.; Wang, R.-Y.; Bi, R.-C. Crystal structure of Trichosanthes kirilowii lectin-1 and its relation to the type 2 ribosome inactivating proteins. Protein Pept. Lett. 2001, 8 , 81-87.

262. Yeung, H.W.; Ng, T.B.; Wong, D.M.; Wong, C.M.; Li, W.W. Chemical and biological characterization of the galactose binding lectins from Trichosanthes kirilowii root tubers. Int. J. Pept. Protein Res. 1986, 27, 208-220.

263. Yeung, H.W.; Wong, D.M.; Ng, T.B.; Li, W.W. Purification of three isolectins from root tubers of Trichosanthes kirilowii (tianhuafen). Int. J. Pept. Protein Res. 1986, 27, 325-333.

264. Falasca, A.I.; Abbondanza, A.; Barbieri, L.; Bolognesi, A.; Rossi, C.A.; Stirpe, F. Purification and partial characterization of a lectin from the seeds of Trichosanthes kirilowii maximowicz. FEBS Lett. 1989, 246, 159-162.

265. Toyokawa, S.; Takeda, T.; Ogihara, Y. Isolation and characterization of a new abortifacient protein, karasurin, from root tubers of Trichosanthes kirilowii max. Var. Japonicum kitam. Chem. Pharm. Bull. 1991, 39, 716-719.

266. Toyokawa, S.; Takeda, T.; Kato, Y.; Wakabayashi, K.; Ogihara, Y. The complete amino acid sequence of an abortifacient protein, karasurin. Chem. Pharm. Bull. 1991, 39, 1244-1249.

267. Kondo, T.; Mizukami, H.; Takeda, T.; Ogihara, Y. Amino acid sequences and ribosome-inactivating activities of karasurin-b and karasurin-c. Biol. Pharm. Bull. 1996, 19, $1485-1489$.

268. Kondo, T.; Kurihara, S.; Yoshikawa, T.; Mizukami, H. Effect of $N$ - and $C$-terminal deletions on the RNA $N$-glycosidase activity and the antigenicity of karasurin-a, a ribosome-inactivating protein from Trichosanthes kirilowii var. Japonica. Biotechnol. Lett. 2004, 26, 1873-1878.

269. Chen, R.; Xu, Y.Z.; Wu, J.; Pu, Z.; Jin, S.W.; Liu, W.Y.; Xia, Z.X. Purification and characterization of trichomaglin-A novel ribosome-inactivating protein with abortifacient activity. Biochem. Mol. Biol. Int. 1999, 47, 185-193.

270. Sultan, N.A.; Kenoth, R.; Swamy, M.J. Purification, physicochemical characterization, saccharide specificity, and chemical modification of a gal/galnac specific lectin from the seeds of Trichosanthes dioica. Arch. Biochem. Biophys. 2004, 432, 212-221.

271. Chi, P.V.; Truong, H.Q.; Ha, N.T.; Chung, W.I.; Binh, L.T. Characterization of trichobakin, a type i ribosome-inactivating protein from Trichosanthes sp. Bac kan 8-98. Biotechnol. Appl. Biochem. 2001, 34, 85-92.

272. Si, Y.-X.; Liu, W.-Y.; Qian, K.-X. Investigation on isolation and functional mechanism of ribosome-inactivating protein from arborvitae seeds. J. Zhejiang Univ. 2005, 39, 423-426.

273. Stirpe, F.; Pession-Brizzi, A.; Lorenzoni, E.; Strocchi, P.; Montanaro, L.; Sperti, S. Studies on the proteins from the seeds of croton tiglium and of jatropha curcas. Toxic properties and inhibition of protein synthesis in vitro. Biochem. J. 1976, 156, 1-6.

274. Sperti, S.; Montanaro, L.; Mattioli, A.; Testoni, G.; Stirpe, F. Inhibition of protein synthesis in vitro by crotins and ricin. Effect on the steps of peptide chain elongation. Biochem. J. 1976, 156, 7-13.

275. Chen, M.H.; Zhou, K.J.; Fu, Z.J.; Pan, K.Z. Preliminary crystallographic studies of crotin ii. J. Mol. Biol. 1993, 234, 908-909. 
276. Iglesias, R.; Escarmis, C.; Alegre, C.; Ferreras, J.M.; Girbes, T. Fusidic acid-dependent ribosomal complexes protect escherichia coli ribosomes from the action of the type 1 ribosome-inactivating protein crotin 2. FEBS Lett. 1993, 318, 189-192.

277. Ferreras, J.M.; Alegre, C.; Iglesias, R.; Girbes, T. Sensitivity of translation by brevibacterium lactofermentum ribosomes to type 1 and type 2 ribosome-inactivating proteins. Biosci. Biotechnol. Biochem. 1994, 58, 1458-1462.

278. Alegre, C.; Iglesias, R.; Ferreras, J.M.; Citores, L.; Girbes, T. Sensitivity of ribosomes from agrobacterium tumefaciens to the ribosome-inactivating protein crotin 2 depending on the translocational state. Cell. Mol. Biol. 1996, 42, 151-158.

279. Barbieri, L.; Falasca, A.; Franceschi, C.; Licastro, F.; Rossi, C.A.; Stirpe, F. Purification and properties of two lectins from the latex of the euphorbiaceous plants hura crepitans 1. (sand-box tree) and Euphorbia characias L. (mediterranean spurge). Biochem. J. 1983, 215, 433-439.

280. Stirpe, F.; Olsnes, S.; Pihl, A. Gelonin, a new inhibitor of protein synthesis, nontoxic to intact cells. Isolation, characterization, and preparation of cytotoxic complexes with concanavalin a. J. Biol. Chem. 1980, 255, 6947-6953.

281. Ebert, R.F.; Spryn, L.A. Immunotoxin construction with a ribosome-inactivating protein from barley. Bioconjug. Chem. 1990, 1, 331-336.

282. Rosenblum, M.G.; Kohr, W.A.; Beattie, K.L.; Beattie, W.G.; Marks, W.; Toman, P.D.; Cheung, L. Amino acid sequence analysis, gene construction, cloning, and expression of gelonin, a toxin derived from gelonium multiflorum. J. Interferon Cytokine Res. 1995, 15, 547-555.

283. Singh, V.; Singh, R.C.; Dubey, R.K.; Alam, A. Purification and characterisation of gelonin from seeds of Gelonium multiflorum. Indian J. Biochem. Biophys. 1999, 36, 258-265.

284. Ferreras, J.M.; Iglesias, R.; Barbieri, L.; Alegre, C.; Bolognesi, A.; Rojo, M.A.; Carbajales, M.L.; Escarmis, C.; Girbes, T. Effects and molecular action of ribosome-inactivating proteins on ribosomes from Streptomyces lividans. Biochim. Biophys. Acta 1995, 1243, 85-93.

285. Jaffe, W.G.; Seidl, D. Crepitin, a phytohemagglutinin from Hura crepitans. Experientia 1969, 25, 891-892.

286. Falasca, A.; Franceschi, C.; Rossi, C.A.; Stirpe, F. Mitogenic and haemagglutinating properties of a lectinpurified from Hura crepitans seeds. Biochim. Biophys. Acta 1980, 632, 95-105.

287. Kaufman, S.J.; McPherson, A. Abrin and hurin: Two new lymphocyte mitogens. Cell 1975, 4, 263-268.

288. McPherson, A.; Hoover, S. Purification o mitogenic proteins from hura crepitans and Robinia pseudaccacia. Biochem. Biophys. Res. Commun. 1979, 89, 713-720.

289. Lin, J.; Zhou, X.; Wang, J.; Jiang, P.; Tang, K. Purification and characterization of curcin, a toxic lectin from the seed of Jatropha curcas. Prep. Biochem. Biotechnol. 2010, 40, 107-118.

290. Qin, W.; Ming-Xing, H.; Ying, X.; Xin-Shen, Z.; Fang, C. Expression of a ribosome inactivating protein (curcin 2) in Jatropha curcas is induced by stress. J. Biosci. 2005, 30, 351-357.

291. Huang, M.-X.; Hou, P.; Wei, Q.; Xu, Y.; Chen, F. A ribosome-inactivating protein (curcin 2) induced from Jatropha curcas can reduce viral and fungal infection in transgenic tobacco. Plant. Growth Regul. 2008, 54, 115-123. 
292. Qin, X.; Zheng, X.; Shao, C.; Gao, J.; Jiang, L.; Zhu, X.; Yan, F.; Tang, L.; Xu, Y.; Chen, F.; et al. Stress-induced curcin-1 promoter in leaves of Jatropha curcas 1 . And characterization in transgenic tobacco. Planta 2009, 230, 387-395.

293. Qin, X.; Shao, C.; Hou, P.; Gao, J.; Lei, N.; Jiang, L.; Ye, S.; Gou, C.; Luo, S.; Zheng, X.; et al. Different functions and expression profiles of curcin and curcin-L in Jatropha curcas L. Z. Naturforsch C 2010, 65, 355-362.

294. Nuchsuk, C.; Wetprasit, N.; Roytrakul, S.; Choowongkomon, K.; Thienprasert, N,T.; Yokthongwattana, C.; Arpornsuwan, T.; Ratanapo, S. Bioactivities of jc-scrip, a type 1 ribosome-inactivating protein from Jatropha curcas seed coat. Chem. Biol. Drug Des. 2013, 82, 453-462.

295. Carnicelli, D.; Brigotti, M.; Alvergna, P.; Pallanca, A.; Sperti, S.; Montanaro, L. Cofactor requirement of ribosome-inactivating proteins from plants. J. Exp. Bot. 1997, 48, 1519-1523.

296. Osborne, T.B.; Mendel, L.B.; Harris, I.F. A study of the proteins of the castor bean, with special reference to the isolation of ricin. Am. J. Physiol. 1905, 14, 259-286.

297. Kabat, E.A.; Heidelberger, M.; Bezer, A.E. A study of the purification and properties of ricin. J. Biol. Chem. 1947, 168, 629-639.

298. Kunitz, M.; McDonald, M.R. Isolation of crystalline ricin. J. Gen. Physiol. 1948, 32, 25-31.

299. Ishiguro, M.; Takahashi, T.; Funatsu, G.; Hayashi, K.; Funatsu, M. Biochemical studies on ricin. I. Purification of ricin. J. Biochem. 1964, 55, 587-592.

300. Ishiguro, M.; Takahashi, T.; Hayashi, K.; Funatsu, M. Biochemical studies on ricin. II. Molecular weight and some physicochemical properties of crystalline ricin d. J. Biochem. 1964, 56, 325-327.

301. Ishiguro, M.; Funatsu, G.; Funatsu, M. Biochemical studies on ricin part iii. Reinvestigation on the purification of ricin. Agric. Biol. Chem. 1971, 35, 724-728.

302. Funatsu, M.; Funatsu, G.; Ishiguro, M.; Nanno, S.; Hara, K. Structure and toxic function of ricin. II: Subunit structure of ricin d. Proc. Jpn. Acad 1971, 47, 718-723.

303. Cawley, D.B.; Hedblom, M.L.; Houston, L.L. Homology between ricin and ricinus communis agglutinin: Amino terminal sequence analysis and protein synthesis inhibition studies. Arch. Biochem. Biophys. 1978, 190, 744-755.

304. Fulton, R.J.; Blakey, D.C.; Knowles, P.P.; Uhr, J.W.; Thorpe, P.E.; Vitetta, E.S. Purification of ricin a1, a2, and b chains and characterization of their toxicity. J. Biol. Chem. 1986, 261, 5314-5319.

305. Endo, Y.; Tsurugi, K. RNA $N$-glycosidase activity of ricin a-chain. Mechanism of action of the toxic lectin ricin on eukaryotic ribosomes. J. Biol. Chem. 1987, 262, 8128-8130.

306. Citores, L.; Ferreras, J.M.; Iglesias, R.; Carbajales, M.L.; Arias, F.J.; Jimenez, P.; Rojo, M.A.; Girbes, T. Molecular mechanism of inhibition of mammalian protein synthesis by some four-chain agglutinins. Proposal of an extended classification of plant ribosome-inactivating proteins (rRNA $N$-glycosidases). FEBS Lett. 1993, 329, 59-62.

307. Olsnes, S. The history of ricin, abrin and related toxins. Toxicon 2004, 44, 361-370.

308. Sehgal, P.; Rao, M.K.; Kumar, O.; Vijayaraghavan, R. Characterization of native and denatured ricin using maldi-tof/ms. Cell. Mol. Biol. 2010, 56, O11385-O11399. 
309. Sehgal, P.; Khan, M.; Kumar, O.; Vijayaraghavan, R. Purification, characterization and toxicity profile of ricin isoforms from castor beans. Food Chem. Toxicol. 2010, 48, 3171-3176.

310. Mise, T.; Funatsu, G.; Ishiguro, M.; Funatsu, M. Isolation and characterization of ricin e from castor beans. Agric. Biol. Chem. 1977, 41, 2041-2046.

311. Araki, T.; Funatsu, G. The complete amino acid sequence of the b-chain of ricin e isolated from small-grain castor bean seeds. Ricin e is a gene recombination product of ricin $\mathrm{d}$ and ricinus Communis agglutinin. Biochim. Biophys. Acta 1987, 911, 191-200.

312. Ladin, B.F.; Murray, E.E.; Halling, A.C.; Halling, K.C.; Tilakaratne, N.; Long, G.L.; Houston, L.L.; Weaver, R.F. Characterization of a cdna encoding ricin e, a hybrid ricin-ricinus Communis agglutinin gene from the castor plant Ricinus communis. Plant Mol. Biol. 1987, 9 , 287-295.

313. Nicolson, G.L.; Blaustein, J. The interaction of ricinus Communis agglutinin with normal and tumor cell surfaces. Biochim. Biophys. Acta 1972, 266, 543-547.

314. Lugnier, A.; Dirheimer, G. Differences between ricin and phytohemagglutinins from Ricinus communis seeds. FEBS Lett. 1973, 35, 117-120.

315. Olsnes, S.; Saltvedt, E.; Pihl, A. Isolation and comparison of galactose-binding lectins from Abrus precatorius and Ricinus communis. J. Biol. Chem. 1974, 249, 803-810.

316. Nicolson, G.L.; Blaustein, J.; Etzler, M.E. Characterization of two plant lectins from Ricinus communis and their quantitative interaction with a murine lymphoma. Biochemistry 1974, 13, 196-204.

317. Nicolson, G.L.; Lacorbiere, M.; Hunter, T.R. Mechanism of cell entry and toxicity of an affinity- purified lectin from ricinus communis and its differential effects on normal and virus-transformed fibroblasts. Cancer Res. 1975, 35, 144-155.

318. Harley, S.M.; Beevers, H. Ricin inhibition of in vitro protein synthesis by plant ribosomes. Proc. Natl. Acad. Sci. USA 1982, 79, 5935-5938.

319. Roberts, L.M.; Lamb, F.I.; Pappin, D.J.; Lord, J.M. The primary sequence of Ricinus communis agglutinin. Comparison with ricin. J. Biol. Chem. 1985, 260, 15682-15686.

320. Sweeney, E.C.; Tonevitsky, A.G.; Temiakov, D.E.; Agapov, I.I.; Saward, S.; Palmer, R.A. Preliminary crystallographic characterization of ricin agglutinin. Proteins 1997, 28, 586-589.

321. Hegde, R.; Podder, S.K. Evolution of tetrameric lectin ricinus communis agglutinin from two variant groups of ricin toxin dimers. Eur. J. Biochem. 1998, 254, 596-601.

322. Helmy, M.; Piéroni, G. Rca60: Purification and characterization of ricin d isoforms from Ricinus sanguineus. J. Plant Physiol. 2000, 156, 477-482.

323. Hegde, R.; Podder, S.K. Studies on the variants of the protein toxins ricin and abrin. Eur. J. Biochem. 1992, 204, 155-164.

324. El-Nikhely, N.; Helmy, M.; Saeed, H.M.; Abou Shama, L.A.; Abd El-Rahman, Z. Ricin a chain from Ricinus sanguineus: DNA sequence, structure and toxicity. Protein J. 2007, 26, 481-489.

325. Lin, J.Y.; Lei, L.L.; Tung, T.C. Purification of abrin from Abrus precatorius L. Leguminosae. J. Formos. Med. Assoc. 1969, 68, 518-521.

326. Olsnes, S.; Pihl, A. Isolation and properties of abrin: A toxic protein inhibiting protein synthesis. Evidence for different biological functions of its two constituent-peptide chains. Eur. J. Biochem. 1973, 35, 179-185. 
327. Olsnes, S.; Heiberg, R.; Pihl, A. Inactivation of eucaryotic ribosomes by the toxic plant proteins abrin and ricin. Mol. Biol. Rep. 1973, 1, 15-20.

328. McPherson, A., Jr.; Rich, A. Studies on crystalline abrin: X-ray diffraction data, molecular weight, carbohydrate content and subunit structure. FEBS Lett. 1973, 35, 257-261.

329. Olsnes, S.; Pihl, A. Abrin, ricin, and their associated agglutinins. In The Specificity and Action of Animal, Bacterial and Plant Toxins; Cuatrecasas, P., Ed.; Springer US: New York, NY, USA, 1977; pp. 129-173.

330. Kumar, O.; Kannoji, A.; Jayaraj, R.; Vijayaraghavan, R. Purification and characterization of abrin toxin from white Abrus precatorius seeds. J. Cell Tissue Res. 2008, 8, 1243-1248.

331. Wei, C.H.; Hartman, F.C.; Pfuderer, P.; Yang, W.K. Purification and characterization of two major toxic proteins from seeds of abrus precatorius. J. Biol. Chem. 1974, 249, 3061-3067.

332. Wei, C.H.; Einstein, J.R. Preliminary crystallographic data for a new crystalline form of abrin. J. Biol. Chem. 1974, 249, 2985-2986.

333. Lin, J.Y.; Lee, T.C.; Tung, T.C. Isolation of antitumor proteins abrin-a and abrin-b from Abrus precatorius. Int. J. Pept. Protein Res. 1978, 12, 311-317.

334. Lin, J.Y.; Lee, T.C.; Hu, S.T.; Tung, T.C. Isolation of four isotoxic proteins and one agglutinin from jequiriti bean (Abrus precatorius). Toxicon 1981, 19, 41-51.

335. Lin, J.Y.; Lee, T.C.; Tung, T.C. Inhibitory effects of four isoabrins on the growth of sarcoma 180 cells. Cancer Res. 1982, 42, 276-279.

336. Herrmann, M.S.; Behnke, W.D. A characterization of abrin a from the seeds of the Abrus precatorius plant. Biochim. Biophys. Acta 1981, 667, 397-410.

337. Hegde, R.; Maiti, T.K.; Podder, S.K. Purification and characterization of three toxins and two agglutinins from Abrus precatorius seed by using lactamyl-sepharose affinity chromatography. Anal. Biochem. 1991, 194, 101-109.

338. Hung, C.H.; Lee, M.C.; Lee, T.C.; Lin, J.Y. Primary structure of three distinct isoabrins determined by cDNA sequencing. Conservation and significance. J. Mol. Biol. 1993, 229, 263-267.

339. Tahirov, T.H.; Lu, T.H.; Liaw, Y.C.; Chen, Y.L.; Lin, J.Y. Crystal structure of abrin-a at 2.14 a. J. Mol. Biol. 1995, 250, 354-367.

340. Li, X.-B.; Xie, G.-H.; Zhou, C.-F.; Zhang, Z.-G.; Song, W.-X.; Zhou, X.-C.; Zhang, N.-S.; Wang, X.-L.; Gao, H.-W.; Wang, Z.; et al. Purification and characterization of abrin-a. Chin. J. Vet. Sci. 2008, 28, 310-313.

341. Wei, C.H.; Koh, C.; Pfuderer, P.; Einstein, J.R. Purification, properties, and crystallographic data for a principal nontoxic lectin from seeds of abrus precatorius. J. Biol. Chem. 1975, 250, 4790-4795.

342. Roy, J.; Som, S.; Sen, A. Isolation, purification, and some properties of a lectin and abrin from Abrus precatorius linn. Arch. Biochem. Biophys. 1976, 174, 359-361.

343. Murray, D.R.; Vairinhos, F. The seed proteins of Abrus precatorius L. Z. Pflanzenphysiol. 1982, $108,471-476$.

344. Liu, C.L.; Tsai, C.C.; Lin, S.C.; Wang, L.I.; Hsu, C.I.; Hwang, M.J.; Lin, J.Y. Primary structure and function analysis of the Abrus precatorius agglutinin a chain by site-directed mutagenesis. Pro(199) of amphiphilic alpha-helix h impairs protein synthesis inhibitory activity. J. Biol. Chem. 2000, 275, 1897-1901. 
345. Panneerselvam, K.; Lin, S.C.; Liu, C.L.; Liaw, Y.C.; Lin, J.Y.; Lu, T.H. Crystallization of agglutinin from the seeds of Abrus precatorius. Acta Crystallogr. D Biol. Crystallogr. 2000, 56, 898-899.

346. Bagaria, A.; Surendranath, K.; Ramagopal, U.A.; Ramakumar, S.; Karande, A.A. Structure-function analysis and insights into the reduced toxicity of Abrus precatorius agglutinin i in relation to abrin. J. Biol. Chem. 2006, 281, 34465-34474.

347. Ramos, M.V.; Mota, D.M.; Teixeira, C.R.; Cavada, B.S.; Moreira, R.A. Isolation and partial characterisation of highly toxic lectins from Abrus pulchellus seeds. Toxicon 1998, 36, 477-484.

348. Silva, A.L.; Horta, A.C.; Moreira, R.A.; Beltramini, L.M.; Araujo, A.P. Production of Abrus pulchellus ribosome-inactivating protein from seeds callus culture. Toxicon 2003, 41, 841-849.

349. Silva, A.L.; Goto, L.S.; Dinarte, A.R.; Hansen, D.; Moreira, R.A.; Beltramini, L.M.; Araujo, A.P. Pulchellin, a highly toxic type 2 ribosome-inactivating protein from Abrus pulchellus. Cloning heterologous expression of a-chain and structural studies. FEBS J. 2005, 272, 1201-1210.

350. Castilho, P.V.; Goto, L.S.; Roberts, L.M.; Araujo, A.P. Isolation and characterization of four type 2 ribosome inactivating pulchellin isoforms from Abrus pulchellus seeds. FEBS J. 2008, 275, 948-959.

351. Lam, S.S.; Wang, H.; Ng, T.B. Purification and characterization of novel ribosome inactivating proteins, alpha- and beta-pisavins, from seeds of the garden pea pisum sativum. Biochem. Biophys. Res. Commun. 1998, 253, 135-142.

352. Ye, X.Y.; Wang, H.X.; Ng, T.B. Sativin: A novel antifungal miraculin-like protein isolated from legumes of the sugar snap Pisum sativum var. Macrocarpon. Life Sci. 2000, 67, 775-781.

353. Van Damme, E.J.; Barre, A.; Barbieri, L.; Valbonesi, P.; Rouge, P.; van Leuven, F.; Stirpe, F.; Peumans, W.J. Type 1 ribosome-inactivating proteins are the most abundant proteins in Iris (iris hollandica var. Professor blaauw) bulbs: Characterization and molecular cloning. Biochem. J. 1997, 324 Pt 3, 963-970.

354. Desmyter, S.; Vandenbussche, F.; Hao, Q.; Proost, P.; Peumans, W.J.; van Damme, E.J. Type-1 ribosome-inactivating protein from Iris bulbs: A useful agronomic tool to engineer virus resistance? Plant Mol. Biol. 2003, 51, 567-576.

355. Mo, H.; van Damme, E.J.; Peumans, W.J.; Goldstein, I.J. Isolation and characterization of an $\mathrm{N}$-acetyl-D-galactosamine-binding lectin from dutch Iris bulbs which recognizes the blood group a disaccharide (galnac alpha 1-3gal). J. Biol. Chem. 1994, 269, 7666-7673.

356. Hao, Q.; van Damme, E.J.; Hause, B.; Barre, A.; Chen, Y.; Rouge, P.; Peumans, W.J. Iris bulbs express type 1 and type 2 ribosome-inactivating proteins with unusual properties. Plant Physiol. 2001, 125, 866-876.

357. Vandenbussche, F.; Peumans, W.J.; Desmyter, S.; Proost, P.; Ciani, M.; van Damme, E.J. The type-1 and type-2 ribosome-inactivating proteins from Iris confer transgenic tobacco plants local but not systemic protection against viruses. Planta 2004, 220, 211-221.

358. Verma, H.N.; Srivastava, S.; Varsha; Kumar, D. Induction of systemic resistance in plants against viruses by a basic protein from Clerodendrum aculeatum leaves. Phytopathology 1996, 86, 485-492. 
359. Kumar, D.; Verma, H.N.; Tuteja, N.; Tewari, K.K. Cloning and characterisation of a gene encoding an antiviral protein from Clerodendrum aculeatum L. Plant Mol. Biol. 1997, 33, $745-751$.

360. Prasad, V.; Srivastava, S.; Varsha; Verma, H.N. Two basic proteins isolated from Clerodendrum inerme gaertn. Are inducers of systemic antiviral resistance in susceptible plants. Plant Sci. 1995, 110, 73-82.

361. Olivieri, F.; Prasad, V.; Valbonesi, P.; Srivastava, S.; Ghosal-Chowdhury, P.; Barbieri, L.; Bolognesi, A.; Stirpe, F. A systemic antiviral resistance-inducing protein isolated from Clerodendrum inerme gaertn. Is a polynucleotide: Adenosine glycosidase (ribosome-inactivating protein). FEBS Lett. 1996, 396, 132-134.

362. Yang, X.-Y.; Xiao, Y.-H.; Pei, Y. Sequence of a Novel Leonurus japonicus Ribosome-Inactivating Protein (Rip) Gene. Patent No. Cn 1563381 a, 12 January 2005.

363. Hou, F.-J.; Wang, B.-Z.; Liu, W.-Y. Comparative studies of three type ii ribosome-inactivating proteins from the seeds of three species of the genus Cinnamomum. Protein Pept. Lett. 2001, 8 , 193-200.

364. Ling, J.; Liu, W.Y.; Wang, T.P. Simultaneous existence of two types of ribosome-inactivating proteins in the seeds of Cinnamonum camphora - Characterization of the enzymatic activities of these cytotoxic proteins. Biochim. Biophys. Acta 1995, 1252, 15-22.

365. Ling, J.; Liu, W.Y. Cytotoxicity of two new ribosome-inactivating proteins, cinnamomin and camphorin, to carcinoma cells. Cell Biochem. Funct. 1996, 14, 157-161.

366. He, W.J.; Liu, W.Y. Cinnamomin: A multifunctional type ii ribosome-inactivating protein. Int. J. Biochem. Cell Biol. 2003, 35, 1021-1027.

367. Xu, H.; Liu, W.Y. Cinnamomin-A versatile type ii ribosome-inactivating protein. Acta Biochim. Biophys. Sin. 2004, 36, 169-176.

368. Hou, F.-J.; Liu, R.-S.; Liu, W.-Y. Cinphorin: A novel type ii ribosome-inactivating protein with miniature active a-chain. Prog. Biochem. Biophys. 2002, 29, 531-532.

369. Li, X.D.; Liu, W.Y.; Niu, C.L. Purification of a new ribosome-inactivating protein from the seeds of Cinnamomum porrectum and characterization of the RNA $N$-glycosidase activity of the toxic protein. Biol. Chem. 1996, 377, 825-831.

370. Kondo, T.; Yoshikawa, T. Purification and characterization of abelesculin, a novel ribosome-inactivating protein from the mature seeds of Abelmoschus esculentus. J. Nat. Med. 2007, 61, 170-174.

371. Verma, H.N.; Awasthi, L.P. Antiviral activity of boerhaavia diffusa root extract and the physical properties of the virus inhibitor. Can. J. Bot. 1979, 57, 926-932.

372. Verma, H.N.; Awasthi, L.P.; Saxena, K.C. Isolation of the virus inhibitor from the root extract of Boerhaavia diffusa inducing systemic resistance in plants. Can. J. Bot. 1979, 57, 1214-1217.

373. Kubo, S.; Ikeda, T.; Imaizumi, S.; Takanami, Y.; Mikami, Y. A potent plant virus inhibitor found in Mirabilis jalapa L. Jpn. J. Phytopathol. 1990, 56, 481-487.

374. Balasaraswathi, R.; Sadasivam, S.; Ward, M.; Walker, J.M. An antiviral protein from Bougainvillea spectabilis roots; purification and characterisation. Phytochemistry 1998, 47, 1561-1565. 
375. den Hartog, M.T.; Lubelli, C.; Boon, L.; Heerkens, S.; Ortiz Buijsse, A.P.; de Boer, M.; Stirpe, F. Cloning and expression of cDNA coding for bouganin. Eur. J. Biochem. 2002, 269, 1772-1779.

376. Narwal, S.; Balasubrahmanyam, A.; Lodha, M.L.; Kapoor, H.C. Purification and properties of antiviral proteins from the leaves of Bougainvillea xbuttiana. Indian J. Biochem. Biophys. 2001, 38, 342-347.

377. Narwal, S.; Balasubrahmanyam, A.; Sadhna, P.; Kapoor, H.; Lodha, M.L. A systemic resistance inducing antiviral protein with $\mathrm{N}$-glycosidase activity from Bougainvillea xbuttiana leaves. Indian J. Exp. Biol. 2001, 39, 600-603.

378. Choudhary, N.L.; Yadav, O.P.; Lodha, M.L. Ribonuclease, deoxyribonuclease, and antiviral activity of escherichia coli-expressed Bougainvillea xbuttiana antiviral protein 1. Biochemistry 2008, 73, 273-277.

379. Choudhary, N.; Kapoor, H.C.; Lodha, M.L. Cloning and expression of antiviral/ribosomeinactivating protein from Bougainvillea xbuttiana. J. Biosci. 2008, 33, 91-101.

380. Vivanco, J.M.; Savary, B.J.; Flores, H.E. Characterization of two novel type i ribosome-inactivating proteins from the storage roots of the andean crop Mirabilis expansa. Plant Physiol. 1999, 119, 1447-1456.

381. Vepachedu, R.; Bais, H.P.; Vivanco, J.M. Molecular characterization and post-transcriptional regulation of me1, a type-i ribosome-inactivating protein from Mirabilis expansa. Planta 2003, 217, 498-506.

382. Habuka, N.; Murakami, Y.; Noma, M.; Kudo, T.; Horikoshi, K. Amino acid sequence of mirabilis antiviral protein, total synthesis of its gene and expression in Escherichia coli. J. Biol. Chem. 1989, 264, 6629-6637.

383. Bolognesi, A.; Polito, L.; Lubelli, C.; Barbieri, L.; Parente, A.; Stirpe, F. Ribosome-inactivating and adenine polynucleotide glycosylase activities in Mirabilis jalapa L. Tissues. J. Biol. Chem. 2002, 277, 13709-13716.

384. Yuan, Y.; Dai, X.; Wang, D.; Zeng, X. Purification, characterization and cytotoxicity of malanin, a novel plant toxin from the seeds of Malania oleifera. Toxicon 2009, 54, 121-127.

385. Voss, C.; Eyol, E.; Frank, M.; von der Lieth, C.W.; Berger, M.R. Identification and characterization of riproximin, a new type ii ribosome-inactivating protein with antineoplastic activity from Ximenia americana. FASEB J. 2006, 20, 1194-1196.

386. Bayer, H.; Ey, N.; Wattenberg, A.; Voss, C.; Berger, M.R. Purification and characterization of riproximin from Ximenia americana fruit kernels. Protein Expr. Purif. 2012, 82, 97-105.

387. Refsnes, K.; Haylett, T.; Sandvig, K.; Olsnes, S. Modeccin-A plant toxin inhibiting protein synthesis. Biochem. Biophys. Res. Commun. 1977, 79, 1176-1183.

388. Olsnes, S.; Haylett, T.; Refsnes, K. Purification and characterization of the highly toxic lectin modeccin. J. Biol. Chem. 1978, 253, 5069-5073.

389. Stirpe, F.; Gasperi-Campani, A.; Barbieri, L.; Lorenzoni, E.; Montanaro, L.; Sperti, S.; Bonetti, E. Inhibition of protein synthesis by modeccin, the toxin of Modecca digitata. FEBS Lett. 1977, 85, 65-67.

390. Barbieri, L.; Zamboni, M.; Montanaro, L.; Sperti, S.; Stirpe, F. Purification and properties of different forms of modeccin, the toxin of Adenia digitata. Separation of subunits with inhibitory and lectin activity. Biochem. J. 1980, 185, 203-210. 
391. Stirpe, F.; Bolognesi, A.; Bortolotti, M.; Farini, V.; Lubelli, C.; Pelosi, E.; Polito, L.; Dozza, B.; Strocchi, P.; Chambery, A.; et al. Characterization of highly toxic type 2 ribosome-inactivating proteins from Adenia lanceolata and Adenia stenodactyla (passifloraceae). Toxicon 2007, 50, 94-105.

392. Monti, B.; D’Alessandro, C.; Farini, V.; Bolognesi, A.; Polazzi, E.; Contestabile, A.; Stirpe, F.; Battelli, M.G. In vitro and in vivo toxicity of type 2 ribosome-inactivating proteins lanceolin and stenodactylin on glial and neuronal cells. Neurotoxicology 2007, 28, 637-644.

393. Barbieri, L.; Falasca, A.I.; Stirpe, F. Volkensin, the toxin of Adenia volkensii (Kilyambiti plant). FEBS Lett. 1984, 171, 277-279.

394. Stirpe, F.; Barbieri, L.; Abbondanza, A.; Falasca, A.I.; Brown, A.N.; Sandvig, K.; Olsnes, S.; Pihl, A. Properties of volkensin, a toxic lectin from Adenia volkensii. J. Biol. Chem. 1985, 260, 14589-14595.

395. Chambery, A.; di Maro, A.; Monti, M.M.; Stirpe, F.; Parente, A. Volkensin from Adenia volkensii harms (kilyambiti plant), a type 2 ribosome-inactivating protein. Eur. J. Biochem. 2004, $271,108-117$.

396. Kataoka, J.; Habuka, N.; Masuta, C.; Miyano, M.; Koiwai, A. Isolation and analysis of a genomic clone encoding a pokeweed antiviral protein. Plant Mol. Biol. 1992, 20, 879-886.

397. Honjo, E.; Dong, D.; Motoshima, H.; Watanabe, K. Genomic clones encoding two isoforms of pokeweed antiviral protein in seeds (pap-s1 and s2) and the $N$-glycosidase activities of their recombinant proteins on ribosomes and DNA in comparison with other isoforms. J. Biochem. 2002, $131,225-231$.

398. Irvin, J.D.; Robertus, J.D.; Monzingo, A.F. Preliminary X-ray diffraction studies on an anti-viral protein. Biochem. Biophys. Res. Commun. 1977, 74, 775-779.

399. Irvin, J.D. Pokeweed antiviral protein. Pharmacol. Ther. 1983, 21, 371-387.

400. Bjorn, M.J.; Larrick, J.; Piatak, M.; Wilson, K.J. Characterization of translational inhibitors from Phytolacca americana. Amino-terminal sequence determination and antibody-inhibitor conjugates. Biochim. Biophys. Acta 1984, 790, 154-163.

401. Lin, Q.; Chen, Z.C.; Antoniw, J.F.; White, R.F. Isolation and characterization of a cDNA clone encoding the anti-viral protein from Phytolacca americana. Plant Mol. Biol. 1991, 17, 609-614.

402. Poyet, J.L.; Hoeveler, A. Cdna cloning and expression of pokeweed antiviral protein from seeds in Escherichia coli and its inhibition of protein synthesis in vitro. FEBS Lett. 1997, 406, 97-100.

403. Irvin, J.D.; Uckun, F.M. Pokeweed antiviral protein: Ribosome inactivation and therapeutic applications. Pharmacol. Ther. 1992, 55, 279-302.

404. Rajamohan, F.; Venkatachalam, T.K.; Irvin, J.D.; Uckun, F.M. Pokeweed antiviral protein isoforms pap-i, pap-ii, and pap-iii depurinate RNA of human immunodeficiency virus (HIV)-1. Biochem. Biophys. Res. Commun. 1999, 260, 453-458.

405. Irvin, J.D.; Kelly, T.; Robertus, J.D. Purification and properties of a second antiviral protein from Phytolacca americana which inactivates eukaryotic ribosomes. Arch. Biochem. Biophys. 1980, 200, 418-425.

406. Barbieri, L.; Bolognesi, A.; Cenini, P.; Falasca, A.I.; Minghetti, A.; Garofano, L.; Guicciardi, A.; Lappi, D.; Miller, S.P.; Stirpe, F.; et al. Ribosome-inactivating proteins from plant cells in culture. Biochem. J. 1989, 257, 801-807. 
407. Park, S.W.; Lawrence, C.B.; Linden, J.C.; Vivanco, J.M. Isolation and characterization of a novel ribosome-inactivating protein from root cultures of pokeweed and its mechanism of secretion from roots. Plant Physiol. 2002, 130, 164-178.

408. Barbieri, L.; Aron, G.M.; Irvin, J.D.; Stirpe, F. Purification and partial characterization of another form of the antiviral protein from the seeds of Phytolacca americana L. (pokeweed). Biochem. J. 1982, 203, 55-59.

409. Parente, A.; Conforto, B.; di Maro, A.; Chambery, A.; de Luca, P.; Bolognesi, A.; Iriti, M.; Faoro, F. Type 1 ribosome-inactivating proteins from Phytolacca dioica L. Leaves: Differential seasonal and age expression, and cellular localization. Planta 2008, 228, 963-975.

410. Di Maro, A.; Valbonesi, P.; Bolognesi, A.; Stirpe, F.; de Luca, P.; Siniscalco Gigliano, G.; Gaudio, L.; Delli Bovi, P.; Ferranti, P.; Malorni, A.; et al. Isolation and characterization of four type-1 ribosome-inactivating proteins, with polynucleotide: Adenosine glycosidase activity, from leaves of Phytolacca dioica L. Planta 1999, 208, 125-131.

411. Severino, V.; Chambery, A.; di Maro, A.; Marasco, D.; Ruggiero, A.; Berisio, R.; Giansanti, F.; Ippoliti, R.; Parente, A. The role of the glycan moiety on the structure-function relationships of pd-11, type 1 ribosome-inactivating protein from p. Dioica leaves. Mol. Biosyst. 2010, 6, 570-579.

412. Di Maro, A.; Chambery, A.; Carafa, V.; Costantini, S.; Colonna, G.; Parente, A. Structural characterization and comparative modeling of pd-1s 1-3, type 1 ribosome-inactivating proteins from summer leaves of Phytolacca dioica L. Biochimie 2009, 91, 352-363.

413. Ruggiero, A.; Chambery, A.; di Maro, A.; Parente, A.; Berisio, R. Atomic resolution (1.1 a) structure of the ribosome-inactivating protein pd-14 from Phytolacca dioica L. Leaves. Proteins 2008, 71, 8-15.

414. Parente, A.; de Luca, P.; Bolognesi, A.; Barbieri, L.; Battelli, M.G.; Abbondanza, A.; Sande, M.J.; Gigliano, G.S.; Tazzari, P.L.; Stirpe, F.; et al. Purification and partial characterization of single-chain ribosome-inactivating proteins from the seeds of Phytolacca dioica L. Biochim. Biophys. Acta 1993, 1216, 43-49.

415. Del Vecchio Blanco, F.; Bolognesi, A.; Malorni, A.; Sande, M.J.; Savino, G.; Parente, A. Complete amino-acid sequence of pd-s2, a new ribosome-inactivating protein from seeds of Phytolacca dioica L. Biochim. Biophys. Acta 1997, 1338, 137-144.

416. Ready, M.P.; Adams, R.P.; Robertus, J.D. Dodecandrin, a new ribosome-inhibiting protein from Phytolacca dodecandra. Biochim. Biophys. Acta 1984, 791, 314-319.

417. Thomsen, S.; Hansen, H.S.; Nyman, U. Ribosome-inhibiting proteins from in vitro cultures of Phytolacca dodecandra. Planta Med. 1991, 57, 232-236.

418. Di Maro, A.; Chambery, A.; Daniele, A.; Casoria, P.; Parente, A. Isolation and characterization of heterotepalins, type 1 ribosome-inactivating proteins from Phytolacca heterotepala leaves. Phytochemistry 2007, 68, 767-776.

419. Moon, Y.H.; Song, S.K.; Choi, K.W.; Lee, J.S. Expression of a cdna encoding Phytolacca insularis antiviral protein confers virus resistance on transgenic potato plants. Mol. Cells 1997, 7, 807-815.

420. Song, S.K.; Choi, Y.; Moon, Y.H.; Kim, S.G.; Choi, Y.D.; Lee, J.S. Systemic induction of a Phytolacca insularis antiviral protein gene by mechanical wounding, jasmonic acid, and abscisic acid. Plant Mol. Biol. 2000, 43, 439-450. 
421. Coleman, W.H.; Roberts, W.K. Inhibitors of animal cell-free protein synthesis from grains. Biochim. Biophys. Acta 1982, 696, 239-244.

422. Asano, K.; Svensson, B.; Poulsen, F.M. Isolation and characterization of inhibitors of animal cell-free protein synthesis from barley seeds. Carlsberg Res. Commun. 1984, 49, 619-626.

423. Endo, Y.; Tsurugi, K.; Ebert, R.F. The mechanism of action of barley toxin: A type 1 ribosome-inactivating protein with RNA $N$-glycosidase activity. Biochim. Biophys. Acta 1988, 954, 224-226.

424. Leah, R.; Tommerup, H.; Svendsen, I.; Mundy, J. Biochemical and molecular characterization of three barley seed proteins with antifungal properties. J. Biol. Chem. 1991, 266, 1564-1573.

425. Asano, K.; Svensson, B.; Poulsen, F.M.; Nygård, O.; Nilsson, L. Influence of a protein synthesis inhibitor from barley seeds upon different steps of animal cell-free protein synthesis. Carlsberg Res. Commun. 1986, 51, 75-81.

426. Chaudhry, B.; Muller-Uri, F.; Cameron-Mills, V.; Gough, S.; Simpson, D.; Skriver, K.; Mundy, J. The barley $60 \mathrm{kDa}$ jasmonate-induced protein (jip60) is a novel ribosome-inactivating protein. Plant J. 1994, 6, 815-824.

427. Salehzadeh, A.; Arasteh, A.; Shafighi, T.; Ranjee, N. Isolation and sequencing of ribosome inactivating protein gene from iranian rice (Oryza sativa). Afr. J. Agric. Res. 2011, 6, 4941-4946.

428. Minami, Y.; Yamaguchi, K.; Yagi, F.; Tadera, K.; Funatsu, G. Isolation and amino acid sequence of a protein-synthesis inhibitor from the seeds of rye (Secale cereale). Biosci. Biotechnol. Biochem. 1998, 62, 1152-1156.

429. Stewart, T.S.; Hruby, D.E.; Sharma, O.K.; Roberts, W.K. An atp-dependent inhibition of protein synthesis in ascites cell extracts by wheat germ protein. Biochim. Biophys. Acta 1977, 479, 31-38.

430. Roberts, W.K.; Stewart, T.S. Purification and properties of a translation inhibitor from wheat germ. Biochemistry 1979, 18, 2615-2621.

431. Coleman, W.H.; Roberts, W.K. Factor requirements for the tritin inactivation of animal cell ribosomes. Biochim. Biophys. Acta 1981, 654, 57-66.

432. Reisbig, R.R.; Bruland, O. The protein synthesis inhibitors from wheat, barley, and rye have identical antigenic determinants. Biochem. Biophys. Res. Commun. 1983, 114, 190-196.

433. Massiah, A.J.; Hartley, M.R. Wheat ribosome-inactivating proteins: Seed and leaf forms with different specificities and cofactor requirements. Planta 1995, 197, 633-640.

434. Di Fonzo, N.; Manzocchi, L.; Salamini, F.; Soave, C. Purification and properties of an endospermic protein of maize associated with the opaque-2 and opaque-6 genes. Planta 1986, 167, 587-594.

435. Di Fonzo, N.; Hartings, H.; Brembilla, M.; Motto, M.; Soave, C.; Navarro, E.; Palau, J.; Rhode, W.; Salamini, F. The b-32 protein from maize endosperm, an albumin regulated by the o2 locus: Nucleic acid (cDNA) and amino acid sequences. Mol. Gen. Genet. 1988, 212, 481-487.

436. Bass, H.W.; OBrian, G.R.; Boston, R.S. Cloning and sequencing of a second ribosome-inactivating protein gene from maize (Zea mays L.). Plant Physiol. 1995, 107, 661-662.

437. Bass, H.W.; Krawetz, J.E.; OBrian, G.R.; Zinselmeier, C.; Habben, J.E.; Boston, R.S. Maize ribosome-inactivating proteins (rips) with distinct expression patterns have similar requirements for proenzyme activation. J. Exp. Bot. 2004, 55, 2219-2233. 
438. Hey, T.D.; Hartley, M.; Walsh, T.A. Maize ribosome-inactivating protein (b-32). Homologs in related species, effects on maize ribosomes, and modulation of activity by pro-peptide deletions. Plant Physiol. 1995, 107, 1323-1332.

439. Cammue, B.P.; Peeters, B.; Peumans, W.J. Isolation and partial characterization of an $\mathrm{N}$-acetylgalactosamine-specific lectin from winter-aconite (Eranthis hyemalis) root tubers. Biochem. J. 1985, 227, 949-955.

440. Kumar, M.A.; Timm, D.E.; Neet, K.E.; Owen, W.G.; Peumans, W.J.; Rao, A.G. Characterization of the lectin from the bulbs of Eranthis hyemalis (winter aconite) as an inhibitor of protein synthesis. J. Biol. Chem. 1993, 268, 25176-25183.

441. Endo, Y.; Oka, T.; Tsurugi, K.; Franz, H. The mechanism of action of the cytotoxic lectin from Phoradendron californicum: The RNA N-glycosidase activity of the protein. FEBS Lett. 1989, 248, 115-118.

442. Mishra, V.; Sharma, R.S.; Yadav, S.; Babu, C.R.; Singh, T.P. Purification and characterization of four isoforms of himalayan mistletoe ribosome-inactivating protein from viscum album having unique sugar affinity. Arch. Biochem. Biophys. 2004, 423, 288-301.

443. Mishra, V.; Ethayathulla, A.S.; Sharma, R.S.; Yadav, S.; Krauspenhaar, R.; Betzel, C.; Babu, C.R.; Singh, T.P. Structure of a novel ribosome-inactivating protein from a hemi-parasitic plant inhabiting the northwestern himalayas. Acta Crystallogr. D Biol. Crystallogr. 2004, 60, 2295-2304.

444. Mishra, V.; Bilgrami, S.; Sharma, R.S.; Kaur, P.; Yadav, S.; Krauspenhaar, R.; Betzel, C.; Voelter, W.; Babu, C.R.; Singh, T.P.; et al. Crystal structure of himalayan mistletoe ribosome-inactivating protein reveals the presence of a natural inhibitor and a new functionally active sugar-binding site. J. Biol. Chem. 2005, 280, 20712-20721.

445. Ziska, P.; Franz, H.; Kindt, A. The lectin from viscum album 1. Purification by biospecific affinity chromatography. Experientia 1978, 34, 123-124.

446. Stirpe, F.; Legg, R.F.; Onyon, L.J.; Ziska, P.; Franz, H. Inhibition of protein synthesis by a toxic lectin from Viscum album L. (mistletoe). Biochem. J. 1980, 190, 843-845.

447. Luther, P.; Theise, H.; Chatterjee, B.; Karduck, D.; Uhlenbruck, G. The lectin from Viscum album L.--Isolation, characterization, properties and structure. Int. J. Biochem. 1980, 11, 429-435.

448. Franz, H.; Ziska, P.; Kindt, A. Isolation and properties of three lectins from mistletoe (Viscum album L.). Biochem. J. 1981, 195, 481-484.

449. Olsnes, S.; Stirpe, F.; Sandvig, K.; Pihl, A. Isolation and characterization of viscumin, a toxic lectin from Viscum album L. (mistletoe). J. Biol. Chem. 1982, 257, 13263-13270.

450. Franz, H. Mistletoe lectins and their a and b chains. Oncology 1986, 43, 23-34.

451. Jung, M.L.; Baudino, S.; Ribereau-Gayon, G.; Beck, J.P. Characterization of cytotoxic proteins from mistletoe (Viscum album L.). Cancer Lett. 1990, 51, 103-108.

452. Sweeney, E.C.; Tonevitsky, A.G.; Palmer, R.A.; Niwa, H.; Pfueller, U.; Eck, J.; Lentzen, H.; Agapov, I.I.; Kirpichnikov, M.P. Mistletoe lectin i forms a double trefoil structure. FEBS Lett. 1998, 431, 367-370. 
453. Eck, J.; Langer, M.; Mockel, B.; Baur, A.; Rothe, M.; Zinke, H.; Lentzen, H. Cloning of the mistletoe lectin gene and characterization of the recombinant a-chain. Eur. J. Biochem. 1999, 264, $775-784$.

454. Yoon, T.J.; Yoo, Y.C.; Kang, T.B.; Shimazaki, K.; Song, S.K.; Lee, K.H.; Kim, S.H.; Park, C.H.; Azuma, I.; Kim, J.B.; et al. Lectins isolated from korean mistletoe (Viscum album coloratum) induce apoptosis in tumor cells. Cancer Lett. 1999, 136, 33-40.

455. Das, M.K.; Sharma, R.S.; Mishra, V. A cytotoxic type-2 ribosome inactivating protein (from leafless mistletoe) lacking sugar binding activity. Int. J. Biol. Macromol. 2011, 49, 1096-1103.

456. Park, C.H.; Lee, D.W.; Kang, T.B.; Lee, K.H.; Yoon, T.J.; Kim, J.B.; Do, M.S.; Song, S.K. Cdna cloning and sequence analysis of the lectin genes of the korean mistletoe (Viscum album coloratum). Mol. Cells 2001, 12, 215-220.

457. Kang, T.B.; Song, S.K.; Yoon, T.J.; Yoo, Y.C.; Lee, K.H.; Her, E.; Kim, J.B. Isolation and characterization of two korean mistletoe lectins. J. Biochem. Mol. Biol. 2007, 40, 959-965.

458. Park, W.B.; Han, S.K.; Lee, M.H.; Han, K.H. Isolation and characterization of lectins from stem and leaves of korean mistletoe (Viscum album var.Coloratum) by affinity chromatography. Arch. Pharm. Res. 1997, 20, 306-312.

459. Lyu, S.Y.; Park, S.M.; Choung, B.Y.; Park, W.B. Comparative study of korean (Viscum album var. Coloratum) and european mistletoes (viscum album). Arch. Pharm. Res. 2000, 23, 592-598.

460. Li, Y.; Jia, Y.; Zhang, Z.; Chen, X.; He, H.; Fang, R.; Hao, X. Purification and characterization of a new ribosome inactivating protein from cinchonaglycoside c-treated tobacco leaves. J. Integr. Plant Biol. 2007, 49, 1327-1333.

461. Sharma, N.; Park, S.W.; Vepachedu, R.; Barbieri, L.; Ciani, M.; Stirpe, F.; Savary, B.J.; Vivanco, J.M. Isolation and characterization of an rip (ribosome-inactivating protein)-like protein from tobacco with dual enzymatic activity. Plant Physiol. 2004, 134, 171-181.

462. Sismindari. Identification of ribosome-inactivating proteins (rips) from Phaleria macrocarpa (scheff) boerl., a possible active compound. Maj. Farm. Indones. 2004, 15, 44-49.

463. Funatsu, G.; Islam, M.R.; Minami, Y.; Sung-Sil, K.; Kimura, M. Conserved amino acid residues in ribosome-inactivating proteins from plants. Biochimie 1991, 73, 1157-1161.

464. Barbieri, L.; Valbonesi, P.; Bonora, E.; Gorini, P.; Bolognesi, A.; Stirpe, F. Polynucleotide: Adenosine glycosidase activity of ribosome-inactivating proteins: Effect on DNA, RNA and poly(a). Nucleic Acids Res. 1997, 25, 518-522.

465. Ferreras, J.M.; Merino, M.J.; Iglesias, R.; Munoz, R.; Girbés, T. Isolation of a ribosomeinactivating type 1 protein from seeds of cucumis melo. Biochem. Int. 1989, 19, 201-207.

466. Rojo, M.A.; Arias, F.J.; Iglesias, R.; Ferreras, J.M.; Soriano, F.; Méndez, E.; Escarmis, C.; Girbés, T. Enzymic activity of melonin, a translational inhibitor present in dry seeds of Cucumis melo L. Plant Sci. 1994, 103, 127-134.

(C) 2015 by the authors; licensee MDPI, Basel, Switzerland. This article is an open access article distributed under the terms and conditions of the Creative Commons Attribution license (http://creativecommons.org/licenses/by/4.0/). 